\title{
MEASUREMENT AND MODELING OF ADVANCED COAL CONVERSION PROCESSES
}

15th Quarterly Report \#523043-48

April 1, 1990 to June 30, 1990

By

Peter R. Solomon " L. Douglas Smoot

Michael A. Serio

B. Scott Brewster

David G. Hamblen

Work Performed Under Contract No. DE-AC21-86MC23075

For

U.S. Department of Energy

Office of Fossil Energy

Morgantown Energy Technology Center

Morgantown, West Virginia

Dr. Richard Johnson

COTR

By

Contractor

Advanced Fuel Research, Inc.

87 Church Street

East Hartford, CT 06108

(203) 528-9806

Progran: Dinector

Peter R. Solomon

President
Subcontractor

Brigham Young University

Provo, Utah 84602

(801) $378-4326$

Program Dinector

L. Douglas Smoot

Dean and Profes\$sor 


\section{DISCLAIMER}

This report was prepared as an account of work sponsored by the United States Government. Neither the United States nor the United States Department of Energy, nor any of their employees, makes any warranty, express or implied, or assumes any legal liability or responsibility for the accuracy, completeness, or usefulness of any information, apparatus, product, or process disclosed, or represents that its use would not infringe privately owned rights. Reference herein to any specific commercial product, process, or service by trade name, mark, manufacturer, or otherwise, does not necessarily constitute or imply its endorsement, recommendation, or favoring by the United States Government or any agency thereof. The views and opinions of authors expressed herein do not necessarily state or reflect those of the United States Government or any agency thereof.

\section{PATENT STATUS}

This technical report is being transmitted in advance of DOE patent clearance and no further dissemination or publication shall be made of the report without prior approval of the DOE patent Counsel. 


\section{ABSTRACT}

The overall objective of this program is the development of predictive capability for the design, scale up, simulation, control and feedstock evaluation in advanced coal conversion devices. This technology is important to reduce the technical and economic risks inherent in utilizing coal, a feedstock whose variable and often unexpected behavior presents a significant challenge. This program will merge significant advances made at Advanced Fuel Research, Inc. (AFR) in measuring and quantitatively describing the mechanisms in coal conversion behavior, with tecinnology being developed at Brigham Young University (BYU) in comprehensive computer codes for mechanistic modeling of entrained-bed gasification. Additional capabilities in predicting pollutant formation will be implemented and the technology will be expanded to fixed-bed reactors.

The foundation to describe coal-specific conversion behavior is $A F R^{\prime} s$ Functional Group (FG) and Devolatilization, Vaporization, and Crosslinking (DVC) models, developed under previous and on-going METC sporisored programs. These models have demonstrated the capability to describe the time dependent evolution of individual gas species, and the amount and characteristics of tar and char. The combined FG-DVC model will be integrated with BYU's comprehensive twodimensional reactor mode1, PCGC-2, which is currently the most widely used reactor simulation for combustion or gasification. The program includes: i) validation of the submodels by comparison with laboratory data obtained in this program, $i i)$ extensive validation of the modified comprehensive code by comparison of predicted results with data from bench-scale and process scale investigations of gasification, mild gasification and combustion of coal or coalderived products in heat engines, and $i i i)$ development of well documented user friendly software applicable io a "workstation" environment.

Success in this program will be a major step in improving the predictive capabilities for coal conversion processes including: demonstrated accuracy and reliability and a generalized "first principles" treatment of coals based on readily obtained composition data. below.

The progress during the fifteenth quarterly of the program is summarized

For Subtask 2.a., work continued on the improvements to the FG-DVC model. A set of rank dependent kinetic parameters has been developed for tar, $\mathrm{CH}_{4}, \mathrm{CO}$, $\mathrm{H}_{2} \mathrm{O}$, and $\mathrm{CO}_{2}$ for each of the Argonne coals. The predictions of the model are being compared to pyrolysis kinetic data from the TG-FTIR system at four heating rates. For a given coal, it is being assumed that the pre-exponential factors are similar for the evolution of the components of a given species $\left(\mathrm{e} . \mathrm{g} ., \mathrm{CO}_{2}-\right.$ Extra Loose, $\mathrm{CO}_{2}$-Loose, and $\mathrm{CO}_{2}$-Tight), but that the activation energies increase in the order Loose -.-> Tight. It is also being assumed that for a given species pool, the frequency factor is fixed (independent of rank) and that the activation energies for each functional group pool increase in the rank order. This approach has been successfuily used for the component pools of the major volatile species $\left(\mathrm{CO}, \mathrm{CO}_{2}, \mathrm{H}_{2} \mathrm{O}, \mathrm{CH}_{4}\right)$ for four of the eight Argonne Premium coals, to date (Utah, Pittsburgh, Upper Freeport, Pocohontas). Work on the remaining coals is in progress.

This complete set of kinetic parameters were tested in both Monte Carlo and the 2- $\sigma$ percolation theory versions of the FG-DVC model. Results for three of the eight coals indicate that only small adjustments are required in the 
kinetic parameters between the two models.

The kinetic parameters are also being validated indirectly through the application of the fluidity model to the Geissler fluidity data for six of the eight Argonne coals. Comparisons are being made to the NMR data of Lynch obtained at CSIRO on the Argonne premium coals. The changes in the fluid fraction predicted from the fluidity model are in good agreement with the change in hydrogen mobility observed in the NMR experiment. We are rechecking the current version of the model with the latest kinetic parameters against van Krevelen's data for fluidity as a function of heating rate and against the isothermal data of $0 x 1$ ey and Pitt.

Work also continued on the swelling model. By using an adjustable parameter for either the diffusion distance or bubble wall thickness in the model, we were able to obtain good predictions for swelling ratio, porosity, and surface area over a range of pyrolysis heating rates.

For subtask 2.b., during the last quarter, significant progress in developing the optical particle imaging system and the reactor collection system was made. The optical stands and brackets were designed and fabricated for the HPCP facility. The time required for size classification of pulverized coal was considerably reduced and the quality of the classification was improved significantiy. Sufficient quantities of narrow size ranges of two of the test coals were produced for upcoming char preparation and oxidation tests. Analytical techniques to determine tar composition directly from tar filters were also developed and improved accuracy of char weight loss analysis through the use of four simultaneous tracers was investigated. Previously collected char and tar from Pittsburgh No. 8 bituminous coal was analyzed and compared using the new procedures.

For subtask 2.c., additional work was done on the coal flame experiments in the TWR using the FT-IR Emission/ Transmission Tomography technique. Two cases have now been completed for the Montana Rosebud coal (low velocity and high velocity). A low velocity case for the Pittsburgh Seam coal is about $50 \%$ complete.

For Subtask 2.d., no work was scheduled.

For Subtask 2.e., the work on the AFR fixed-bed reactor (FBR) system continued. A redesign of the experiment has been proposed and approved which will allow better quantitation of the tar yields and independent control of the temperature of the second bed. Assembly has begun on a redesign of the experiment. Samples of large particles for each of the eight premium coals have been ordered from Argonne and should be received by July 1, 1990.

Discussions continued with BYU about the single particle FG-DVC model for use in the fixed bed reactor. For this purpose, AFR is developing an ordinary different equation (ODE) version of the 2- $\sigma$ percolation FG-DVC model. Additional refinements were done to the model to improve its speed. The code was sent to BYU for integrition into the Advanced Fixed-Bed Model. A meeting was scheduled at AFR to discuss the single particle model which will involve members of both teams.

For Subtask 2.f., work continued on designing a large-particle insert to be $\mathrm{placed}$ in the HPCP reactor and evaluating analytical procedures for monitoring 
the rates of large-particle oxidation. A second set of preliminary oxidation experiments were carried out with large char particles made from Utah Bituminous coal, and mass reactivities were determined. The average value of $0.0358 \mathrm{~min}^{-1}$ compares favorably with the value of $0.0475 \mathrm{~min}^{-1}$ reported previously. Some problems with temperature measurement were experienced.

For Subtask 2.g., pollutant predictions for coal combustion and gasification cases were completed to verify the extended and alternative fuel NO mechanisms of the submodel. The ability to predict NO formation during gasification of North Dakota 1 ignite was given special consideration. Joint fuel and thermal NO predictions were al so completed for combustion and gasification cases. The revised submodel has been fully integrated into PCGC-2 and a user's guideline has been prepared. Work is in progress to complete a sorbent reactions submodel.

For Subtask 3.a., work was nearly completed on modeling the transparent wall reactor for code validation and on developing a graphical, user-friendly interface. After modifying for up-firing, gas buoyancy, and laminarization, reasonable results were achieved for the simulation of the non-reacting flow case and the "fast-flow" Rosebud coal flame. Key flame properties, such as ignition point, burnout profile, and gas and particle temperature, have been reasonably well predicted. Complex flow patterns at the nozzle promote particle dispersion, and have not been adequately resolved with current grid spacing. Code predictions are sensitive to inlet boundary conditions for the coal stream at the nozzle exit, and detailed characterization of this boundary condition is needed. Soot formation seems to correlate with equilibrium concentration of condensed carbon, but decays more slowly than predicted from equilibrium. The energy feedback to particles or the $\mathrm{CO}_{2} / \mathrm{CO}$ ratio produced at the particle is not adequately predicted.

A window was added to the graphical user interface (GUI) on the Sun workstation for specifying the composition and temperature of the inlet streams. The thermodynamic input file can now be generated automatically using information in the main data file and a chemical species database. Work was also initiated to apply two graphical programs that have been developed under independent funding, a pre- and a post-processor, to PCGC-2. The preprocessor generates a grid file and the post-processor presents computational results. The format of the grid file used by PCGC-2 differs from that used by the pre-processor, and a program was written for converting files between the two formats. A subroutine was modified and added to PCGC-2 for writing the plotting file needed by the post-processor. Both the pre- and post-processors were applied to the TWR simulation described above.

For subtask 3.b., work continued on reviewing, coding, and validating submodels. To enhance user-friendliness, the input file was rewritten to segregate input parameters for the two-zone and one-dimensional submodels. Also, the fixed-bed code was rewritten in a modular fashion with extensive comment statements. The two-zone submodel was improved to accommodate user-specified burnout. Also, two heat transfer zones were added to the well-mixed model to account for heat loss in the freeboard and heat transfer between solid and gas in the ash zone of the reactor. The ash enthalpy calculation was improved.

The fixed-bed code was evaluated by parametric sensitivity analysis. Sensitivity runs were divided into model options, model parameters and operational parameters. Model options include tar vapor reaction equilibrium, 
volatile "mass transport, char ash layer formation, and combustion product distribution. Model parameters include the solid-to-gas heat transfer correction factor, effective diffusivity, bed-to-wall heat transfer, potential tar forming fraction, functional group composition (coal rank), oxidation and gasification kinetics. Operational parameters include the temperature of the feed gas, reactor pressure, coal mass flow rate, steam mass flow rate, air mass flow rate, proximate ash content of the feed coal, proximate moisture content of the feed coal, particle diameter, and bed void fraction. injection.

For subtask 3.C., work was initiated on modifying PCGC-2 to allow sorbent

For Subtask 4.a., this subtask has not been initiated.

For Subtask 4.b., duririg the last quarter, work continued on collecting fixed-bed design and test data. The advanced fixed-bed code was applied to seven new test cases, including the dry-ash Lurgi gasifier, the Wellman-Galusha gasifier, the METC gasifier, and the slagging BGC-Lurgi gasifier. A presentation was given at the joint METC/AFR/BYU project review meeting, and discussions were held with AFR concerning code development.

Four different gasifier types were simulated: the high pressure, oxygenfired Lurgi gasifier; the low pressure, air-fired Wellman-Galusha gasifier; the medium pressure, air-fired METC gasifier; and the high pressure oxygen-fired BGC-Lurgi slagging gasifier. Twelve coal types were simulated, which range from lignite to bituminous. 
MEASUREMENT AND MODELING OF COAL CONVERSION PROCESSES

Contract No. DE-AC21-86MC23075

Table of Contents

DISCLAIMER ............................

ABSTRACT ......................... . . . i i

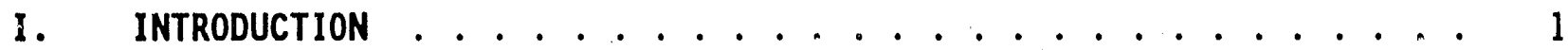

I.A. Program Background and Description . . . . . . . . . . 1

I.B. Objectives . . . . . ................ 1

I.C. Approach . . . . . . . . . . . . . . . . . . . 2

I.D. Critical Technical Issues... . . . . . . . . . . . 2

I.E. Fifteenth Quarter Progress . . . . . . . . . . . . 3

II. TASK 2 - SUBMODEL DEVELOPMENT AND EVALUATION . . . . . . . . . . . 8

II.A. Subtask 2.a. - Coal to Char Chemistry Submode1 . . . . . . . 9

II.B. Subtask 2.b. - Fundamental High-Pressure Reaction Rate

Data . . . . . . . . . . . . . . . . 26

II.C. Subtask 2.C. - Secondary Reaction of Pyrolysis Product

and Burnout Submodels ............... 37

II.D. Subtask 2.d. - Ash Physics and Chemistry Submodel . . . . . 38

II.E. Subtask 2.e. - Large Particle Submodels . . . . . . . . . . 39

II.F. Subtask 2.f. - Large Char Particle Oxidation at High

Pressures ................... 43

II.G. Subtask 2.g. - $\mathrm{SO}_{\mathrm{x}}-\mathrm{NO}$ Submodel Development . . . . . . . . 49

III. TASK 3 - COMPREHENSIVE MODEL DEVELOPMENT AND EVALUATION . . . . . 64

III.A. Subtask 3.a. - Integration of Advanced Submodels into

Entrained-Flow Code, with Evaluation and

Documentation............... 65

III.B. Subtask 3.b. - Comprehensive Fixed-Bed Modeling Review,

Development Evaluation and Implementation ..... . . 79

III.C. Subtask 3.c. - Generalized Fuels Feedstock Submodel . . . . 99

IV. TASK 4 - APPLICATION OF INTEGRATED CODES . . . . . . . . . . . 100

IV.A. Subtask 4.a. - Application of Generalized Pulverized

Coal Comprehensive Code ............. . 101

IV.B. Subtask 4.b. - Application of Fixed-Bed Code . . . . . . . 102

V. REFERENCES ......................... 112

APPENDIX A - FG-DVC Model Implementation Notes . . . . . . . 116 


\section{SECTION 1. INTRODUCTION}

\section{I.A. PROGRAM BACKGROUND AND DESCRIPTION}

During the past 5 years, significant advances have been made at Brigham Young University (BYU) in comprehensive two-dimensional computer codes for mechanistic modeling of entrained-bed gasification and pulverized coal combustion. During the same time period, significant advances have been made at Advanced Fuel Research, Inc. (AFR) in the mechanisms and kinetics of coal pyrolys is and secondary reactions of pyrolysis products. The proposed program presents a unique opportunity to merge the technology developed by each organization to provide detailed predictive capability for advanced coal conversion processes. This predictive capability will incorporate advanced coal characterization techniques in conjunction with comprehensive computer models to provide accurate process simulations.

The program will streamline submodels existing or under development for coal pyrolysis chemistry, volatile secondary reactions, tar formation, soot formation, char reactivity, and $\mathrm{SO}_{x}-\mathrm{NO}_{x}$ pollutant formation. Submodels for coal viscosity, agglomeration, tar/char secondary reactions, sulfur capture, and ash physics and chemistry would be developed or adapted. The submodels would first be incorporated into the BYU entrained-bed gasification code and subsequently, into a fixed-bed gasification code (to be selected and adapted). These codes would be validated by comparison with small scale laboratory and PDU-scale experiments. The validated code could then be employed to simulate and to develop advanced coal conversion reactors of interest to METC.

\section{I.B. OBJECTIVES}

The objectives of this proposed study are to establish the mechanisms and rates of basic steps in coal conversion processes, to integrate and incorporate this information into comprehensive computer models for coal conversion processes, to evaluate these models and to apply them to gasification, mild gasification and combustion in heat engines. 


\section{I.C. APPROACH}

This program will be a closely integrated, cooperative effort between AFR and BYU. The program will consist of four tasks: 1) Preparation of Research Plans, 2) Submodel Development ar 1 Evaluation, 3) Comprehensive Model Development and Evaluation, and 4) Applications and Implementation.

\section{I.D. CRITICAL TECHNICAL ISSUES}

To achieve the goals of the program, the computer models must provide accurate and reliable descriptions of coal conversion processes. This will require the reduction of very complicated and interrelated physical and chemical phenomena to mathematical descriptions and, subsequently, to operational computer codes. To accomplish this objective, a number of technical issues must be addressed as noted below. The status of each of these tasks is also indicated.

A Separation of Rates for Chemical Reaction, Heat Transfer, and Mass Transfer

A Particle Temperature Measurements Using FT-IR E/T Spectroscopy

A Functional Group Description of Coal, Char, and Tar

A Tar Formation Mechanisms

I Char Formation Mechanisms

A Viscosity/Swelling

A Intraparticle Transport

I Pyrolysis of Volatiles and Soot Formation

I Secondary Reaction of Tar

I Particle Ignition

A Char Reactivity

I Ash Cremistry and Physics

A Particle Optical Properties

I Code Efficiency and Compatibility for Submodels

I Coupling of Submodels with Comprehensive Codes

I Comprehensive Code Efficiency

I Turbulence

I $\mathrm{SO}_{x}$ and $\mathrm{NO}_{x}$

- Generalized Fuels Model 
I Fixed-Bed Model

(0) to be addressed; (I) initiated; (A) almost completed.

These technical issues are addressed in the three Tasks as described in Sections II-IV.

\section{I.E. FIFTEENTH QUARTER PROGRESS}

Subtask 2.a. Coal to Char Chemistry Submodel Development and Evaluation

Work continued on the improvements to the FG-DVC model. A set of rank dependent kinetic parameters has been developed for tar, $\mathrm{CH}_{4}, \mathrm{CO}, \mathrm{H}_{2} \mathrm{O}$, and $\mathrm{CO}_{2}$ for each of the Argonne coals. The predictions of the model are being compared to pyrolysis kinetic data from the TG-FTIR system at four heating rates. For a given coal, it is being assumed that the pre-exponeintial factors are similar for the evolution of the components of a given species (e.g., $\mathrm{CO}_{2}$-Extra Loose, $\mathrm{CO}_{2}$-Loose, and $\mathrm{CO}_{2}$-Tight), but that the activation energies increase in the order Loose -.-> Tight. It is also being assumed that the activation energies for each functional group pool increase in the rank order. This approach has been successfully used for the component pools of the major volatile species $\left(\mathrm{CO}_{2} \mathrm{CO}_{2}\right.$, $\mathrm{H}_{2} \mathrm{O}, \mathrm{CH}_{4}$ ) for four of the eight Argonne Premium coals, to date (Utah, Pittsburgh, Upper Freeport, Pocohontas). Work on the remaining coals is in progress.

This complete set of kinetic parameters were tested in both Monte Carlo and the 2- $\sigma$ percolation theory version of the FG-DVC model. Results for three of the eight coals indicate that only small adjustments are required in the kinetic parameters between the two models.

The kinetic furameters are also being validated indirectly through the application of the fluidity model to the Geissler fluidity data for six of the eight Argonne coals. Comparisons are being made to the NMR data of Lynch obtained at CSIRO on the Argonne premium coals. The changes in the fluid fraction predicted from the fluidity model are in good agreement with the change in hydrogen mobility observed in the NMR experiment. We are rechecking the current version of the model with the latest kinetic parameters against van Krevelen's data for fluidity as a function of heating rate and against the isothermal data of $0 \times 1$ ey and Pitt. 
Work also continued on the swelling model. By using an adjustable parameter for either the diffusion distance or bubble wall thickness in the mode1, we were able to obtain good predictions for swelling ratio, porosity, and surface area over a range of pyrolysis heating rates.

\section{Subtask 2.b. Fundamental High-Pressure Reaction Rate Data}

During the last quarter, significant progress in developing the optical particle imaging system and the reactor collection system was made. The optical stands and brackets were designed and fabricated for the HPCP facility. The time required for size classification of pulverized codl was considtiably reduced and the quality of the classification was improved significantly. Sufficient quantities of narrow size ranges of two of the test coals were produced for upcoming char preparation and oxidation tests. Analytical techniques to determine tar composition directly from tar filters were also developed and improved accuracy of char weight loss analysis through the use of four simultaneous tracers was investigated. Previously collected char and tar from Pittsburgh No. 8 bituminous coal was analyzed and compared using the new procedures.

\section{Subtask 2.c. Secondary Reaction of Pyrolys is Products and Char Burnout}

Additional work was done on the coal flame experiments in the TWR using the FT-IR Emission/ Transmission Tomography technique. Two cases have now been completed for the Montana Rosebud coal (low velocity and high velocity). A low velocity case for the Pittsburgh Seam coal is about $50 \%$ complete.

\section{Subtask 2.d. Ash Physics and Chemistry Submodel}

No wor'k was scheduled.

\section{Subtask 2.e. Large Particle Submodels}

The work on the AFR fixed-bed reactor (FBR) system continued. A redesign of the experiment has been proposed and approved which will allow better quantitation of the tar yields and independent control of the temperature of the second bed. Assembly has begun on a redesign of the experiment. Samples of 
large particles for each of the eight premium coals have been ordered from Argonne and should be received by July 1, 1990.

Discussions continued with BYU about the single particle FG-DVC model for use in the fixed bed reactor. For this purpose, AFR is developing an ordinary different equation (ODE) version of the 2- $\sigma$ percolation FG-DVC model. Additional refinements were done to the model to improve its speed. The code was sent to BYU for integration into the Advanced Fixed-Bed Model. A meeting was scheduled at AFR to discuss the single particle model which will involve members of both teams.

\section{Subtask 2.f. Large Char Particle Oxidation at High Pressure}

Work continued on designing a large-particle insert to be placed in the HPCP reactor and evaluating analytical procedures for monitoring the rates of large-particle oxidation. A second set of preliminary oxidation experiments were carried out with large char particles made from Utah Bituminous coal, and mass reactivities were determined. The average value of $0.0358 \mathrm{~min}^{-1}$ compares favorably with the value of $0.0475 \mathrm{~min}^{-1}$ reported previously. Some problems with temperature measurement were experienced.

\section{Subtask 2.g. $\quad \mathrm{SO}_{\mathrm{O}}=\mathrm{NO} \times$ Submodel Development}

Pollutant predictions for coal combustion and gasification cases were completed to verify the extended and alternative fuel No mechanisms of the submodel. The ability to predict No formation during gasification of North Dakota lignite was given special consideration. Joint fuel and thermal No predictions were also completed for combustion and gasification cases. The revised submodel has been fully integrated into PCGC-2 and a user's guideline has been prepared. Work is in progress to complete a sorbent reactions submode1.

Subtask 3.a. Integration of Advanced Submodels into Entrained-Flow Code, with Evaluation and Documentation

Work was nearly completed on modeling the transparent wall reactor for code validation and or developing a graphical, user-friendly interface. After 
modifying for up-firing, gas buoyancy, and laminarizatior, reasonable results were achieved for the simulation of the non-reacting flow case and the "fastflow" Rosebud coal flame. Key flame properties, such as ignition point, Lurnout profile, and gas and particle temperature, have been reasonably well predicted. Complex flow patterns at the nozzle promote particle dispersion, and have not been adequately resolved with current grid spacing. Code predictions are sensitive to inlet boundary conditions for the coal stream at the nozzle exit, and decaile characterization of this boundary condition is needed. Soot formation seems to correlate with equilibrium concentration of condensed carbon, but decays more slowly than predicted from equilibrium. The energy feedback to particles or the $\mathrm{CO}_{2} / \mathrm{CO}$ ratio produced at the particle is not adequately predictei.

A window was added to the graphical user interface (GUI) on the Sun workstation for specifying tha composition and temperature of the inlet streams. The thermodynamic input file can now be generaied automaticaliy using information in the main data file ind a chemical species database. Work was also initiated to apply two graphical programs that have been developed under independent funding, a pre- and a post-processor, to PCGC-2. The preprocessor generates a grid file and the post-processor presents computational results. The format of the grid file used by $P C G C-2$ differs from that used by the pre processor, and a program was written for converting files beiween the ty/o formats. A subroutine was modified and added to PCGC-2 for writing the plotting file needed by the post-processor. Both the pre-and post-processors vere applied to the TWR simulation described above.

Subtask 3.b. Comprehensive Fixed.-Bed Modeling Review, Development, Evaiuation, and Implementation

Work continued on reviewing, coding, and validating submodels. To enhance user-friendliness, the input file was rewritten to segregate input parameters for the two-zone and one-dimensional submodels. Also, the fixed-bed code was rewritten in a modular fashion with extensive comment statements. The two-zone submodel was improyed to accommodate user-specified burnout. Aiso, two heat transfer zones were added to the well-mixed model to account for heat loss in the freeboard and heat transfer between so?id and gas in the ash zone of the reactor. The ash enthalpy calculation was improved. 
The fixed-bed code was evaluated by parametric sensitivity analysis. Sensitivity runs were divided into model options, model parameters and operational parameters. Model options include tar vapor reaction equilibrium, volatile mass transport, char ash layer fo:mation, and combustion product distribution. Model parameters include the solid-to-gas heat transfer correction factor, effective diffusivity, bed-to-wal? heat transfer, potential tar forming fraction, functional group composition (coal rank), oxidation and gasification kinetics. Operational parameters include the temperature of the feed gas, reactor pressure, coal mass flow rate, steam mass flow rate, air mass flow rate, proximate ash content of the feed coal, proximate moisture content of the feed coal, particle diameter, and bed void fraction.

\section{Subtask 3.c. Generalized Fuels Feedstock Submodel}

Work was initiated on modifying PCGC-2 to allow sorbent injection.

\section{Subtask 4,a. Application of Generalized Pulverized Coal Comprehensive Code}

This subtask has not been initiated.

\section{Subtask 4.b. Application of Fixed-Bed Code}

During the last quarter, work continued on collecting fixed-bed design and tect. data. The advanced fixed-bed code was applied to seven new test cases, including the dry-ash Lurgi gasifier, the Wellman-Galusha gasifier, the METC gasifier, and the slagging BGC-Lurgi gasifier. A presentation was given at the joint METC/AFR/BYU project review meeting, and discussions were held with AFR concerning code development.

Four different gasifier types were simulated: the high pressure, oxygen-fired Lurgi gasifier; the low pressure, air-fired Wellman-Galusha gasifier; the medium pressure, air-fired METC gasifier; and the high pressure oxygen-fired BGC-Lurgi slagging gasifier. Twelve coal types were simulated, which range from lignite to bituminous. 


\section{SECTION II. TASK 2. SUBMODEL DEVELOPMENT AND EVALUATION}

\section{Objectives}

The objectives of this task are to develop ar adapt advanced physics and chemistry submodels for the reactions of coal in an entrained-bed and a fixed-bed reactor and to validate the submodels by comparison with laboratory scale experiments.

\section{Task Outline}

The development of advanced submodels for the entrained-bed and fixed-bed reactor models will be organized into the following categories: a) Coal Chemistry (including coal pyrolysis chemistry, char formation, particle mass transfer, particle thermal properties, and particle physical behavior); b) Char Reaction Chemistry at high pressure; c) Secondary Reactions of Pyrolysis Products (including gas-phase cracking, soot formation, ignition, char burnout, sulfur capture, and tar/gas reactions); d) Ash Physics and Chemistry (including mineral characterization, evolution of volatile, molten and dry particle components, and ash fusion behavior); e) Large Coal Particle Effects (including temperature, composition, and pressure gradienis and secondary reactions within the particle, and the physical effects of melting, agglomeration, bubble formation and bubble transport; f) Large Char Particle Effects (including oxidation); g) $\mathrm{SO}_{\mathrm{x}}-\mathrm{NO}_{\mathrm{x}}$ Submodel Development (including the evolution and oxidation of sulfur and nitrogen species); and $h$ ) $\mathrm{SO}_{x}$ and $\mathrm{NO}_{x}$ Model Evaluation. 


\section{II.A. SUBTASK 2.a. - COAL TO CHAR CHEMISTRY SUBMODEL DEVELOPMENT AND EVALUATION}

Senior Investigators - David G. Hamblen and Michael A. Serio

Advanced Fuel Research, Inc.

87 Church Street, East Hartford, CT 06108

(203) 528-9806

\section{Objective}

The objective of this subtask is to develop and evaluate, by comparison with laboratory experiments, an integrated and compatible submodel lo describe the organic chemistry and physical changes occurring during the transformation from coal to char in coal conversion processes.

\section{Accomplishments}

Work continued on the impruvements to the FG-DVC model. A set of rank dependent kinetic parameters has been developed for tar, $\mathrm{CH}_{4}, \mathrm{CO}, \mathrm{H}_{2} \mathrm{O}$, and $\mathrm{CO}_{2}$ for each of the Argonne coals. The predictions of the model are being compared to pyrolysis kinetic data from the TG-FTIR system at four heating rates. The 2- $\sigma$ percolation theory version of the model is currently being used to develop the kinetic parameters for the gaseous volatile species, since it has a much faster execution time than the Monte Carlo version. Since the gas evolutions are predicted by the FG part of the FG-DVC model, these are independent of the type of network decomposition calculations. For a given coal, it is being assumed that the pre-exponential factors are similar for the evolution of the componenis of a given species (e.g., $\mathrm{CO}_{2}$-Extra Loose, $\mathrm{CO}_{2}$-Loose, and $\mathrm{CO}_{2}$-Tight), but that the activation energies increase in the order Loose.$- \rightarrow$ Tight. It is also being assumed that for a given species pool, the frequency factor is fixed (independent of rank) and that the activation energies for each functional group pool increase in the rank order. This approach has been successfully used for the component pools of the major volatile species $\left(\mathrm{CO}, \mathrm{CO}_{2}, \mathrm{H}_{2} \mathrm{O}, \mathrm{CH}_{4}\right)$ for four of the eight Argonne Premium coals, to date (Utah, Pittsburgh, Upper Freeport, Pocohontas). Work on the remaining coals is in progress.

Some of this work was summarized in a paper that will be presented at the ACS Washington Meeting (Serio et al., 1990). Additional work needs to be done 
on refining the tar evolution kinetics for the two lowest rank coals (Zap, Wyodak) because of interferences from the polymethylene (PM) species which make the bridge breaking rates appear lower than they really are. For the low rank coals, experiments with demineralized coal are being used to elucidate the rates. In this case, the tar species are more important in contributing to the tar peak.

The kinetic parameters were tested in both Monte Carlo and the 2- $\sigma$ percolation theory version of the FG-DVC model. Results for three of the eight coals indicate that only small adjustments are required in the model kinetic parameters between the two models. Of course, the network configuration parameters are inherently different. We will be doing a sersitivity analysis to see which parameters should be changed so that the two versiuns are as similar as possible.

The kinetic parameters are also being validated indirectly through the application of the fluidity model to the Geissler fluidity data for six of the eight Argonne coals. The fluidity predictions are strongly dependent on the kinetics of bridge breaking and crosslinking. In the FG-DVC model, crosslinking is tied to the evolution of $\mathrm{CO}_{2}$ at low temperatures and $\mathrm{CH}_{4}$ at high temperatures. Most of the recent adjustments have been in the kinetic parameters for $\mathrm{CH}_{4}$-Loose and $\mathrm{CH}_{4}$-Tight. Additional work has been done with the fluidity model.

Comparisons are also being made to the NMR data of Lynch obtained at CSIRO on the Argonne premium coals. The changes in the fluid fraction predicted from the fluidity model are in good agreement with the change in hydrogen mobility observed in the NMR experiment. We are rechecking the current version of the model with the latest kinetic parameters against van Krevelen's data for fluidity as a function of heating rate and against the isothermal data of 0xley and Pitt.

Work also continued on the swelling model. By using an adjustable parameter for either the diffusion distance or bubble wall thickness in the model, we were able to obtain good predictions for swelling ratio, porosity, and surface area over a range of pyrolysis heating rates. However, we are concerned by the absence of bubble rupture in the model, as the data obtained at Rice University suggest that this is an important phenomenon. We are supposed to receive some videotapes of the experiments done at Rice, and we plan to examine these before reformulating the model. 


\section{Determination of Kinetic Rates}

Considerable effort has been made in the past three months in the attempt to determine the kinetic rate parameters for major devolatilization products in the Argonne coals based on the TG-FTIR and other available experimental data. During this process, attention has been paid to the rank variation of these kinetic parameters, as well as to the relationships between different volatile products.

For most gas evolution data, the measured rate curves often show several distinct peaks or peaks overlapping each other. This implies that more than one reaction is required to describe the gas evolution. In our FG-DVC model, we often use several different pools (such as $\mathrm{CO}_{2}$ - Extra Loose, $\mathrm{CO}_{2}-\mathrm{Loose}_{2} \mathrm{CO}_{2}$ Tight) to describe a multiple evolution curve. Each pool is associated with its own rate constant including frequency factor $A$ and activation energy $E$ with a distribution $\sigma$. The rate expression has the form

$$
K=A \exp (-(E \pm \sigma) / R T)
$$

In addition to the three parameters, each pool has another parameter, namely a weight fraction to be determined. It is obvious that when there are so many parameters associated with a single gas specie, the goal of finding a unique solution based on the limited data is sometime impossible. The widely scattered kinetic data reported in literature are at least partially due to this difficulty.

In order to derive a set of kinetic rates reasonable for the major volatile products in the Argonne coals, we laid down the following guidelines to determine the kinetic parameters based on our understanding of the Arrhenius equation and the rank variation of coal kinetics. The experimental data used to determine these parameters include the TG-FTIR measurements at four different heating rates and some high heating rate data.

\section{The Frequency Factor}

The literature data show a great scatter in the frequency factor of coal pyrolysis, which ranges from the order of $10^{3} / \mathrm{sec}$ up to $10^{20} / \mathrm{sec}$. For gas phase 
reactions, the frequency factor is conceptually understood as the number collisions of the reactants per unit time. For coal devolatilization products, the reactions are mainly the dissociation of functional groups from a coal macromolecular network which falls into the category of unimolecular reactions. The mechanism of these reactions is widely accepted as the following: when enough energy gets into a particular mode of vibration, the vibration of the molecule in this mode leads to dissociation of the molecule.

Although the theoretical calculation of the frequency factor for unimolecular dissociation is rather complex, it is reasonable to assume that the frequency factor of dissociation is comparable to the average vibrational frequency of a molecule which is known to be in the order of $10^{13} / \mathrm{sec}$ for solids. Therefore, we propose an upper limit of the frequency factor to be $1 \times 10^{15} / \mathrm{sec}$, taking into account the degree of uncertainty and some possible self-activated high frequency modes.

It is also known that the frequency factor could be weakly temperature dependent, as predicted by the collision theory to be pronortional to $T$ and by the theory of absolute reaction rates to be proportional to $T$ (Castellan). The weak dependency is meant to be compared with the exponential dependency of temperature in the Arrhenius equation. Based on this reasoning, we allow some increase in the frequency factor with temperature, but not exceeding the proposed upper limit. For example, the $\mathrm{CO}_{2}$ - Tight pool that evolves at higher temperature would have the frequency factor $7.5 \times 10^{12} / \mathrm{sec}$, higher than $5.0 \times$ $10^{12} / \mathrm{sec}$ chosen for the $\mathrm{CO}_{2}-$ Loose pool.

\section{The Activation Energy}

The activation energy is considered as the energy barrier that the reactants have to overcome to accomplish the reaction. The rule of thumb is that the higher the temperature at which a reaction takes place, the higher the activation energy the reaction is associated with.

The activation energy of a reaction $(E)$ and its distribution $(\sigma)$, together with its frequency factor $(A)$, can be determined to a certain accurac $y$ if the evolution rates and the corresponding peak temperatures of the reaction are measured accurately at several different heating rates. We have used the curve 
fitting approach to determine the bond-breaking rate for eight Argonne coals based on the TG-FTIR measured tar evolution curves at different heating rates. Since the tar evolution is usually a single-peak curve, the above approach worked we11.

However, for the multi-peak evolution curves, the determination of the kinetic parameters is more complicated. In addition to the above-mentioned guidelines for choosing the activation energy and the frequency factor, we have defined certain rules for rank variation and the relationships between the gas pools of different species.

\section{Rank Dependency}

When comparing the multi-peak evolution curves of a given specie in different coals, one would notice an interesting feature. As the coal is increased in rank, the leading edges and the early peaks (Extra Loose or Loose pools) shift to higher temperatures while the trailing edge (Tight or Extra Tight pools) renlain at the same temperature. An example of this is shown for water for five coals in Fig. II.A-1 (Solomon et a1., 1990b). From this figure it appears that this feature can be explained in the light of the geological aging process of coal formation. With increasing aging temperature and time, maturation process gradually evolves the loosely bounded functional groups and leaves the tightly bounded groups intact.

This feature also provides us with a guideline for the kinetic rates, namely, we keep the same frequency factor for the same pool. The activation energy of the pool then increases with increasing coal rank to fit the data. We find that the activation energy of tight pools generally change with rank much less than do the loose pools.

\section{Relationships between Kinetic Rates of Different Volatile Species}

It is found that some pools in the different gas species have peak evolution rates at the same temperature and those peaks have the same shifts when the heating rate changes. The Utah Blind Canyon coal gives a good example as shown in Fig. II.A-2. The TG-FTIR measurements indicate that the tar evolution, the $\mathrm{CO}_{2}$-Loose, $\mathrm{CO}$-Loose, and the $\mathrm{H}_{2} \mathrm{O}$-Loose pools all show very close peak 


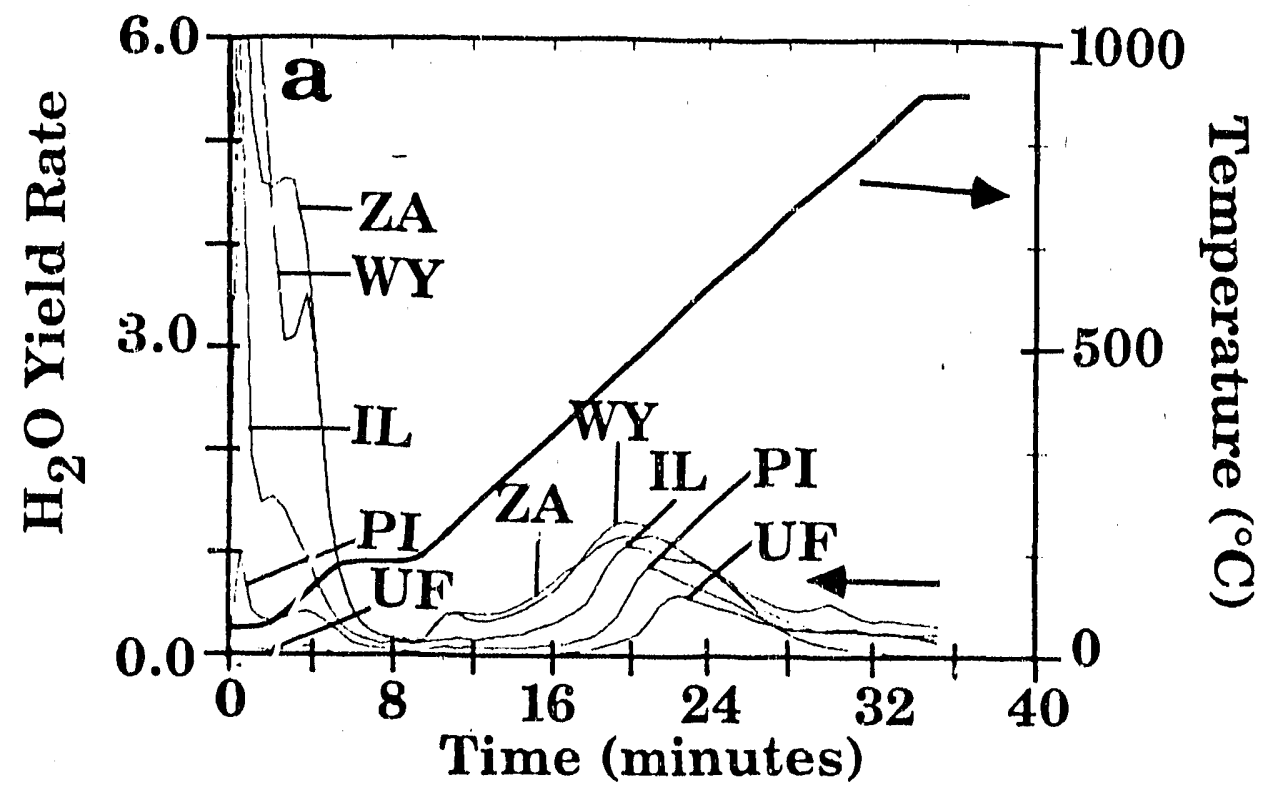

Figure II.A-1. Evolution Curves for $\mathrm{H}_{2} \mathrm{O}$ Measured in a TG/Plus for Five Coals from the Argonne Premium Samples Collected at $30^{\circ} \mathrm{C} / \mathrm{min}$ (UF-Upper Freeport, PI-Pittsburgh, IL-Illinois, WY-Wyodak, ZA-Zap Lignite). 


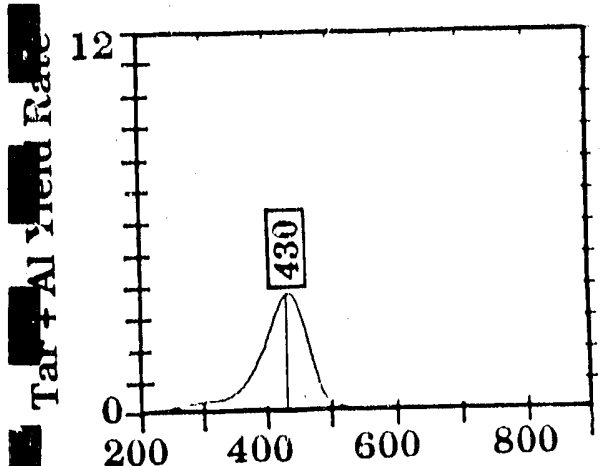

Temperature $\left({ }^{\circ} \mathrm{C}\right)$

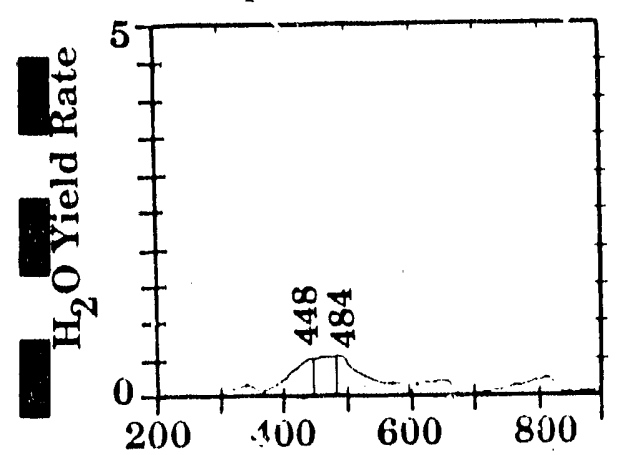

Temperature $\left({ }^{\circ} \mathrm{C}\right)$

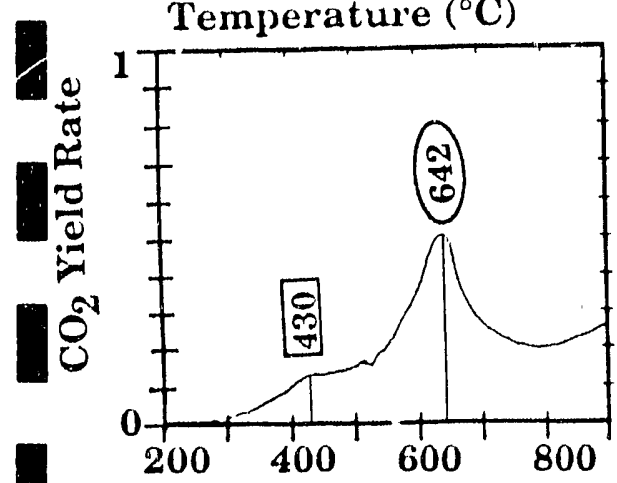

Temperature $\left({ }^{\circ} \mathrm{C}\right)$

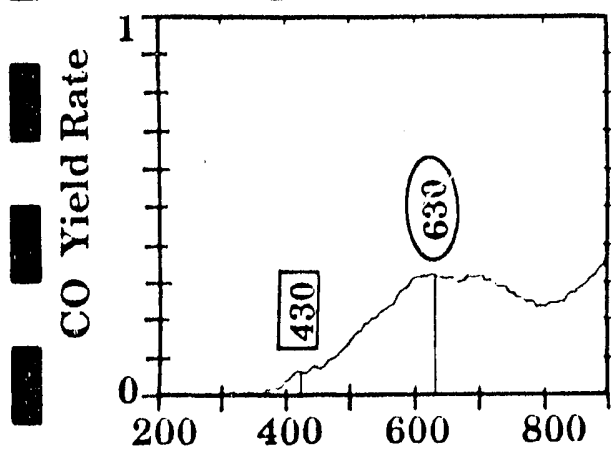

Temperature $\left({ }^{\circ} \mathrm{C}\right)$

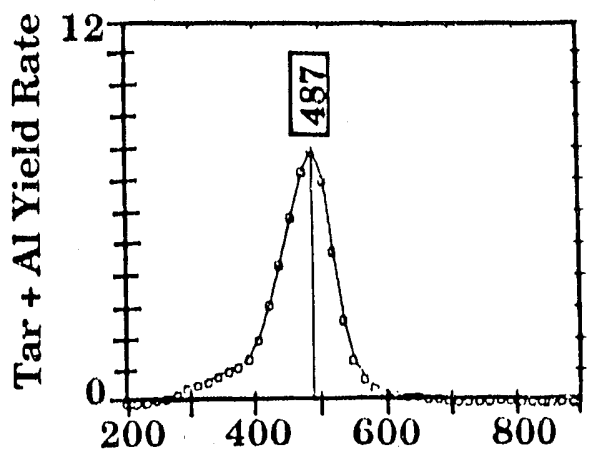

Tr mperature $\left({ }^{\circ} \mathrm{C}\right)$

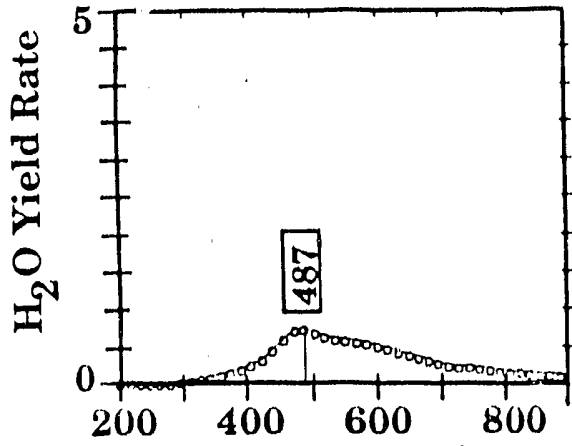

Temperature $\left({ }^{\circ} \mathrm{C}\right)$

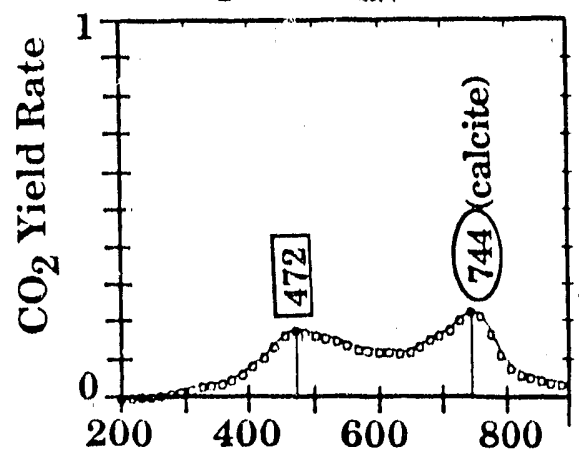

Temperature $\left({ }^{\circ} \mathrm{C}\right)$

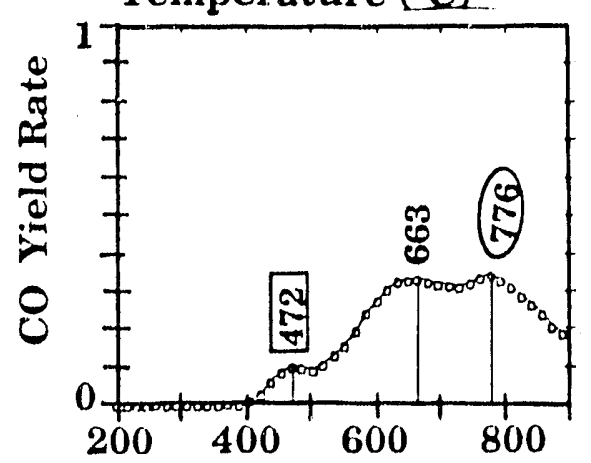

Temperature $\left({ }^{\circ} \mathbf{C}\right)$

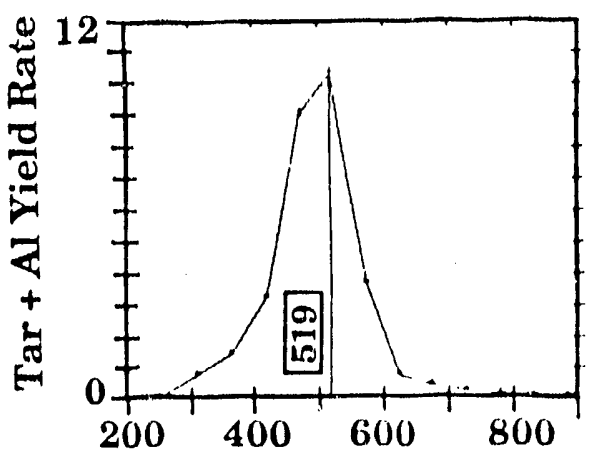

Temperature $\left({ }^{\circ} \mathrm{C}\right)$

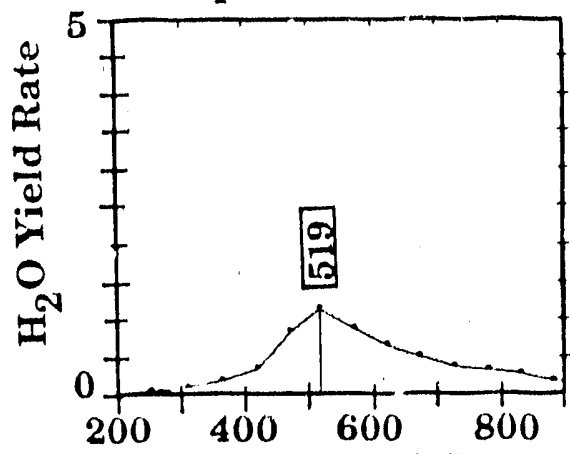

Temperature $\left({ }^{\circ} \mathrm{C}\right)$

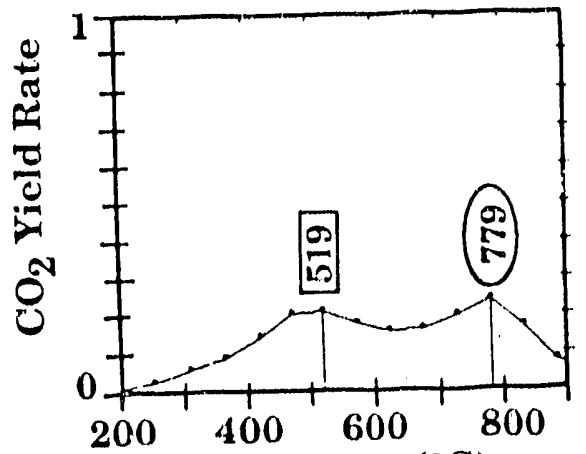

Temperature $\left({ }^{\circ} \mathrm{C}\right)$

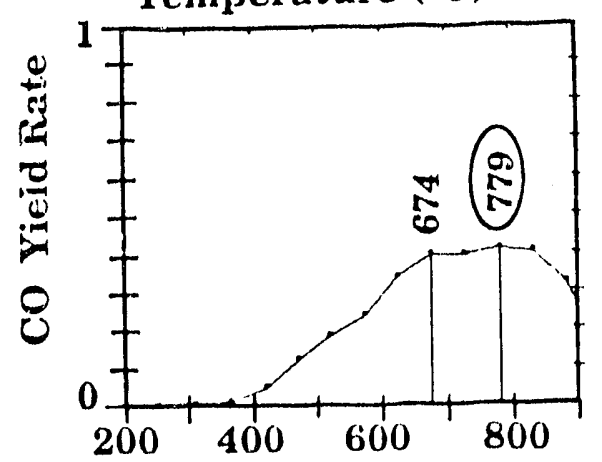

Temperature $\left({ }^{\circ} \mathrm{C}\right)$
$\mathrm{H}_{2} \mathrm{O}$

$\mathrm{CO}_{2}$

Tar

Aliphatics

CO

Figure II.A-2. Evolution of Tar, $\mathrm{H}_{2} \mathrm{O}, \mathrm{CO}_{2}$, and $\mathrm{CO}$ from Utah Blind Canyon Coal at Three Heating Rates. 
temperature at about $480^{\circ} \mathrm{C}$ for $30^{\circ} \mathrm{C} / \mathrm{min}$, at about $519^{\circ} \mathrm{C}$ for $100^{\circ} \mathrm{C} / \mathrm{min}$ and at about $430^{\circ} \mathrm{C}$ for $3{ }^{\circ} \mathrm{C} / \mathrm{min}$ runs. This feature implies that these volatile pools can be fit with the same kinetic parameters. This may also imply that there is some common cheritstry.

By using all the guidelines discussed so far, we were able to narrow down the range of choice for the kinetic parameters and determine a reasonable set of rank dependent kinetic rates for the Argonne Premium coals.

\section{Results}

A typical comparison of theory and TG-FTIR experiments is shown in Figs. II.A-3 to II.A-5 for three heating rates. The agreement between the theory and experiment is generally quite good except for $\mathrm{CO}_{2}$. For this specie, residual oxygen in the reactor causes some oxidation at the slowest heating rate and minerals contribute evolved $\mathrm{CO}_{2}$ which is not modeled. $\mathrm{CO}$ also shows some differences in the predicted amplitude, while the agreement is good for water, $\mathrm{U}$-loss, $\mathrm{CH}_{4}$, tar and $\mathrm{H}_{2} \mathrm{O}$.

We have applied these curve fitting procedures for the eight Argonne coals according to the rules cited above (i.e., frequency factor 1 ess than $10^{15} / \mathrm{sec}$ and constant for a seven gas species pool independent of coal rank). Preliminary results for the three co pools are presented as a factor of the coals' oxygen concentration in Fig. II.A-6. As can be seen, there is a systematic increase in activation energy with increasing rank. The variation in activation energy is maximum for the loose pool and reduces as the activation energy increases.

As mentioned previousiy, the lowest rank coals exhibit tar evolution which does not follow the trend of decreasing peak temperature with decreasing rank. Daia in Fig. II.A-7 shows the temperature for Wyodak coal tar is higher than that for 111 inois No. 6 coal. The Wyodak tar is also substantially more aliphatic than is the Illinois No. 6, and it appears that the Wyodak tar is dominated by polymethylenes.

As discussed by Serio et a1. (1990a), demineralization increases the tar yield. Results for the Wyodak subbituminous coal are presented in Fig. II.A-8. There is more tar for the demineralized coal. This tar is less influenced by 

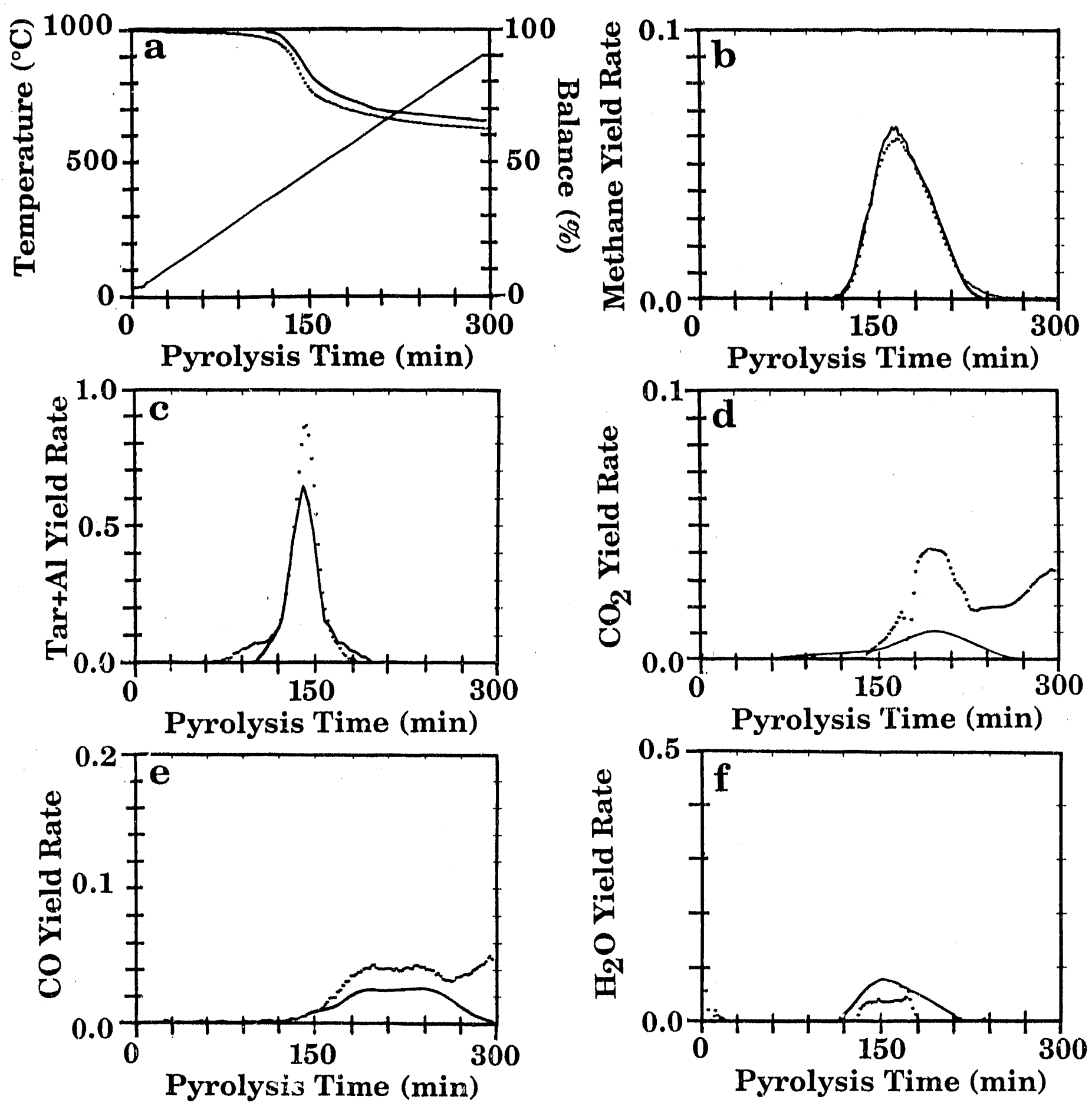

Figure II.A-3. Data from TG-FTIR Heating Rates $(\cdots)$ and Predictions of FG-DVC Model for Pittsburgh No. 8 Bituminous Coal at $3^{\circ} \mathrm{C} / \mathrm{min}$. a) Weight Loss and Temperature; b) Methane; c) Tar + Aliphatics Gases; d) $\mathrm{CO}_{2}$; e) CO; f) $\mathrm{H}_{2} \mathrm{O}$. 


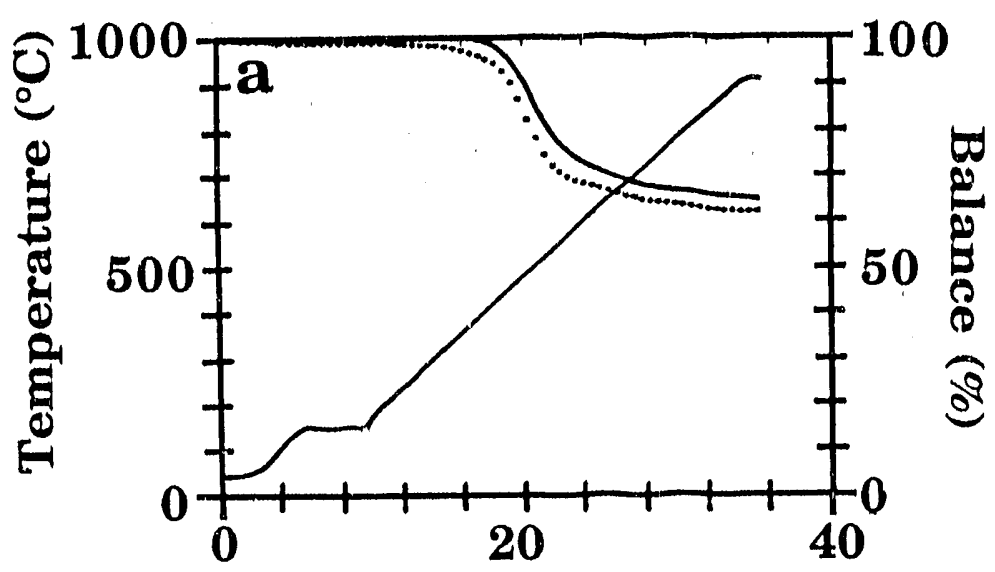

Pyrolysis Time (min)
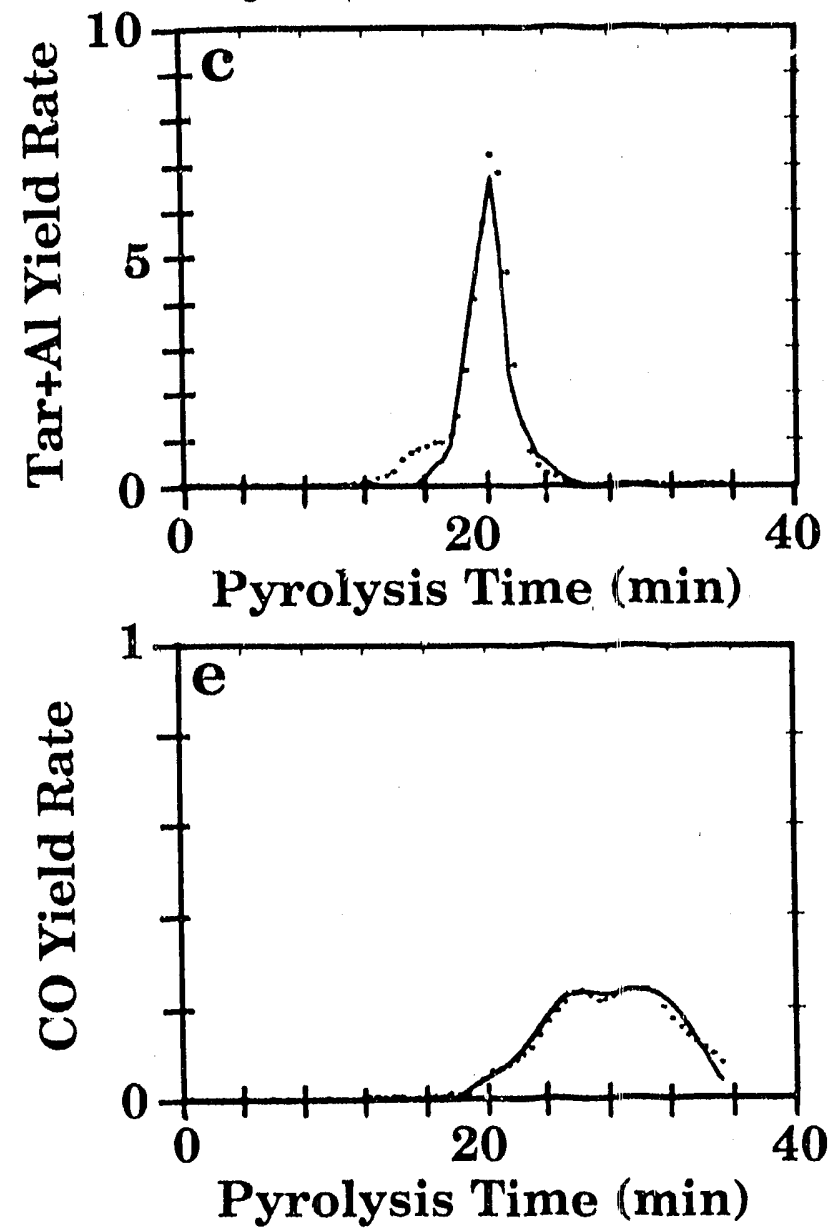

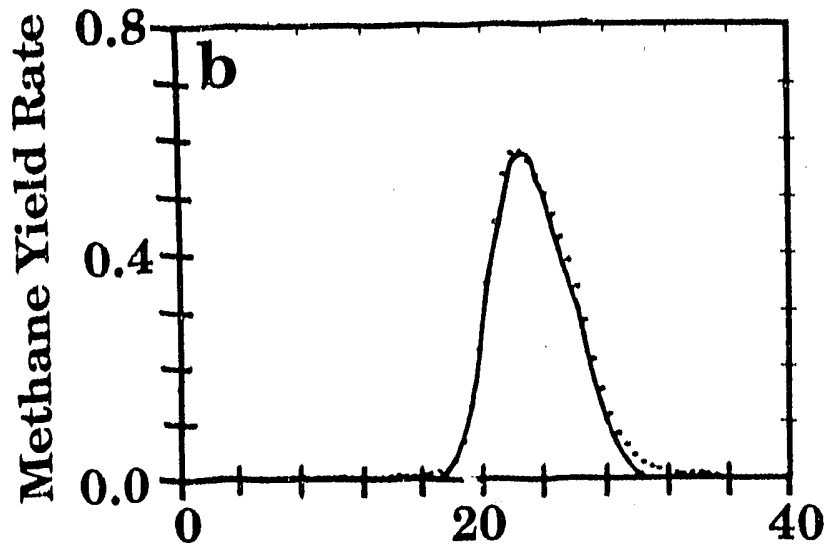

Pyrolysis Time (min)
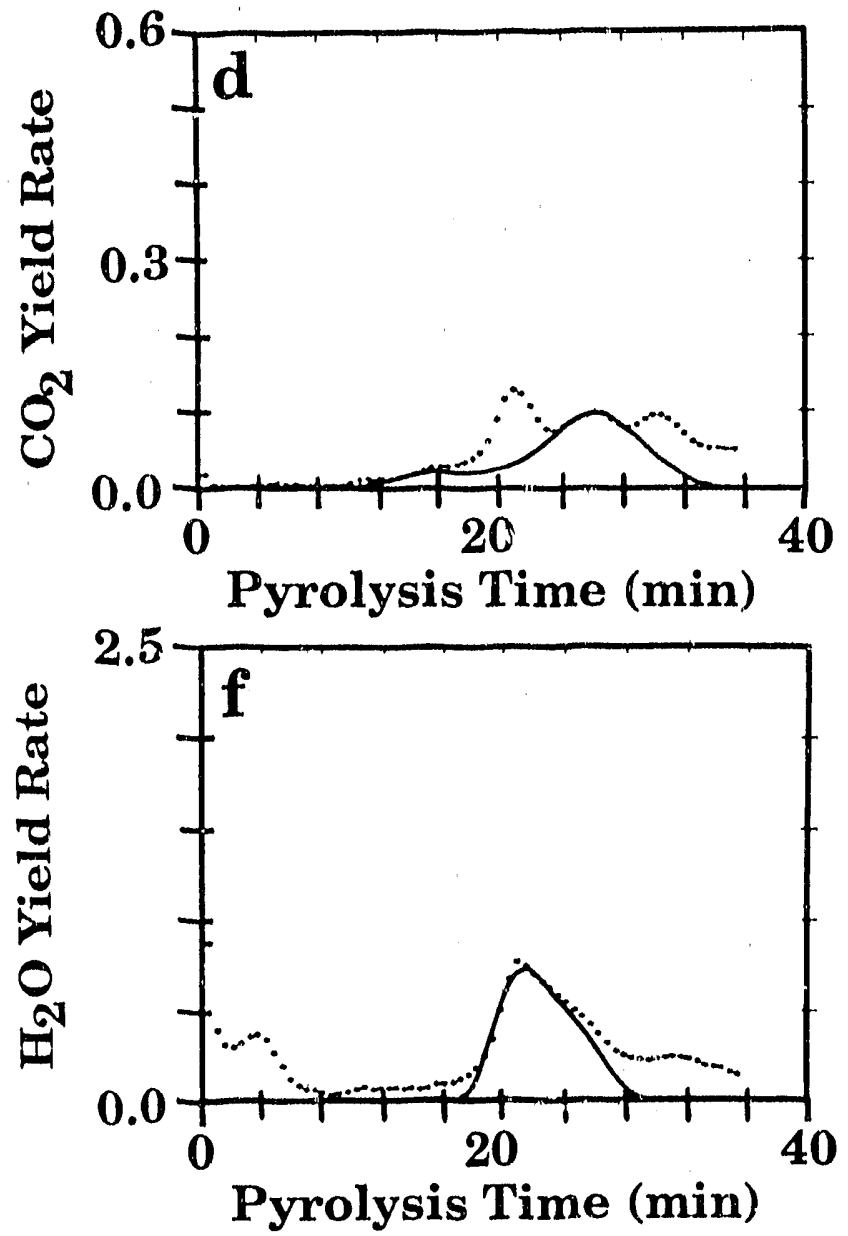

Figure II.A-4. Data from TG-FTIR Heating Rates $(\cdot \cdots)$ and Predictions of FG-DVC Model for Pittsburgh No. 8 Bituminous Coal at $30^{\circ} \mathrm{C} / \mathrm{min}$. a) Weight Loss and Temperature; b) Methane; c) Tar + Aliphatics Gases; d) $\mathrm{CO}_{2}$; e) CO; f) $\mathrm{H}_{2} \mathrm{O}$. 

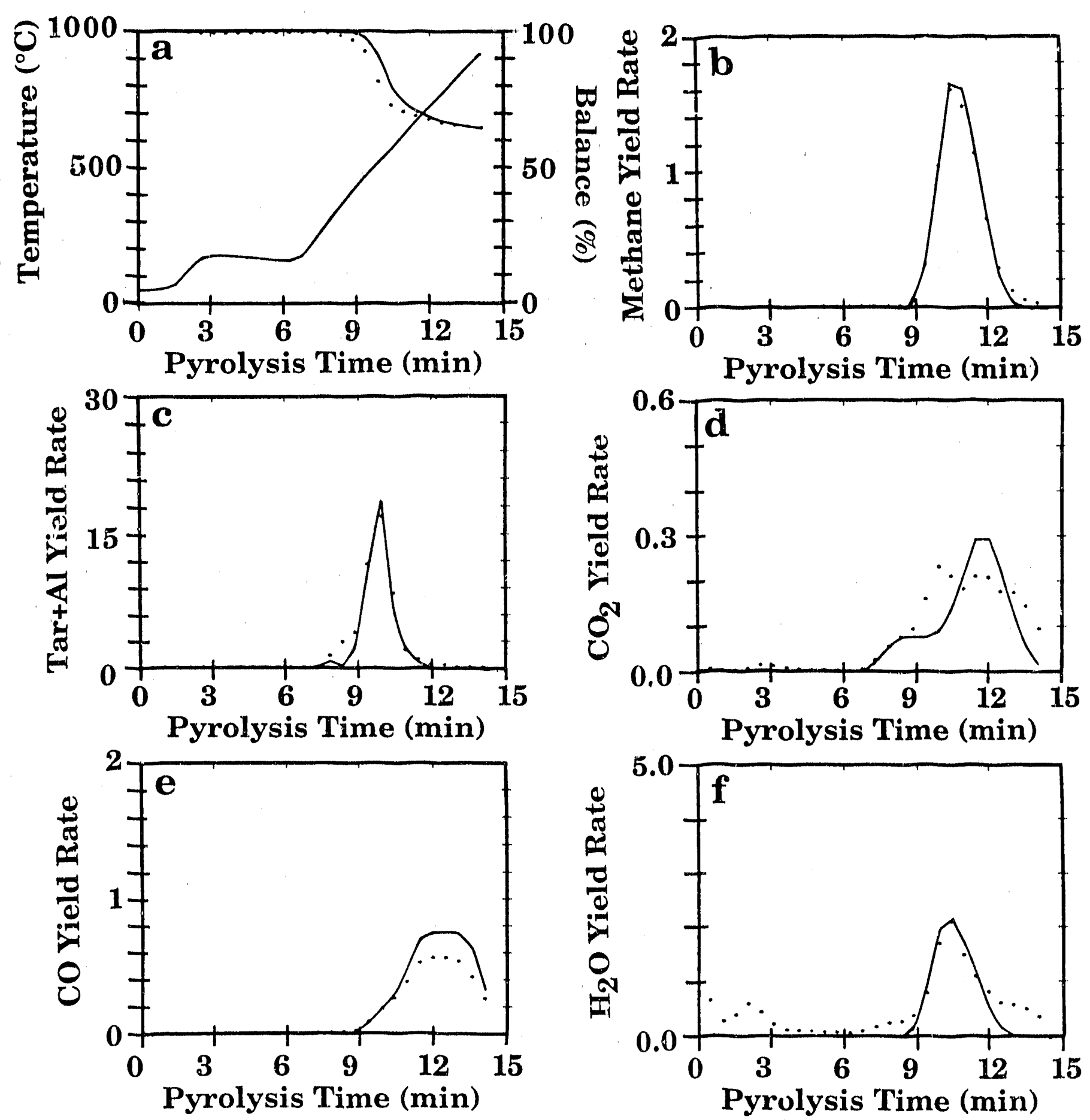

Figure II.A-5. Data from TG-FTIR Heating Rates (...) and Predictions of FG-DVC Model for Pittsburgh No. 8 Bituminous Coal at $100^{\circ} \mathrm{C} / \mathrm{min}$. a) Weight Loss and Temperature; b) Methane; c) Tar + Aliphatics Gases; d) $\mathrm{CO}_{2}$; e) CO; f) $\mathrm{H}_{2} \mathrm{O}$. 


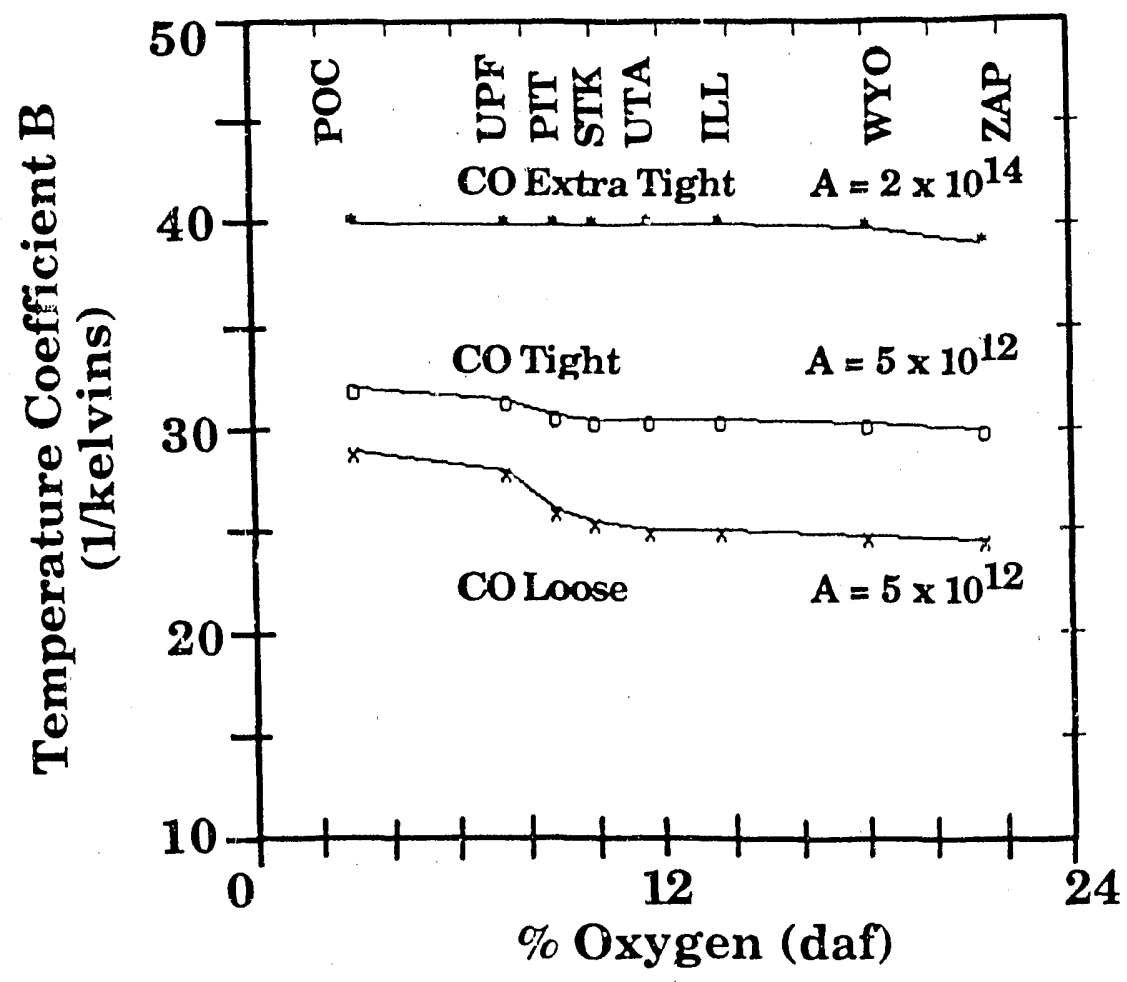

Figure II.A-6. Activation Energies for CO Loose, CO Tight and CO Extra Tight as a Function of the Coals Oxygen Concentration. The Frequency Factors are Shown in Parenthesis. 


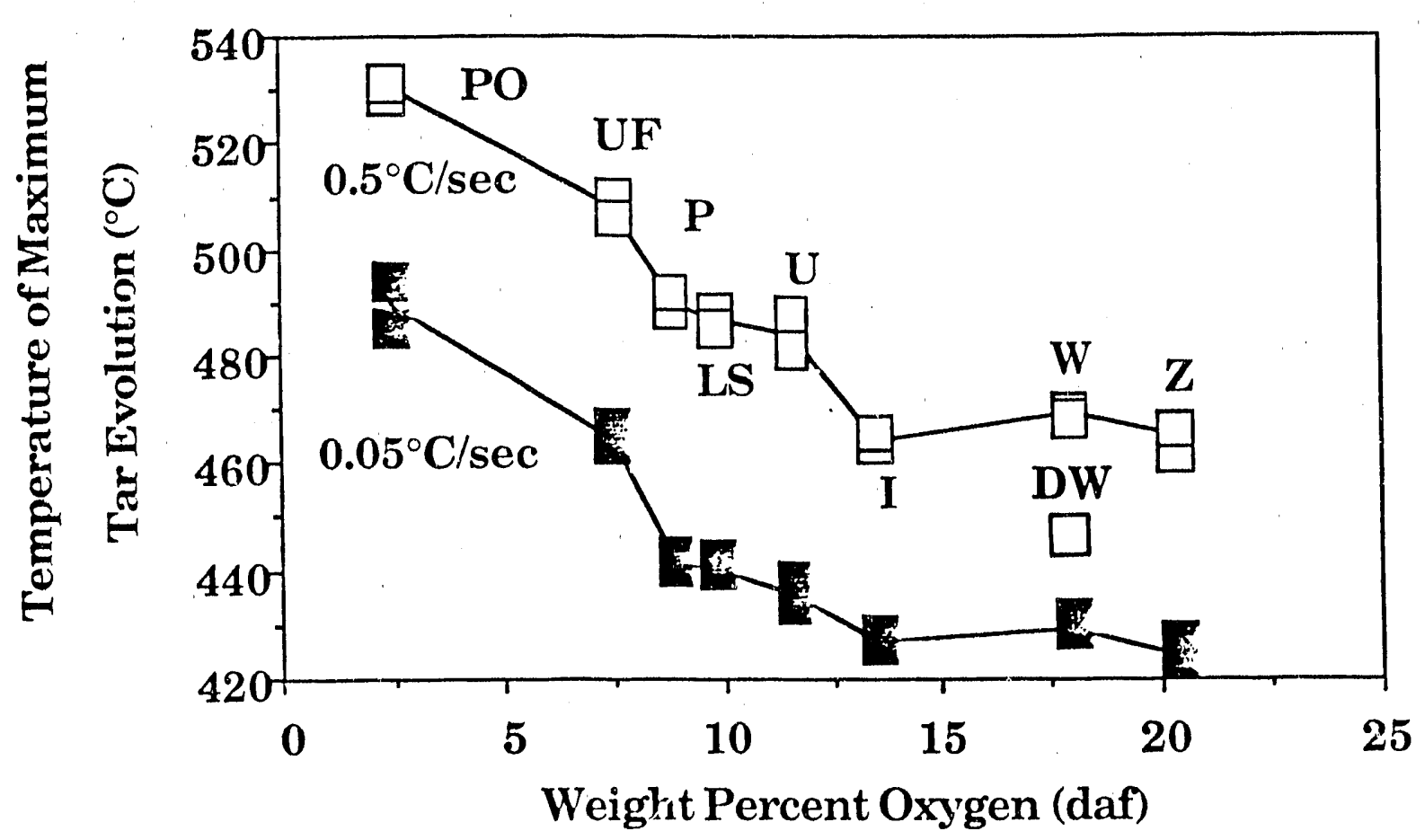

Figure II.A-7. Rank Variation of Tar Evolution Temperature. 


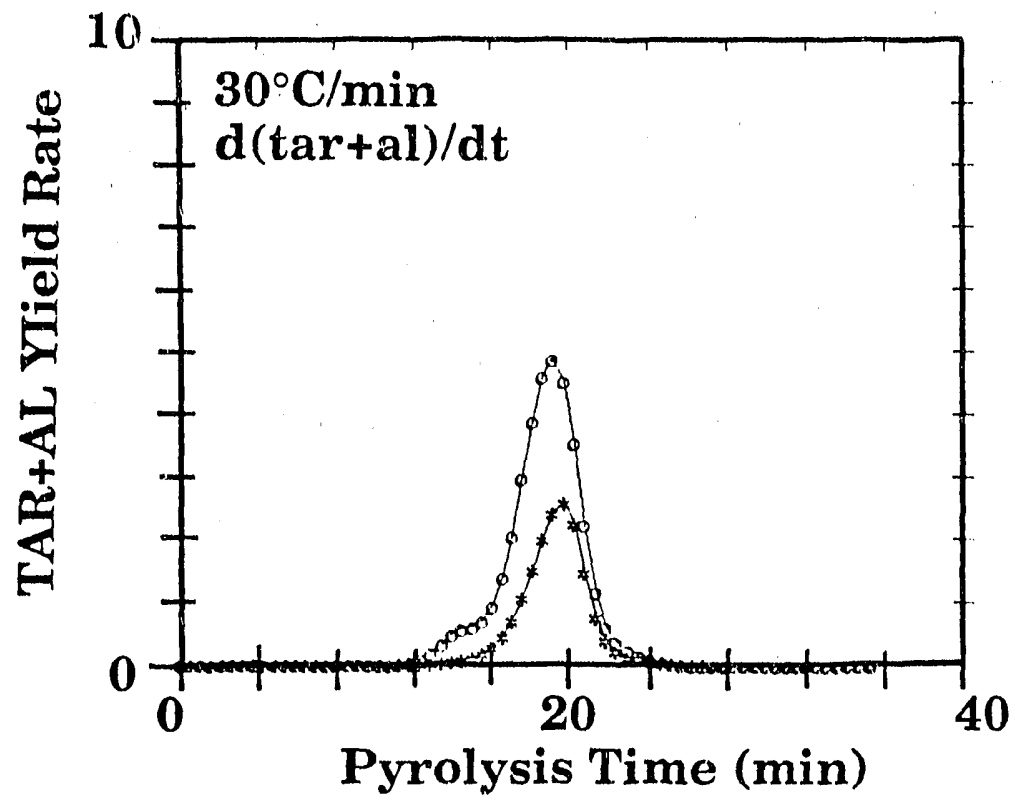

Figure II.A-8. TG-FTIR Analysis of Raw (*-*) and Demineralized (0-0) Wyodak Coal. 
polymethylenes and the peak appears at a temperature about $20^{\circ} \mathrm{C}$ lower. The peak for the demineralized Wyodak (Markel DW) continues the trend for decreasing temperature with decreasing rank as shown in Fig. II.A-7.

\section{Comparison of Monte Carlo and 2- $\sigma$ Percolation Models}

The prediction of the FG-DVC model using both the Monte Carlo and 2- $\sigma$ percolation tests are being compared. It appears that the 2- $\sigma$ percolation theory can give equivalent predictions to the Monte Carlo version. It is preferable to use the 2- $\sigma$ percolation theory version because of its speed and lack of statistical variation. Figure II.A-9 presents a comparison of the two models for predicting the liquid fraction, the tar, and the fluidity. The prediction of tar is compared to the tar yield measured in the TG/Plus. The predictions of fluidity are compared to Geissler fluidity measurements (Solomon et al., 1990c). Both models give comparable predictions which are in good agreement with the data.

The liquid fraction predictions are different. This difference has to do with what is defined as liquid. In the Monte Carlo model, the three largest network fragments are defined as char and the rest liquids. For the 2- $\sigma$ percolation model, all unattached fragments were defined as liquid. We will be examining the appropriate definition to use for the 2- $\sigma$ percolation model during the following quarters.

The 1 iquid fraction was compared to unpublished data of Sakurovs and Lynch (1990), using proton magnetic resonance thermal analysis (PMRTA). The technique discussed by Lynch et a1. (1988, 1988a) and Barton and Lynch (1989) measures the fraction of "mobile" hydrogen, where the mobility depends on the molecule's ability to rotate. The "mobile" fraction is zero at low temperatures because the temperature keeps even non-covalently bonded molecules rigid. As the temperature increases and the coal becomes fluid, the mobile fraction starts to resemble the predicted liquid fraction. Both predicted and measured "mobile" fractions reach a peak at the same temperature and decline in a comparable fashion. 

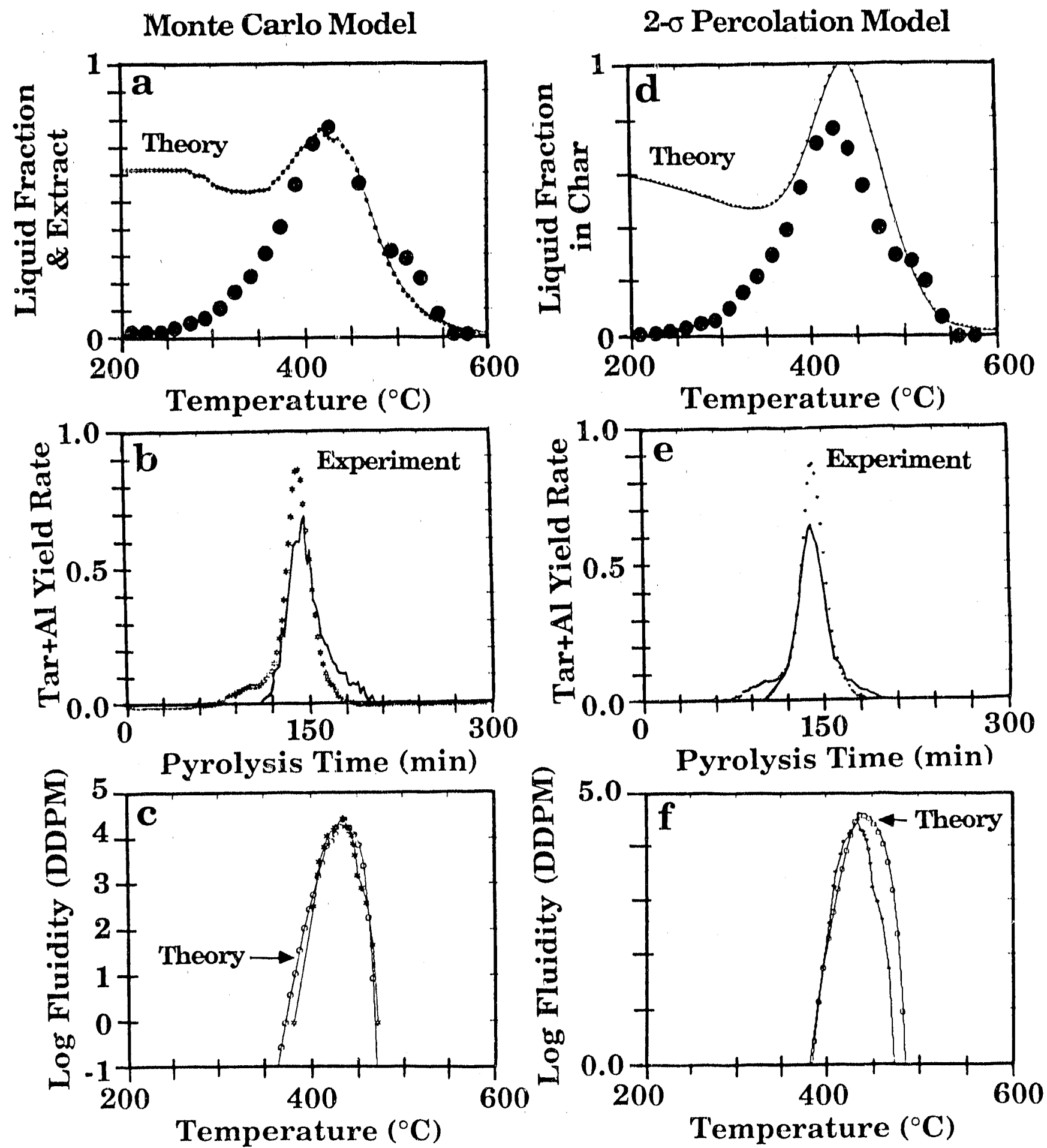

Figure II.A-9. Comparison of Monte Carlo and 2- $\sigma$ Percolation Theory for Liquid Fraction, Tar Yield and Fluidity for Pittsburgh No. 8 Bituminous Coal at $3^{\circ} \mathrm{C} / \mathrm{min}$. 


\section{Plans}

Determination of the rank dependent parameters will be completed and tested in the percolation theory version of the model by comparison to several data sets. In addition, the work on the swelling model will be continued. Work will be initiated on studying the evolution of sulfur and nitrogen species. 


\section{II.B. SUBTASK 2.B. - FUNDAMENTAL HIGH-PRESSURE REACTION RATE DATA \\ Senior Investigators - Geoffrey J. Germane and Angus U. Blackham Brigham Young University \\ Provo, Utah 84602 \\ (801) $378-2355$ and 6536}

Student Research Assistants - Charles R. Monson. Gary Pehrson. David Wheeler, and James Rigby

\section{Summary}

Diring the last quarter significant progress in developing the optical particle imaging system and the reactor collection system was made. The optical stands and brackets were designed and fabricated for the HPCP facility. The time required for size classification of pulverized coal was considerably reduced and the quality of the classification was improved significantly. Sufficient quantities of narrow size ranges of two of the test coals were produced for upcoming char preparation and oxidation tests. Analytical techniques to determine tar composition directly from tar filters were also developed and improved accuracy of char weight loss analysis through the use of four simultaneous tracers was investigated. Previously collected char and tar from Pittsburgh No. 8 bituminous coal was analyzed and compared using the new procedures.

\section{Qbjectives}

The overall objective of this subtask is to measure and correlate reaction rate coefficients for pulverized-cual char particles as a function of char burnout in oxygen at high temperature and pressure.

\section{Accomplishments}

Three components of the subtask have been identified to accomplish the objectives outlined above: 1) develop the laminar-flow, high-pressure. controlled-profile (HPCP) reactor, 2) prepare char at high temperature and pressure, and 3 ) determine the kinetics of char-oxygen reactions at high pressure. The HPCP reactor, capable of functioning at 400 psi 127 $\therefore$ iospheres), has been constructed to perform the fundamental reaction rate measurements required for the study. Data from another char oxidation study 
(atmospheric pressure) conducted at Brigham Young University will also be used.

Work continued during the last quarter on development of the optical particle imaging system and the reactor collection system. Significant progress was made in improving the size classification of pulverized coal and in reducing the time required. Sufficient quantities of narrow size ranges of two of the test coals were produced for upcoming char preparation and oxidation tests. Analytical techniques to determine tar composition directly from tar filters have been developed and improved accuracy of char analysis through the use of four simultaneous tracers has been investigated.

\section{High Pressure Reactor Development and Characterization}

Work during the reporting period has mainly focused on assembly of the optical instrument and improved size classification of pulverized test coals for char preparation and oxidation.

Optical Instrumentation - Mounting fixtures for all of the optical components as well as the laser, laser detector, and photomultiplier bases have been fabricated. A rotating pinhole wheel and mount was also fabricated for the calibration system. These fixtures provide sturdy mounting and easy adjustment for the instrument components. Alignment of the optics has begun as fixtures have been completed. Implementation of the optical instrument in the char oxidation experiments will improve the accuracy of the particle temperature history, resulting in more accurate reaction rate parameter determination.

The optical instrument is patterned after a system developed at Sandia National Laboratories for in situ measurement of single particle temperature, velocity and diameter (Tichenor et a 1., 1984). This system obtains temperature measurements by two-color pyrometry and particle velocity and diameter measurements through the use of an image-plane, coded-aperture technique. A new coded-aperture that improves diameter measurement accuracy, designed by wells (1990), is also included in the optical instrument being assembled for this project. A description of the instrument and its operation follows.

Particle Imaging system - Figure II.B-1 is a schematic of the optical instrument. Incandescent particles moving along the centerline of the reactor 


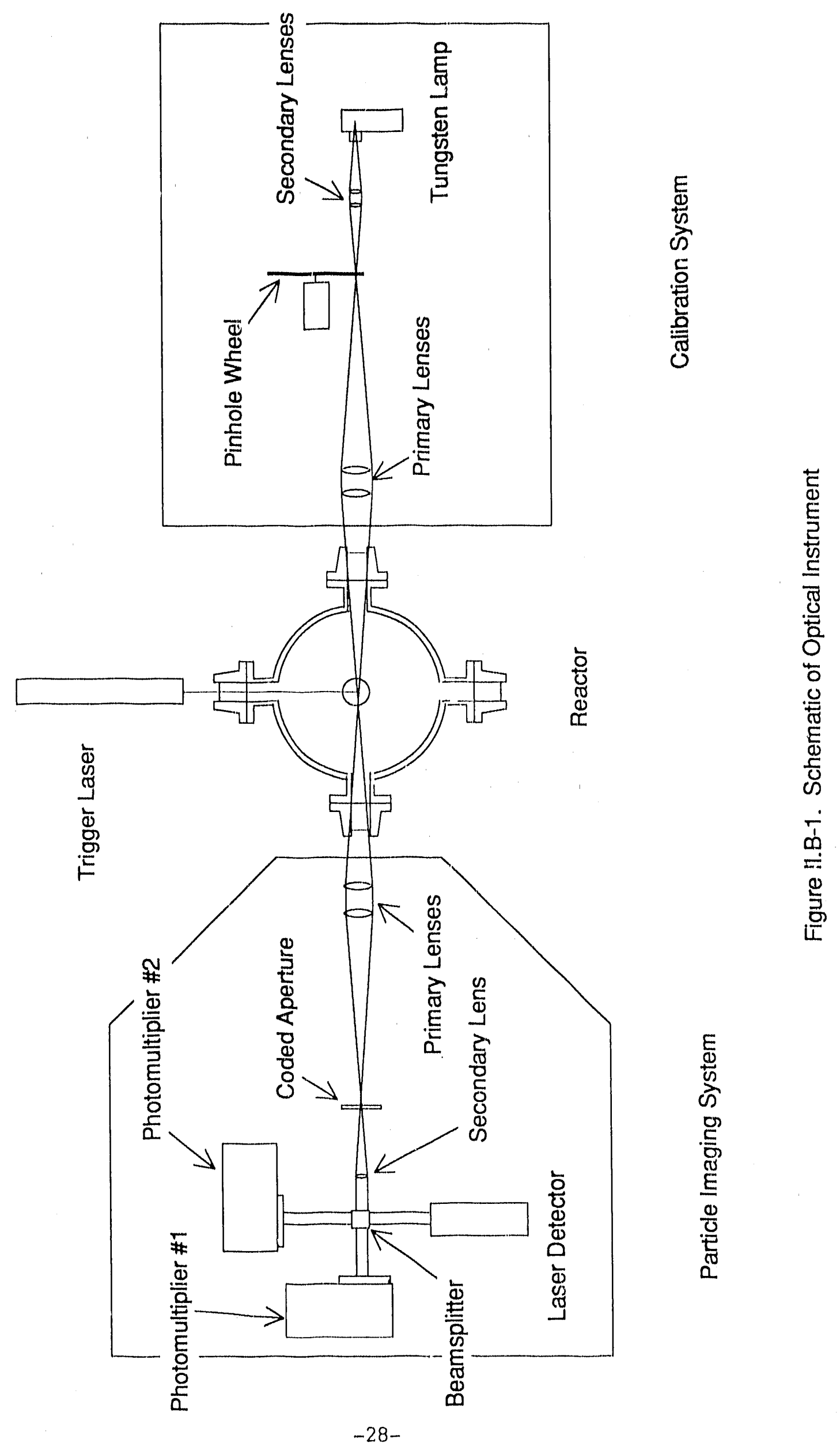


will be imaged at actual size onto a coded-aperture by a pair of lenses. The light transmitted through the aperture will be separated into two wavelength bands by a beamsplitter and two bandpass filters. The intensity of each of these wavelength bands will be detected by a photomultiplier tube and recorded by a high-speed digitizing oscilloscope. A laser beam, positioned perpendicular to the centerline of the optics immediately upstream of the sample volume, will act as a trigger. A particle moving down the centerline of the reactor will pass through the laser beam. scattering the laser 1 ight. A portion of this scattered light will travel through the optics to the laser detector. A pulse output from the laser detector will indicate that a particle is about to enter the sample volume and will trigger the oscilloscope to record the photomultiplier outputs. Because the laser is perpendicular to the optics centerline and directly above the optics focal point, only particles in focus will be measured. Specifications for the system components are 1 isted in Table II.B-1.

The coded aperture with its dimensions is shown in Figure II.B-2. The utper-most slit provides passage of the scattered laser light that will be used for the trigger. This slit is much narrower than the others to ensure that only particles passing through the center of the optical volume will be sampled. Errors in particle diameter measurements would occur if the entire particle width is not visible through the wider slits. The large slit centered on the aperture is for temperature and velocity measurements. This slit is large enough to allow the entire particle to be visible for a short duration. The three blackouts that make up the lower portion of the aperture will be used to obtain particle diameter. As a particle passes behind a blackout, its signal will be attenuated, which occurs as a function of particle diameter.

Calibration system - A calibration system, alsu shown in Figure II.B-I. is built into the instrument to provide temperature, velocity and diameter standards as well as to determine the system gain constant. The calibration system will project a false particle image into the sample volume of the reactor. This image will be formed by focusing a tungsten strip lamp of known temperature onto a series of pinholes that are mounted on a disc rotating at a known speed. The pinholes $(25,50,75$, and $100 \mu \mathrm{m}$ diameters) will chop the tungsten strip light beam and a pair of lenses will focus the false particle images into the sample volume. 


\section{Table II.B-1}

\section{Optlcal Instrument Component Specifications}

\section{Optics}

Primary Lenses: $\quad 356 \mathrm{~mm}$ F.L. $\quad \frac{f}{5.6} \quad$ Cemented Achromat

Secondary Lenses: $\quad 127 \mathrm{~mm}$ F.L. $\quad \frac{f}{5} \quad$ Cemented Achromat

Beam Splitter: $\quad 35 \mathrm{~mm} \times 35 \mathrm{~mm} \quad 50 \%$ Transmission \& Reflectlon

Fllters:

$\frac{\text { Center wavelength (nm) }}{400}$

$\frac{\text { Bandwidth (nm) }}{40}$

Transmittance $\theta$

at $C W L(\%)$

54

58

\section{Photomultipller Tubes}

Hamamatsu R928

(Quantum Efflclency: 20\%@400 nm, 4\%@700 nm, thermoelectrically cooled to $250 \mathrm{~K}$ )

\section{Trigger}

$5 \mathrm{~mW}$ HeNe Laser

Thorn EMI DA-603 Laser Detector

Data Aquisition

Nicolet 2090-3C $2 \mathrm{MHz}$ Digital Ocilloscope 


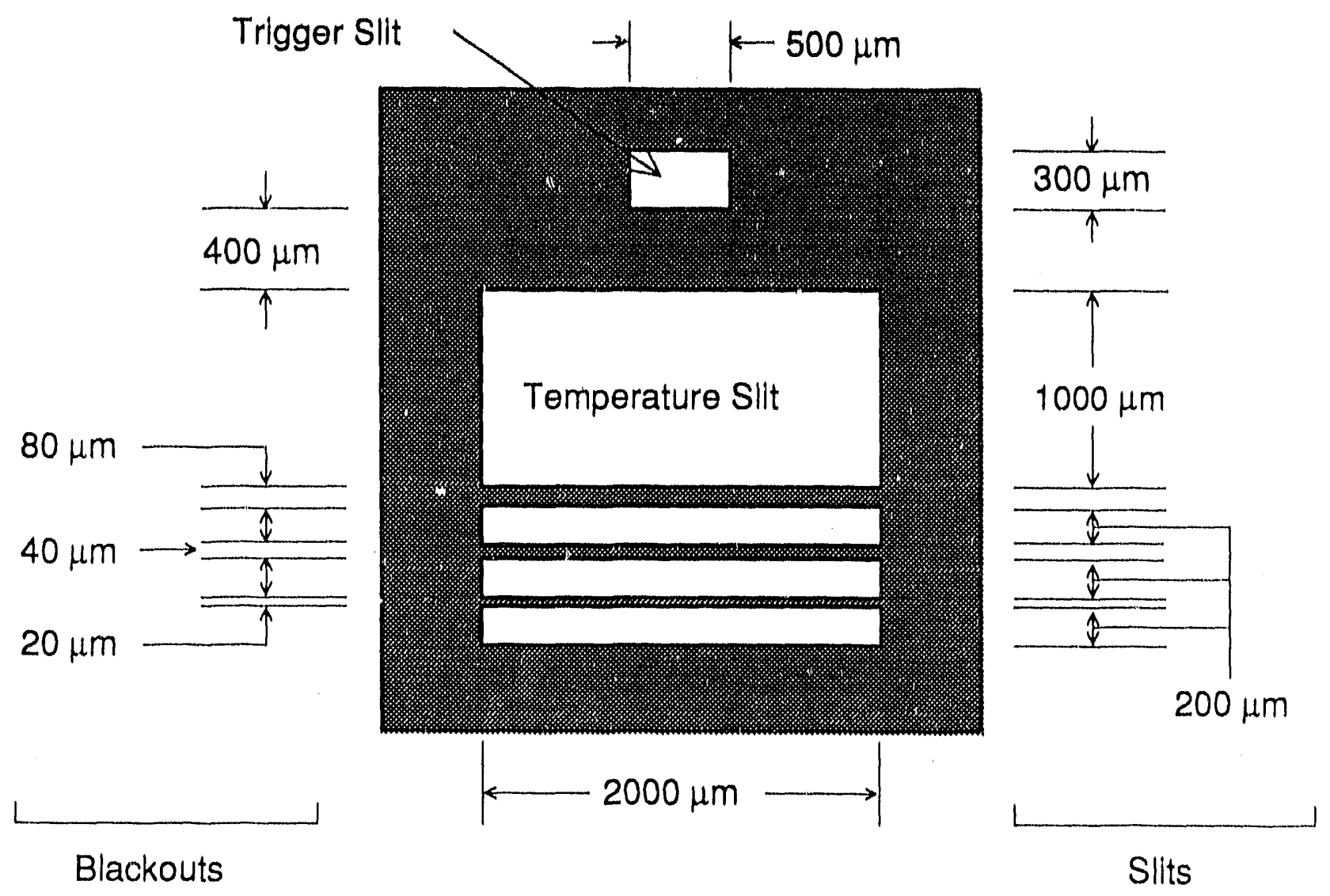

Figure II.B-2. Coded Aperture Configuration

Table II.B.2

Elemental Analysis of Char/Tar Sets

Sample

$\%$

$\% \mathrm{H}$

$\%$

$\mathrm{H} / \mathrm{C}$

P8-P.15 Char

72.0

3.2

2.6

0.044

P8-P-15 Tar

79.4

4.7

2.8

0.060

P8-P-19 Char

75.1

2.6

2.7

0.035

P8-P.19 Tar

80.2

3.8

2.9

0.047

P8-P.22 Char

76.5

0.8

2.5

0.010

P8-P.22 Tar

82.3

1.5

2.8

0.018 
Temperature Determination - Particle temperature will be determined using the relative intensity of emitted inllation in the two wavelength bands. Using planck's radiation law and assumlig that the particles behave as gray body emitters, the temperature is related to the photomultiplier outputs by the following equation.

$$
T=\frac{C_{2}\left(I_{1}-I_{2}\right)}{I_{1} I_{2}}\left[5 \ln \left(\frac{I_{1}}{I_{2}}\right)+\ln K\right]^{-1}
$$

where $T$ is particle temperature. $1_{1}$ is the center wavelength of channel $\|_{1} 1_{2}$ is the center wavelength of channel $z_{2}, C_{2}$ is the second thermal radiation constant, and $k$ is the calibration gain constant.

Velocity Determination - The vertical component of particle velocity will be determined from the transit time of the particle through the temperature slit of the coded-aperture:

$$
V=\frac{h}{t}
$$

where $V$ is particle velocity, $h$ is the aperture temperature slit height, and $t$ is the particle transit time.

Diameter Determination - At a given wavelength and temperature, the intensity of emitted radiation from a particle is proportional to the projected particle area. Assuming a spherical particle, the particle image will be that of a full circle in the temperature slit of the coded-aperture. When the particle passes behind ore of the blackouts, a smaller area will be visible. This can be used to determine the following relation between particle diameter and the relative intensity of particle emission when fully visible and when partially blocked. Because this is based on the assumption of a spherical particle, some error will be introduced with nonspherical particles. The size measurement is an indication of the particle height as follows:

$$
\frac{S_{b}}{S_{1}}=\frac{2}{p} \arccos \left(\frac{a}{d}\right)-\frac{2 a}{p d^{2}} \sqrt{d^{2}-a^{2}}
$$


where $d$ is the particle diameter, a is the aperture blackout height. $S_{b}$ is the signal of a partially blocked particle, and $S_{f}$ is the signal of fully vistble particle.

Detection Limits - The minimum particle size and temperature that can be measured with the optical instrument will be limited by the shot noise in the system. With a system similar to the one being assembled for this project, Wells (1990) found that at a signal to noise ratio of 10 , the temperature of a $30 \mu \mathrm{m}$ particle could be detected at a temperature as $10 \mathrm{w}$ as $1100 \mathrm{~K}$. At the same signal to noise ratio. while using the $20 \mu \mathrm{m}$ blackout on the coded. aperture, the diameter of a $30 \mu \mathrm{m}$ particle could be detected at a temperature as $10 \mathrm{w}$ as $1000 \mathrm{~K}$.

Iar/Char/Gas Collection System - A new version of the collection and separation system was designed under a separately funded project during the reporting period. In the modified design, a sintered stainless steel tube extends from the entrance of the collection probe to the virtual impactor nozzle. Cold nitrogen passes through this tube, quenching reactions in the collection probe and reducing tar buildup on its inner surface. The modifications are intended to reduce tar buildup in the virtial impactor by considerably reducing the overall size of the impactor body.

\section{Char Preparation at High Temperature and High Pressure}

During the reporting period, emphasis has been given to decrease the particle size range of the fractions of the selected coals. Work has also continued on the analysis of the tar fractions from earlier char preparation runs with the Pittsburgh 非 coal. The tar fractions were collected on glass microfibre filters. The CHN analyses of these tar/filter samples has been attempted without removing the tar from the filter.

Coal/char size classification - Previously, some of the coal samples appeared to have small particles adhering to the particles in the expected size range. Considerable reduction in the amount of these small particles has been achieved using a combination of sieving and aerodynamic classification. Therefore, samples of the selected coals are being fractionated by this procedure into the two size ranges for the oxidation kinetic runs. These narrow size fractions are being characterized by a coulter counter for 
particle size distribution, and a scanning electron microscope for size and shape determination.

In addition to the North Dakota Lignite. Pitt 非 bituminous coal was also classified for testing. The same procedure of classification. sieving. and grinding was used as was described in the last quarterly progress report. However, because of the large initial size of the Pitt 非 sample, the coal was pulverized before being classified with the Vortec classifier. Currently, the pulverizer produces coal particles with a mean diameter of $50 \mu \mathrm{m}$. A higher mean diameter is desired for future sizing runs in order to reduce the production of particles with diameters less than $39 \mu \mathrm{m}$. A larger mesh pulverizer screen is expected to produce a mean diameter of $75 \mu \mathrm{m}$.

The coulter counter has been primarily used for checking coal classification since there have not been many tests. The electrolytic solution for the coulter counter is now being produced at BYU. The resistive properties of the solution are slightly different than those of commercially prepared solutions and requires recalibration of the coulter counter. After recalibration, this solution is expected to work as well as commercial solutions while also being more cost-effective.

Char/Tar Analysis - A procedure to determine the elemental composition of the tar has been developed. The tar collected on the glass fiber filters is used to measure the $\mathrm{H} / \mathrm{C}$ ratio of the tar. This ratio should be higher than for the corresponding char from that char/tar set. The procedure leaves the tar undisturbed on the filter, enabling analysis of all tar samples, not only those with heavy tar loading on the filters. The sample placed in the Leco CHN-800 contains the tar and the filter. The mass of the glass-fiber filter is tared out prior to the analysis. Thus, the only mass the instrument sees is that of the tar. The filter residue is ashed and doesn't affect analysis.

Three samples from the Pitt 非 char/tar sets are compared in Table II.B.2. The H/C ratio in each case increases for the tars. An effect of temperature, pressure or residence time can be seen as the $H / C$ ratio steadily decreases as those three variables are increased. This indicates that the tars are being cracked after evolution from the char before they reach the quenched collection probe. 


\section{Kinetics of Char-Oxygen Reactions at High Pressure}

Literature Review - In a recent set of papers by Fletcher (1989a, 1989b), the importance of particle temperature measurements is discussed. It is thought that the wide difference in reported kinetic parameters of coal chars can be attributed to errors in determining particle temperatures. The weight loss measurements are improved using multi-element tracers (titanium. silicon and aluminum) in addition to ash. It is noted that the use of titanium as a tracer yields data that monotonically increase. while the other three tracers produced results with some occasional low data points. However. simultaneous use of all four tracers generally gave narrower confidence limits than could be determined using three or fewer tracers.

\section{Other Activities}

The senior investigator received several visitors from the people's Republic of china during the reporting period to discuss the ongoing work in coal combustion and high pressure char oxidation. The research team continued participation in the char oxidation coordination activities at BYU in which resources and results from three independent char oxidation studies are shared.

\section{Plans}

During the next quarter the installation of the new collection probe and virtual impactor will be completed for coal devolatilization and char oxidation tests, under independent funding. Alignment of the optical instrument will be completed during the next reporting period. The instrument will also be completely enclosed in a light-tight cover that will attach to the HPCP reactor. Since any stray light introduced into the optical system drastically increases noise, this will improve the instrument accuracy and allow operation of the system with the room lights on.

Computer control of the reactor wall heaters will also be implemented during this same period. This will reduce temperature deviation and improve repeatability of reactor conditions in addition to improving ease of reactor operation. 
Work will continue to carefully size coal particles prior to char preparation and oxidation. An experimental plan will be finalized for the remaining coals using a predictive reaction code to suggest test conditions. Char preparation and oxidation using at least three of the test coals for this study will be initiated under carefully controlled conditions in the HPCP reactor. 


\title{
II.C. SUBTASK 2.c. - SECONDARY REACTION OF PYROLYSIS PRODUCTS AND CHAR BURNOUT SUBMODEL DEVELOPMENT AND EVALUATION
}

\author{
Senior Investigator - James R. Markham and Michael A. Serio \\ Advanced Fuel Research, Inc. \\ 87 Church Street, East Hartford, CT 06108
}

(203) 528-9806

\section{Objective}

The objective of this subtask is to develop and evaluate by comparison with laboratory experiments, an integrated and compatible submodel to describe the secondary reactions of volatile pyrolysis products and char burnout during coal conversion processes. Experiments on tar cracking, soot formation, tar/gas reactions, char burnout, and ignition will continue during Phase II to allow validation of submodels in Phase II.

\section{Accompl ishments}

Additional work was done on the coal flame experiments in the TWR using the FT-IR Emission' Transmission Tomography technique. Two cases have now been completed for the Montana Rosebud coal (low velocity and high velocity). A low velocity case for the Pittsburgh Seam coal is about $50 \%$ complete. A paper based on a comparison of the two velocities and the two coal types was prepared for the ACS Washington meeting (Solomon et al., 1990d).

\section{Plans}

Complete tomography measurements for the two different coals (Montana Rosebud subbituminous, Pittsburgh Seam bituminous). Do color maps for presentation of tomography data. Continue characterization of TWR geometry and interact with BYU on PCGC-2 simulations of this system. 
S/15th-B. \#94 METC 15th Quartehly 7/80 - 11

\section{II.D. SUBTASK 2.d. - ASH PHYSICS AND CHEMISTRY SUBMODEL \\ Senior Investigators - James Markham and Michael Serio Advanced Fuel Research, Inc. \\ 87 Church Street, East Hartford, CT 06108}

(203) 528-9806

\section{Objective}

The objective of this task is to develop and validate, by comparison with laboratory experiments, an integrated and compatible submodel to describe the ash physics and chemistry during coal conversion processes. AFR will provide the submodel to BYU together with assistance for its implementation into the BYU PCGC-2 comprehensive code.

To accomplish the overall objective, the following specific objectives are: 1) to develop an understanding of the mineral matter phase transformations during ashing and slagging in coal conversion; 2) To investigate the catalytic effect of mineral matter on coal conversion processes. Data acquisition will be focused on: 1) design and implementation of an ash sample collection system; 2) developing methods for mineral characterization in ash particles; 3 ) developing methods for studying the catalytic effects of minerals on coal gasification.

\section{Accompl ishments}

No work was scheduled.

Plans

Continue study of mineral effects on the reactivity of low and high rank coals. Resume analysis of material and element balances from ash collections in the entrained flow reactor. 


\section{II.E. SUBTASK 2.e. - LARGE PARTICLE SUBMODELS \\ Senior Investigator - Michael A. Serio \\ Advanced Fuel Research, Inc. \\ 87 Church Street \\ East Hartford, CT 06108 \\ (203) 528-9806}

\section{Objective}

The objectives of this task are to develop or adapt advanced physics and chemistry submodels for the reactions of "large" coal particles (i.e., particles with significant heat and/or mass transport limitations) and to validate the submodels by comparison with laboratory scale experiments. The result will be coal chemistry and physics submodels which can be integrated into the fixed-bed (or moving-bed) gasifier code to be developed by BYU in subtask 3.b. Consequently, this task will be closely coordinated with Subtask 3.b.

\section{Accomplishments}

The work on the AFR fixed-bed reactor (FBR) system continued. No additional experiments were done during the past quarter. We are still evaluating the data which has been taken for the two stage experiments and the variable bed depths. A redesign of the experiment has been proposed and approved which will allow better quantitation of the tar yields and independent control of the temperature of the second bed. Assembly has begun on a redesign of the experiment.

Samples of large particles for each of the eight premium coals have been ordered from Argonne and shoula be received by July 1, 1990.

Discussions continued with BYU about the single particle FG-DVC model for use in the fixed bed reactor. For this purpose, AFR is developing an ordinary different equation (CDE) version of the 2- $\sigma$ percolation FG-DVC model. Additional refinements were done to the model. The speed has been increased so that it is now only four times slower than the standard percolation theory version. However, it is still two times faster than the standard Monte carlo version. 
The code was sent to BYU for integration into the Advanced Fixed-Bed Model. Further refinements were done of the ODE/percolation version of the FG-DVC model by using a different technique for integration of the activation energy distribution. This change affords an additional increase in the execution speed of a factor of five. This change can also be incorporated into other versions of the model. Discussions continued with BYU about the single particle FG-DVC mode1. A meeting was scheduled at AFR to discuss the single particle model which will involve members of both teams.

\section{Differential Equation (ODE) Version of the 2- $\sigma$ Percolation Model}

During the current quarter, we have developed a version of the FG-DVC model which can be solved using a standard solver for ordinary differential equations (ODE). The solver used is the Livermore Solver of Ordinary Differential Equations with Sparse jacobian (LSODES). Previously, we had solved the equations with a combination of analytic solutions, where known, and Newton's method. We had used the assumption that the temperature was constant over a time step so that many of the equations could be solved analytically, and we used a suitably small time step to treat cases where the temperature was changing. For integration with the Fixed Bed modelling of Task 3, we needed to treat variable time-temperature behaviors in a more general manner; so the FG-DVC equations were cast into a form suitable for the LSODES code. The details of the equations are described in the attached Appendix $A$.

The model is identical in concept to that described in the general model paper (Solomon et a1., 1988) and the network paper (Solomon et a1., 1990e) except for a change made in the treatment of the distributed activation energy model (DAEM) of the kinetic rates. In the old versions, the assumption is that the starting distribution of activation energies, $E_{1}$, is assumed to be a truncated gaussian, and is simulated using 21 subpools, each of which is evolved over time and temperature. This means that after a short time, these distributions are no longer gaussian. Since the low energy subpools in the distribution evolve much faster (exponentially) than the higher energy pools, we were led in the new version to keep the distribution as a truncated guassian, but to evolve the low energy truncation point with time. The validity of this assumption is supported by Figure II.E-1, which shows the evolution of the shape of the distribution in the original version of the model for several pools as 


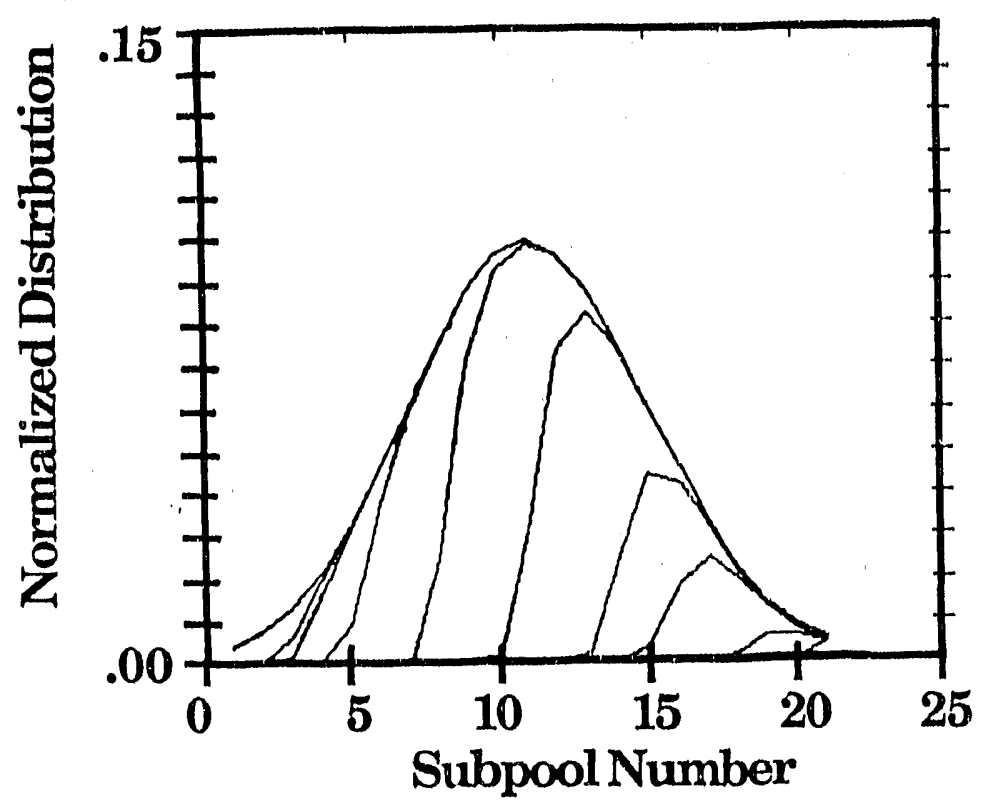

Figure II.E-1. Shape of the Species Source Distribution Function as it is Depleted $\left(\mathrm{CO}_{2}\right.$ extra loose at $\left.30^{\circ} \mathrm{C} / \mathrm{min}\right)$. 
a function of time. The improved version would have a vertical ine for the leading edge of the pool and is thus a reasonable approximation of the shapes in Fig. II.E-1. The benefit is of course that we have replaced 21 ODE's with a single one, for each of 27 functional groups.

The cpu run time in seconds for several cases run on a SUN $3 / 50$ with a 68881 floating point chip is shown below:

\begin{tabular}{cccccc} 
Improved & $\begin{array}{c}\text { Standard } \\
\text { ODE Version } \\
\text { (7 subpools) }\end{array}$ & $\begin{array}{c}2-\sigma \text { Percolation } \\
(21 \text { subpools) }\end{array}$ & $\begin{array}{c}\text { Monte Carlo } \\
\text { FG-DVC (high } \\
\text { rank coal) }\end{array}$ & $\begin{array}{c}\text { Monte Carlo } \\
\text { FG-DVC (low } \\
\text { rank coal) }\end{array}$ \\
\hline 1 & $105 \mathrm{sec}$ & $500 \mathrm{sec}$ & $25 \mathrm{sec}$ & $180 \mathrm{sec}$ & $1600 \mathrm{sec}$ \\
2 & $126 \mathrm{sec}$ & $619 \mathrm{sec}$ & $25 \mathrm{sec}$ & $180 \mathrm{sec}$ & $1600 \mathrm{sec}$ \\
3 & $129 \mathrm{sec}$ & $632 \mathrm{sec}$ & $25 \mathrm{sec}$ & $180 \mathrm{sec}$ & $1600 \mathrm{sec}$ \\
4 & $112 \mathrm{sec}$ & $287 \mathrm{sec}$ & $25 \mathrm{sec}$ & $180 \mathrm{sec}$ & $1600 \mathrm{sec}$
\end{tabular}

Case 1 is the slow heating rate $\left(3^{\circ} \mathrm{C} / \mathrm{min}\right)$ simulation of the TG.Plus (rio tar cracking).

Case 2 is the regular heating raie $\left(30^{\circ} \mathrm{C} / \mathrm{min}\right.$ ) simulation of the TG-Plus (no tar cracking).

Case 3 is the fast heating rate $\left(100^{\circ} \mathrm{C} / \mathrm{mln}\right)$ simulation of the TG-Plus (no tar cracking).

Case 4 is the slow heating rate $\left(3^{\circ} \mathrm{C} / \mathrm{s}\right)$ simulation of thu viscosity measurement (with tar cracking).

The predicted gas and tar evolutions using the improved ODE version 10ok identical to the original prediction using 21 subpools with a minimum adjustment of the activation energies ( $3 \%$ reduction).

\section{Plans}

Complete redesign of fixed-bed reactor system. Complete initial set of experiments on secondary reaction effects in thick beds. Continue development of single particle model with BYU and send the complete ODE version to BYU. Begin work on tar repolymerization model. 


\section{II.F. SUBTASK 2.F. - LARGE PARTICLE OXIDATION AT HIGH PRESSURES \\ Senior Investigators: Angus U. Blackham and Geoffrey J. Germane Brigham Young University \\ Provo. Utah 84602 \\ (801) $378-2355$ and 6536}

Student Research Assistants: Gary Pehrson and Michael Scheetz

\section{Objectives}

The overall objective for this subtask is to provide data for the reaction rates of large char particles of interest to fixed-bed coal gasification systems operating at pressure. The specific objectives for this quarter include selecting an additional individual for work on this study. reviewing more extensively the literature on the use of force transducers in high-pressure, high-temperature thermobalances, continuing discussion and evaluation of equipment design features, continuing evaluation of analytical procedures for monitoring the kinetics of oxidation of large particles, and conducting additional preliminary oxidation experiments.

\section{Accomplishments}

Two components of this subtask to accomplish the overall objective have been suggested in the plans outlined earlier: 1) high-pressure, large. particle reactor design, fabrication and preliminary data: 2) experimental reaction rate data for chars from five coals. The general features of the experimental unit will be a "large particle insert" to be placed in the HPCP facility of subtask 2b. The "large particle insert" will consist of: (a) the reactor tube, (b) the balance unit, and (c) the connecting pipe. In this quarter, attention has been given to the development of the balance unit. A force transducor with specifications to permit monitoring of weight loss of 1 5 gram particles has been selected and ordered. An individual in the mechanical engineering program has been selected to work on the specific details of the design of the balance unit while experimental testing of the force transducer at atmospheric pressure is proceeding. Familiarity with the system at atmospheric pressure will help in anticipating difficulties when the balance unit is placed under pressure. A more extensive review of the literature on the use of force transducers in high-pressure, high-temperature thermobalances has been accomplished. 
The testing of the new. single column for the gas chromatographic analysis of carbon monoxide and carbon dioxide was temporartly postponed during this quarter and will be accomplished during this next quarter.

An additional set of large particles of a Utah bituminous coal have been oxtdized in platinum crucibles and compared with the results reported in the 14 th Quarterly (Solomon. 1990).

\section{High-Pressure Large-Particle Reactor Design}

Introduction and Literature survey - The earlier review of the literature on thermobalances operating at high pressures was more concerned with use in coal combustion and gasification. Extension of this literature survey to the use of thermobalances in other types of chemical reactions has given additional information for the design of the experimental unit for this subtask.

Bae (1972) describes a simple thermogravimetric apparatus which was used at pressures up to $70 \mathrm{~atm}$. The device was dumbbe11-shaped with the furnace at one end and the balance unit at the other. A microforce transducer is used as the weighing device with an accompanying transducer amplifier-indicator to report and record the output. The maximum sensitivity of the transducer was approximately $\pm 0.1 \mathrm{mg}$. Satisfactory weight-loss thermograms were reported for the oxidation (with air) and evaporation of crude oil at temperatures up to $600^{\circ} \mathrm{C}$ and at pressures up to $70 \mathrm{~atm}$.

Williams and Wendlandt (1973) reported the use of a high pressure thermobalance to study thermogravimetric curves of $\mathrm{BaBr}_{2} \cdot 2 \mathrm{H}_{2} \mathrm{O}, \mathrm{CuSO}_{4} \cdot 5 \mathrm{H}_{2} \mathrm{O}$ and $\mathrm{NaHCO}_{3}$ at different pressures of nitrogen, and/or carbon dioxide. The thermobalance was constructed by placing a Dupont Model 950 balance into a stainless steel enclosure. Maximum operating conditions were $500 \mathrm{~atm}\left(\mathrm{~N}_{2}\right)$ and $5000 \mathrm{C}$. A change in sample mass due to a gas buoyancy effect as the pressure increased was easily corrected.

Dobner et al. (1976) discussed a high pressure thermobalance with maximum operating capabilities of $30 \mathrm{~atm}, 1100^{\circ} \mathrm{C}$, with corrosive atmospheres and steam partial pressures up to $20 \mathrm{~atm}$. A modified Dupont 950 TG was encased in a stainless steel pressure vessel. This modification of the TG was necessary to avoid damage by corrosive gases or steam. The reactions studied 
were the cyclic $\mathrm{CO}_{2}$-acceptor reaction for half-calctnated dolointte and the cyclic $\mathrm{H}_{2} \mathrm{~S}$ absorption and regeneration reaction for half-calcinated dolomite. Two problems were assoclated with this system. First, at 1 atm the baseline welght continuously increased with temperature at a rate of $\sim 0.07 \mathrm{mg} / 1000 \mathrm{C}$. second, the baseline weight increased with total gas flow rate at a rate of $\sim 0.08 \mathrm{mg} / 100 \mathrm{ml}$ at $25^{\circ} \mathrm{C}$ and $\sim 0.19 \mathrm{mg} / 100 \mathrm{ml}$ at $925^{\circ} \mathrm{C}$. These effects were caused by aerodynamic drag forces exerted by reacting gases flowing over the sample pan.

Li and Rogan (1978) reported the construction of a thermogravimetric system for corrosive environments at high pressures and temperatures. The reactor had a DuPont 951 thermogravimetric analyzer encased in a stainless steel high-pressure vesse1. The maximum operating conditions were 60 atm and $11000 \mathrm{C}$ with corrosive gases. Thermogravimetric studies were performed on the calcination of dolomite in $\mathrm{CO}_{2} / \mathrm{N}_{2}$ atm and the sulfidation of dolomite in $\mathrm{H}_{2} \mathrm{~S}_{\mathrm{N}_{2}}$ gas mixtures. A serious problem with this system concerns the initial transient readings of either sample temperature or gas composition.

Ghodsi et al (1979) describe a pressurized thermobalance featuring two symmetrical pans. The use of two symmetrical pans avoids thermogravimetric errors under pressure such as Archimedes' forces, viscosity forces and therma 1 gradient forces. A Sartorius 4406 thermobalance was modifled for use at pressures up to $50 \mathrm{~atm}$ of $\mathrm{H}_{2}$ ant temperatures reaching $1000^{\circ} \mathrm{C}$. The balance was tested using the hydrogenation of a lignite char as a preliminary application.

Forgac and Angus (1979) constructed a pressure chamber which held a Perkin-Elmer AM-1 autobalance within the walls. The sample is suspended in the hot zone with a wire $(15 \mathrm{~cm}$ length) made from nichrome, platinum and iridium. Sample holders were cylindrical crucibles made from 0.025 min platinum foil. The thermobalance was run as a static system but is capable of dynamic flow. Experiments were done at temperatures of $1633 \mathrm{~K}$ and 70 atm. Although the design calculations allow for $2000 \mathrm{~K}$ and $136 \mathrm{~atm}$.

Treptau and Miller (1987) describe a novel thermobalance. The reactor is internally heated and the entire reactor is weighed on a Mettler PE-360 toploading electronic balance with a capacity of $60 \pm 0.001 \mathrm{~g}$. The solid sample can be a fixed or fluidized bed through which reactant gas can flow. Gasification tests with $\mathrm{CO}_{2}$, and $\mathrm{O}_{2}$ were performed on coconut charcoal samples. 
Experimental samples were $970^{\circ} \mathrm{C}$ and $600 \mathrm{ps} 1$ with a balance sensitivity of $\pm 10 \mathrm{mg}$ for a $2 \mathrm{~g}$ sample. The purpose of welghing the entire reactor was to provide direct measurement of sample temperature and elimination of external mass-transfer resistances via gas flowing through the sample bed. Nevertheless, a large scale drift on the balance of $0.1-0.5 \mathrm{~g} / \mathrm{hr}$ was noticed when the gas flow rate was changed or pressure was increased during heating of the sample.

Experimental Approach. Analytical - It was indicated in the previous quarterly report. (Solomon et a 1.. 1990) that a new gas chromatographic column for simultaneous $\mathrm{CO}$ and $\mathrm{CO}_{2}$ would be evaluated. The testing of this new column was temporarily postponed. However, this evaluation will be made soon and reported in the next quarterly.

Additional analyses have been made on coal. char and tar samples of coals to be used in this subtask. These analyses include CHN analyses with the LICO-CHN-800 instrument and Ti analyses with an ICP instrument. These procedures are ready for the analyses needed for this subtask.

The equipment for preparing sections of char and ash imbedded in epoxy resin has been received. Although this equipment is funded by another project, its availability for use in preparing samples for this subtask has been established. The necessary resins have been ordered so that thin section samples can be prepared from the preliminary large-particle oxidation runs and examined with the scanning electron microscope.

\section{Experimental Reaction Rate Data}

Prelininary Large Particle exidation Measurements - A set of 1arge particles of a Utah bituminous coal was oxidized in platinum crucibles and the results reported in the 14 th Quarterly Report (Solomon, 1990a). A similar set of particles of the same coal has been oxidized this quarter in platinum crucibles but in a small muffle furnace instead of with Mekker burners.

The results are presented in Table II. F-7. Six samples ranging in mas from 0.6 to 1.2 grams were first devolatilized in the flame of a Mekker burner so the flame would burn the volatile maierial. Samples were then placed in a muffle furnace for the oxidation of the char. The mass reactivity value of about 0.2 min -1 reflects the mass loss during devolatilization. The overall average of $0.036 \mathrm{~min}^{-1}$ is less than the value reported previously $0.046 \mathrm{~min}$. 
TABLE II. $F \cdot 1$

\section{PRELIMINARY LARGE PARTICLE OXIDATION MEASUREMENTS}

Coal: Utah Bltuminous

Temperature: approximately $1230 \mathrm{~K}$

Conditions: Oxidation in Alr with Platinum Crucibles and a Muffle Furnace

\begin{tabular}{|c|c|c|c|c|c|}
\hline Cruclbl甘1 & $\# 2$ & \# 3 & $\# 4$ & $\# 5$ & \#6 \\
\hline $\begin{array}{l}\text { Mass of } \\
\text { Sample } 1.048 \\
\text { (grams) }\end{array}$ & 0.781 & 1.184 & 0.0697 & 0.645 & 0.774 \\
\hline$\%$ Volatiles & 46.1 & 43.9 & 44.2 & 37.6 & 34.1 \\
\hline$\%$ Ash & 6.5 & 7.5 & 7.0 & 10.5 & 6.6 \\
\hline
\end{tabular}

Time

Mass Reactlvity (Minutes-1)

(minutes)

2.0

7.0

12.0

17.0

22.0

32.0

47.0

62.0

82.0
.23

.029

.038

.026

.032

.033

.005

.003
.22

.032

.044

.037

.046

.029

.0316
.22

.026

.032

.025

.028

.025

.026

.036

.007

\section{Average}

(except first and last values)

Overall average 0.0358 
1). However, the temperature in these runs has a higher value. Both temperatures, however, are approximate and measured in different ways. The thermocouple junction of the muffle furnace is in back of the furnace half way up. The crucibles were positioned two at a time in the front of the furnace box with the door just slightly opened. Therefore, the temperature is probably less than the $1240 \mathrm{~K}$ and would appear to be also less than $1150 \mathrm{~K}$ reported previously. This shows the usefulness of making preliminary measurements to help anticipate the problems that may arise later. The ash values were less in the earlier measurements. The reason for this is not readily apparent.

\section{plans}

During the next quarter the force transducer will be tested in a balance unit to be operated at atmospheric pressure. With this simple unit the characteristics of the force transducer in monitoring weight loss of coal samples at atmospheric pressure will be determined. The details of the balance unit for operation at high pressures will be included in the design of the "large particle insert." Machinirg of certain parts of the large particle insert will start.

Evaluation of the new gas chromatographic column will continue. Samples of char and ash imbedded in resin will be prepared and examined with the SEM equipment.

Preliminary measurements of large particle oxidation will continue. 


\title{
II.G. SUBTASK 2.G. - SOX $/$ NOX SUBMODEL DEVELOPMENT
}

\author{
Senior Investigators: L. Douglas Smoot and B. Scott Brewster \\ Brigham Young University \\ Provo, Utah 84602 \\ (801) 378-4326 and (801) 378-6240
}

Research Assistant: Richard D. Boardman

\section{Objectives}

The objectives of this subtask are 1) to extend an existing pollutant submodel in PCGC-2 for predicting $\mathrm{NO}_{x}$ formation arid destruction to include thermal NO. 2) to extend the submodel to include $\mathrm{SO}_{x}$ reactions and $\mathrm{SO}_{\mathrm{x}}$-sorbent reactions (effects of $\mathrm{SO}_{3}$ nonequilibrium in the gas phase will be considered). and 3 ) to consider the effects of fuel-rich conditions and high-pressure on sulfur and nitrogen chemistry in pulverized-fuel systems.

\section{Accomplishments}

Predictions for coal combustion and gasification cases have been completed to verify the extended and alternative fuel NO mechanisms of the NO model. The ability to predict No formation during gasification of North Dakota lic,nite was given special consideration. Joint fuel and thermal NO predictions were also completed for combustion and gasification cases. Some of the cases that were evaluated will be discussed in this report.

The revised NO model has been fully integrated into PCGC-2 and a user's guideline has been prepared (Boardman, 1990). Work is in progress to complete a sorbent reactions submodel. There are three main components associated with this subtask: 1) modification of $P C G C-2$ to track reactive sorbent particles. 2) incorporation of a sorbent reaction chemical model into PCGC-2, and 3 ) evaluation of the model by comparing predictions to experimental data. A brief discussion on this work will also be given in this report.

\section{NOx Submodel Development}

Euel NO Mechanisms Evaluation - A discussion about the improvements and revisions that were made to the exiscing NO model of Hill et al. (1984) was 
given in the 3 rd Annual Report (Solomon et a 1.. 1990). In summary, a pathway for coal nitrogen to be released as $\mathrm{NH}_{3}$ and an alternative fuel No mechanism framework which includes $\mathrm{NH}_{3}$ as a key intermediate were incorporated into the model (see figure II.G-1). The improved NO model is generalized to allow the global kinetics reported by de Soëte (1975). Mitchell and Tarbel1 (1982) or Wendt and coworkers (Bose et a 1.. 1988) to be used for predicting homogeneous formation and destruction of $\mathrm{HCN}, \mathrm{NH}_{3}$ and NO. Table II.G-1 lists the alternative kinetic rate expressions used in the revised NO model.

Pulverized Coal Combustion Comparisons - Coal combustion cases that were previously predicted by $\mathrm{Hill}$ et a1. (1984) and Boardman and Smoot (1988) were re-evaluated using the revised NO model to examine revisions in the model. only the results for a Wyoming subbituminous coal combustion case simulation will be discussed in this report. The burnout plot shown in Figure II.G-2 suggests that governing the flame structure is reasonably predicted for this case.

Figure II.G-3 compares the measured nitrogen-containing pollutant data with the profiles predicted using the global kinetics of de Soëte (1975). Excellent agreement is shown between the measured and predicted axial integrated profiles using a pre-exponential factor of $3.5 \times 1010$ for the global rate equation describing $H C N$ oxidation to NO. The reported value of 1010 (de Soëte, 1975) underpredicts NO formation. The value of $3.5 \times 1010$ is within the range of experimental variability (de soëte, 1986) and was determined to best fit several coal combustion and gasification cases. Therefore, it is recommended for predicting fuel NO when de Soëte's global kinetics are chosen to predict NO formation.

Mitchell and Tarbell (1982) give the only set of global kinetics which accounts for NO destruction by fuel fragments $\left(\mathrm{CH}_{j}{ }^{\prime} \mathrm{s}\right)$. The expression used to describe "reburning" reactions is:

$$
\frac{d X_{N O}}{d t}=(10,000) X_{N O} X_{C_{m} H_{b}} s^{-1}
$$

The major limitation to using this expression is predicting the local concentration and molecular formula of fuel fragments, $\mathrm{C}_{b} H_{m}$. An exact approach for predicting unreacted hydrocarbon concentrations would require using comprehensive reaction kinetics to predict the fuel oxidation process. 


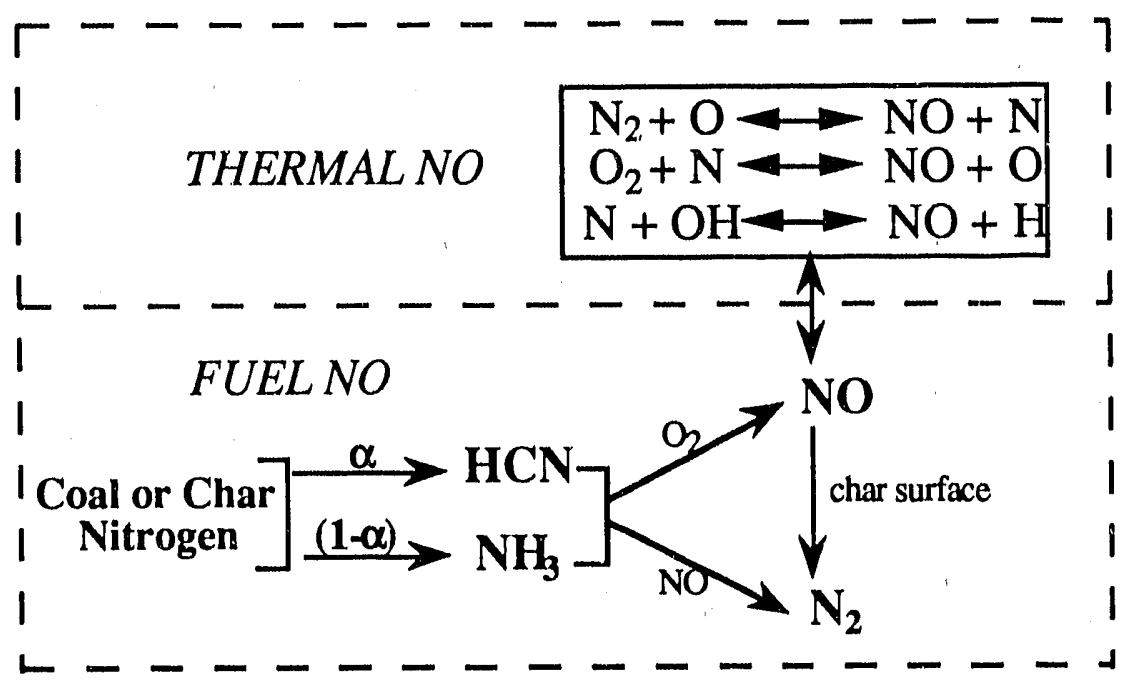

a. Extended fuel No mechanism for the global kinetics of de Soëte (1975)

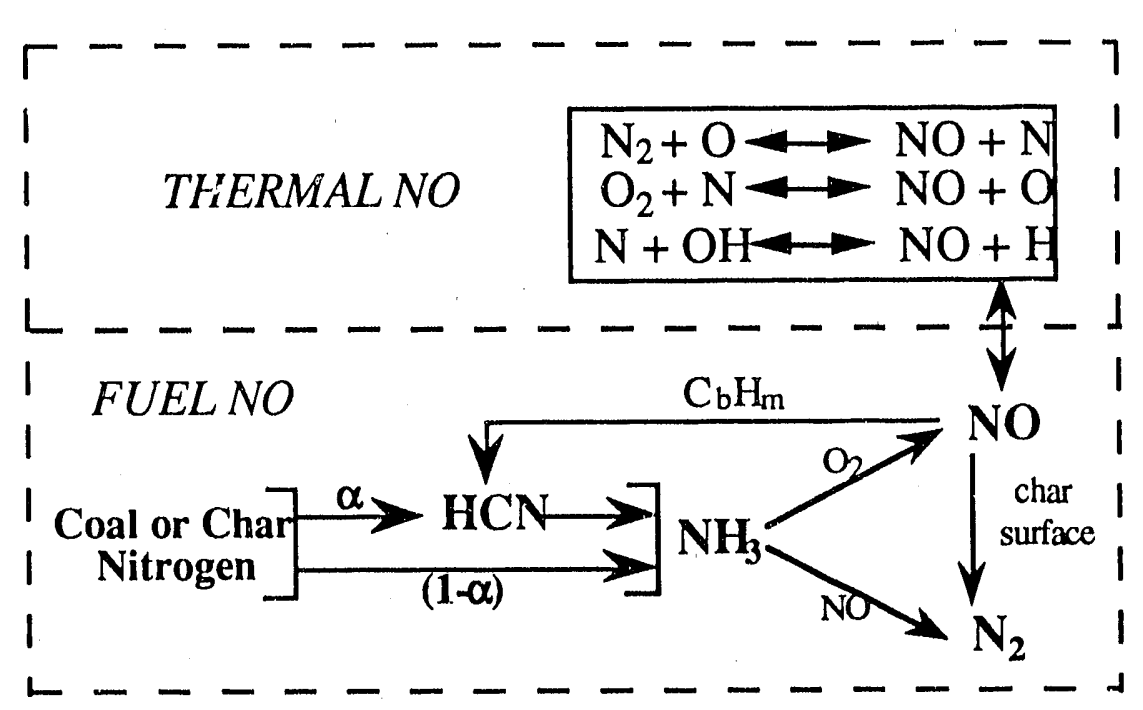

b. Alternative fuel No mechanism for the kinetics of Mitchell and Tarbell (1982) and Wendt and coworkers (Bose et al., 1988).

Fig. II.G-1. Generalized mechanisms incorposated into the revised No model of PCGC-2 for joint or separate prediction of fuel and thermal No. Thermal NO is predicted by the zel'dovich mechanism. Fuel No is predicted using any of the optional fuel No kinetics listed. 
Table II.G-1

Reaction Expression Alternatives for the Revised NO Model.

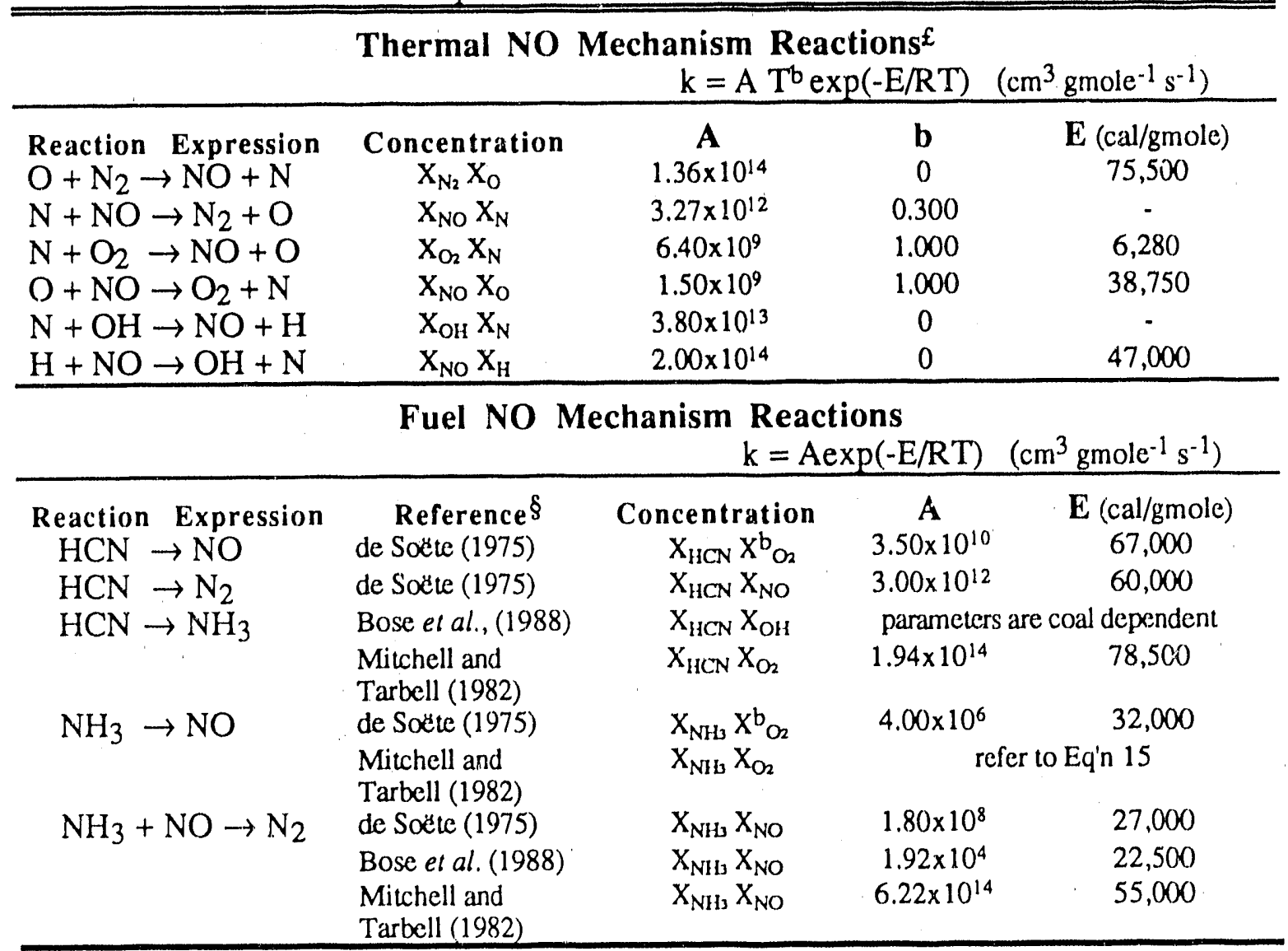

£ Rate parameters are from Miller and Bowman (1989) and Bowman (1975).

$\S$ The power for oxygen concentrations is determined from and auto correlation, $b=f\left(\mathrm{O}_{2}\right)$, given by de Soëte (1975).

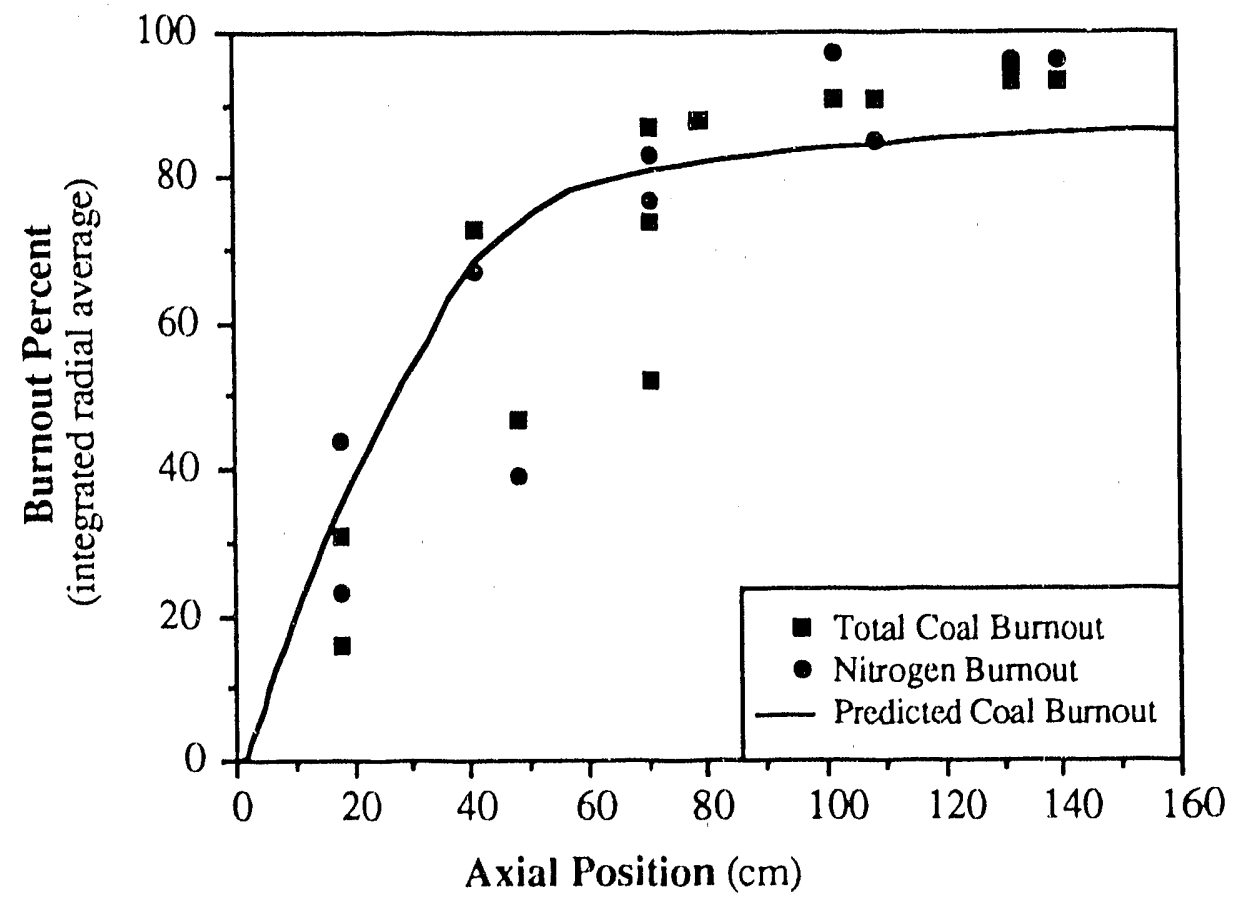

Fig. II.G-2. Wyoming subbituminous coal burnout. Experimental data are from Asay, (1982). 

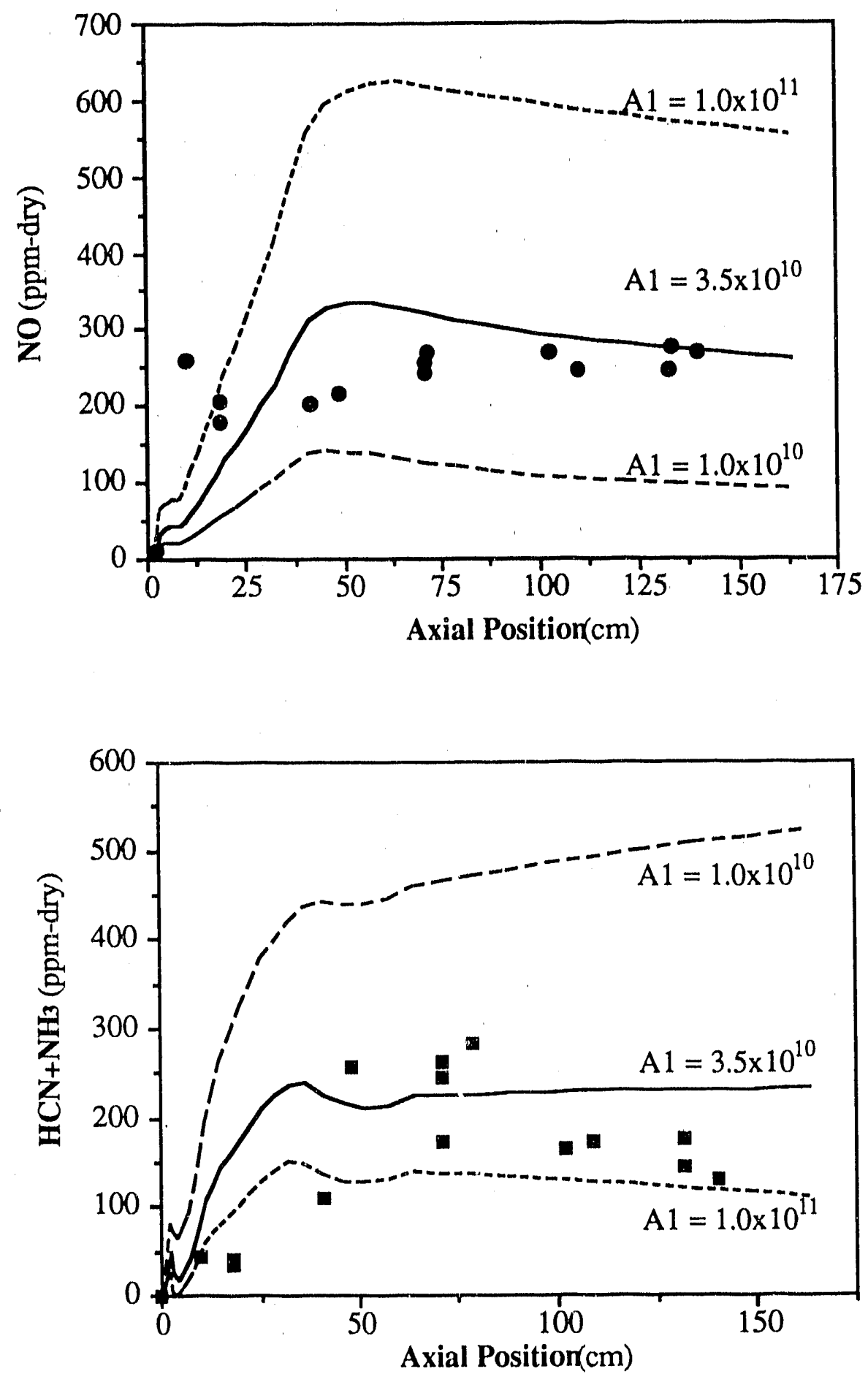

Fig.II.G-3. Comparison between predicted (curves) and measured (symbols) nitrogen integrated profile data for wyoming subbituminous coal combustion. Different values of pre-exponential factor are for global conversion of HCN to No. Data are from Asay (1982). 
Mitche 11 and Tarbel1 suggest a value of $b=8$ with $m$ being calculated from the coal ultimate analysis.

In the current evaluation study, the concentration of hydrocarbon fragments was related to the local amount of coal off-gas material. This approach gives spurious concentrations since coal off-gas material is rapidly oxidized as soon as the volatiles and oxidizer are mixed and is not continuously available for reaction with No.

The comparisons with experimental data are plotted in Figure II.G-4. Calculated No centerline concentrations rise above the measured data but then decay and drop below the aft-combustor measurements. The decrease in NO is a result of overpredicting the recycle reaction by assuming all coal off-gas material can react with NO. As NO concentrations diminish. HCN concentrations rise above the measured data. $\mathrm{NH}_{3}$ concentrations are always predicted below measurements due the significantly lower activation energy with respect to HCN and NO reactions. This may be coilsidered the most serious limitation of the global kinetic of Mitchell and Tarbell (1982).

Predictions with the global kinetics reported by Wendt and coworkers (Bose et a 1, 1988) show somewhat better agreement with the measured No concentrations (see Fig. II,G-5). However, the predicted HCN concentrations are far above the experimental data while the predicted $\mathrm{NH}_{3}$ concentrations do not match the measurements aft in the reactor. This is due to low prediction of $\mathrm{OH}$ concentrations by PCGC-2. Wendt et a 1. (1989) presented an equation for estimating the "overshoot" in radical $\mathrm{OH}$ concentrations as a function of temperature:

$$
O H=O H_{e q}\left[1.1 \times 10^{-4} \exp \left(\frac{15469}{T}\right)\right]
$$

Using this expression to adjust the predicted equilibrium $\mathrm{OH}$ concentrations, the comparison between $\mathrm{HCN}$ and $\mathrm{NH}_{3}$ profiles was improved. Because the expression given by wendt et al. (1989) was correlated for their reactor conditions (which were fuel-rich), this expression is not recommended for al 1 systems. However, the improved results obtained by employing this expression demonstrate that favorable predictions can be achieved when $\mathrm{OH}$ concentrations can be adequately predicted. 

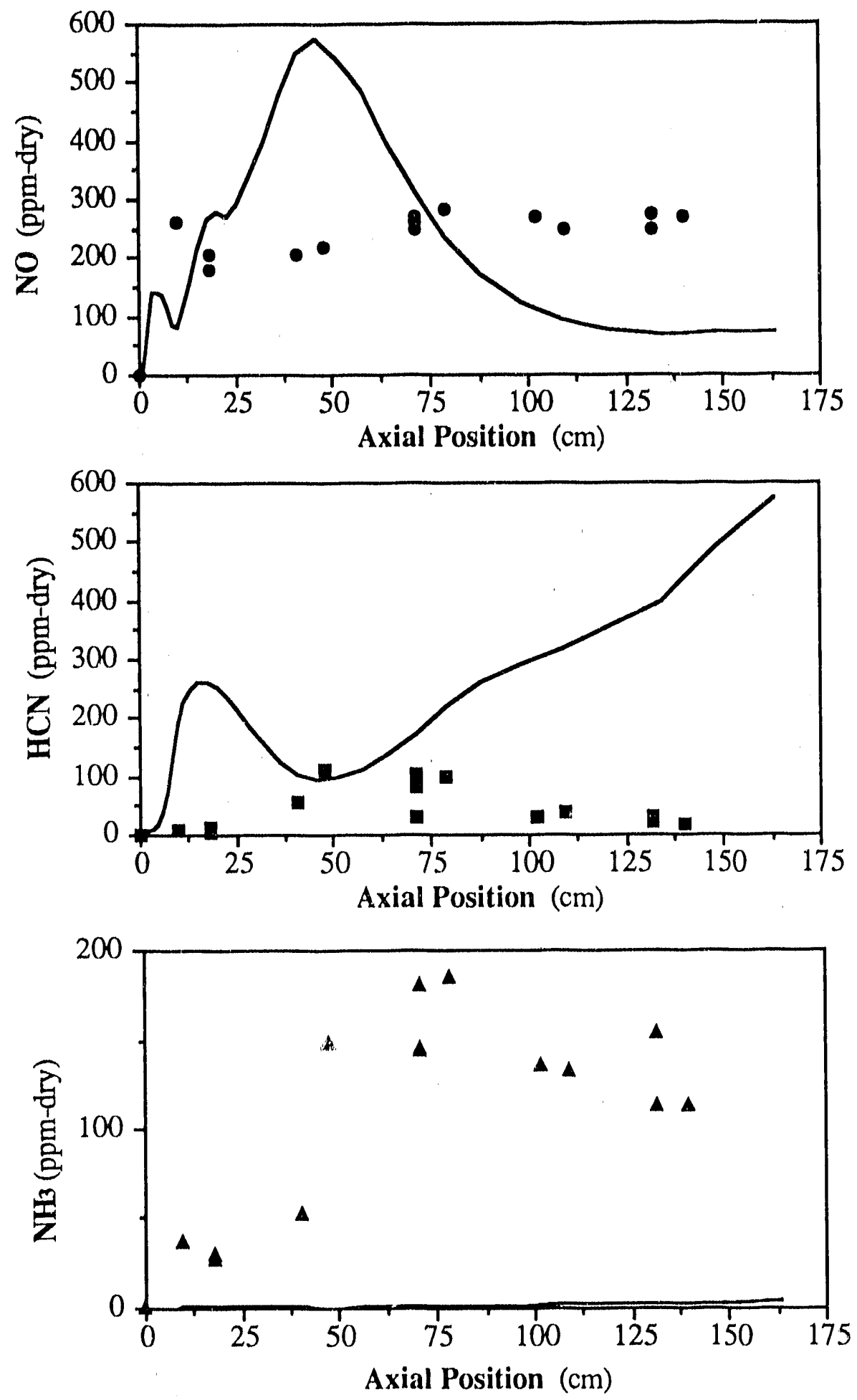

Fig.II.G-4. Comparison between predicted and measured nitrogen pollutant centerline profiles for Wyoming subbituminous coal using the alternative fuel No mechanism with the empirical rates of Mitchell and Tarbell (1982). Data are form Asay (1982). 

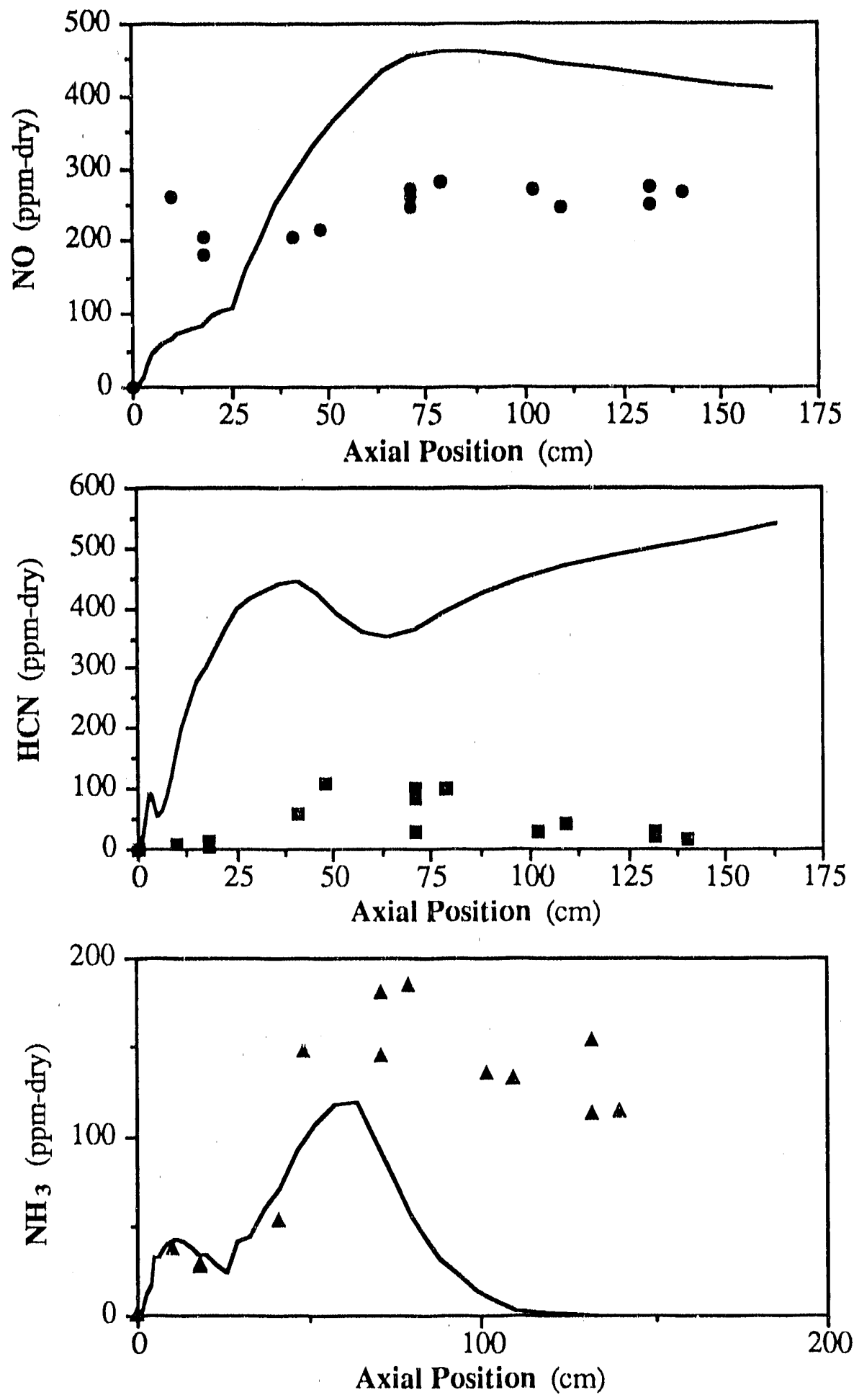

Fig. II.G-5. Comparison between predicted and measured nitrogen pollutant centerline profiles for Wyoming subbituminous coal. using the alternative fuel No mechanism with the global rate correlations reported by Bose et al., (1988). Data are from Asay $(1982)$. 
North Dakota Lignite Gasification - One of the primary objectives of this work was to investigate nitrogen conversion pathways during fuel-rich lignite coal combustion. Experimental evidence suggest that low-rank coal nitrogen is released as 1 ight gas $\mathrm{NH}_{3}$ or is quickly converted from HCN to $\mathrm{NH}_{3}$ in the vicinity of the coal particle (Chen et a 1.. 1982). The observation of high $\mathrm{NH}_{3}$ concentrations during low-rank codl processes provides the tmpetus for incorporating global reactions involving $\mathrm{NH}_{3}$ into the model. The improved No model allows nitrogen released from the coal and char to be partitioned between light gas $\mathrm{HCN}$ and $\mathrm{NH}_{3}$. The amount of total nitrogen assumed to be released as. HCN is specified by the product $\left(\alpha_{n} \cdot b c n\right)$. where bon is the percent of nitrogen in the codi. The remainder of volatile nitrogen. (1. $\left.\alpha_{n}\right) \cdot$ bcn, is assumed to be instantaneously converted to $\mathrm{NH}_{3}$.

Experimental evidence also suggests that early coal volatiles during coal gasification are essentially nitrogen-free (Poh1 and Sarofim, 1977; and Haussmann et al, 1988). A simple expression which relates nitrogen loss to coal off-gas mixture fraction was used to delay nitrogen release for the lignite case.

Figure II.G-6 shows that favorable agreement between predicted and measured $\mathrm{HCN}$ and $\mathrm{NH}_{3}$ profiles when fuel nitrogen release was delayed until 20 percent of the total coal mass loss had occurred and was equally partitioned between $\mathrm{HCN}$ and $\mathrm{NH}_{3}$. The comparison between measured and predicted NO still lacks quantitative agreement but is substantially improved over former predictions (Boardman, 1987). These results demonstrate the need, for an advanced nitrogen devolatilization model which includes an adequate description of light gas nitrogen devolatilization and species production depending on coal type.

Figure II.G-7 shows the NO centerline profile that was predicted for gasification of North. Dakota lignite using the global kinetics of Wendt and coworkers (Bose et a 1., 1988). The lower curve was obtained by assuming half of the volatile nitrogen is released as $\mathrm{NH}_{3}$. Although the profiles vary significantly from the reported data, they are similar to the predictions made with the revised fuel No mechanism.

The empirical kinetics of Mitchell and Tarbell (1982) did not match any of the nitrogen-containing pollutant profiles for this. case. 
a. Centerline HCN profiles

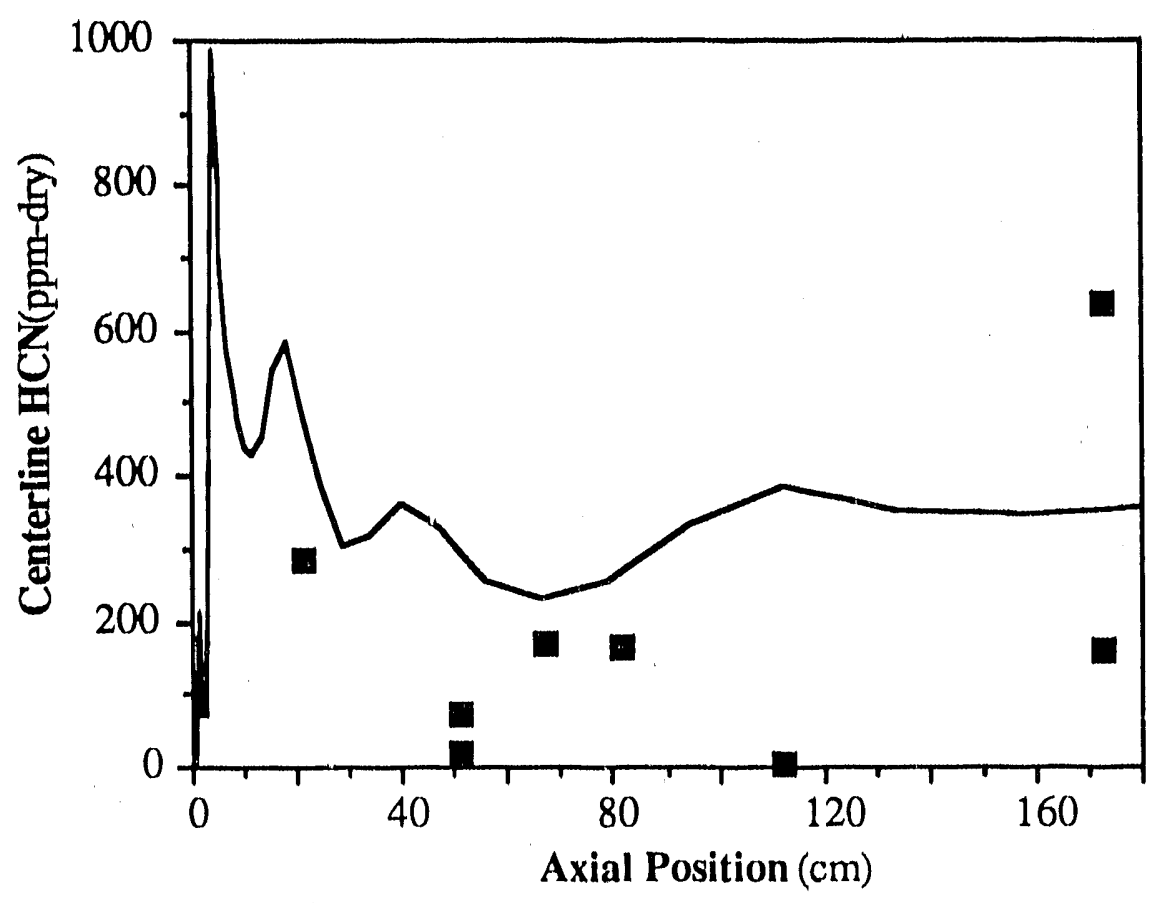

b. Centerline $\mathrm{NH}_{3}$ profiles

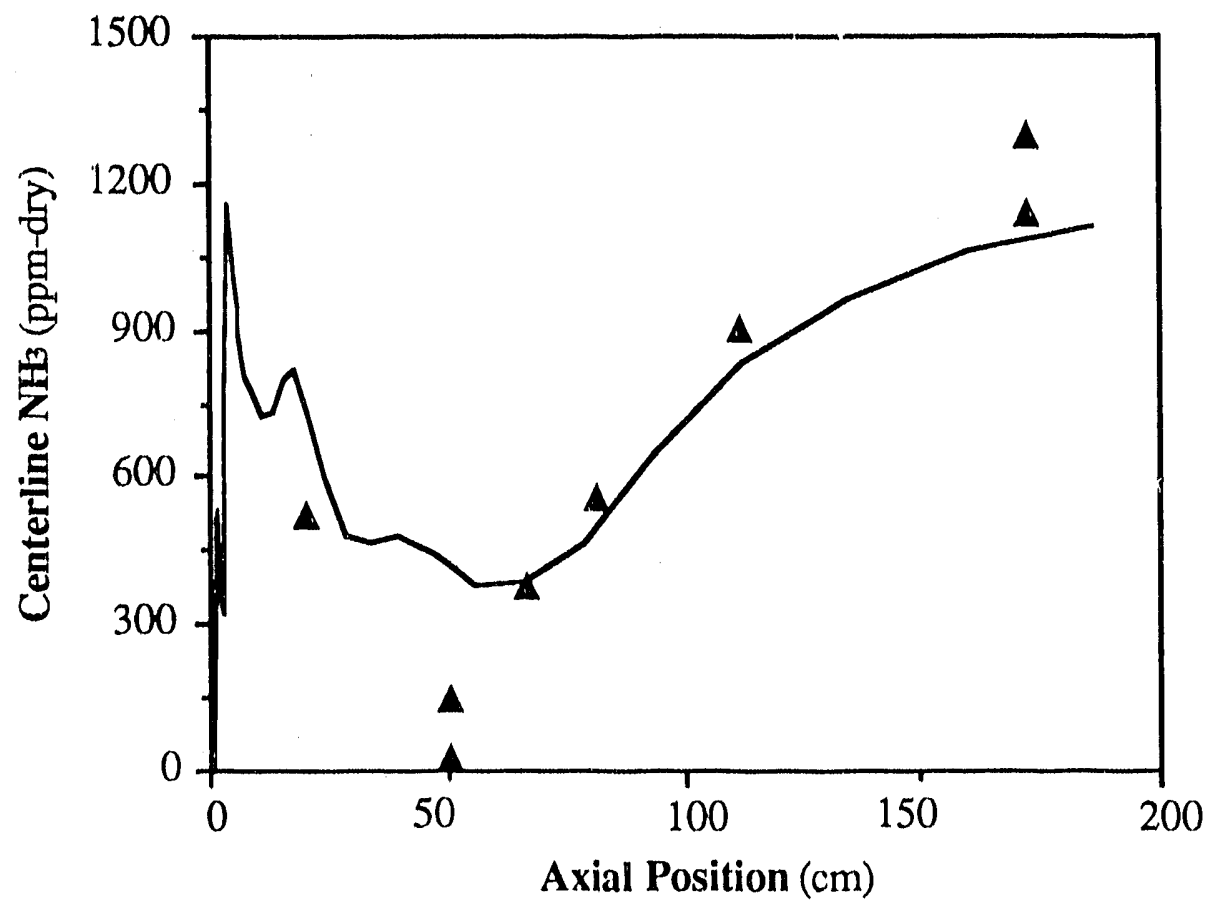

Figure II.G-6. Comparison between predicted and measured NO centerline profiles with delayed release of volatile North Dakota lignite nitrogen and equal partitioning between $\mathrm{HCN}$ and $\mathrm{NH}_{3}$. Data are from Brown (1985). 


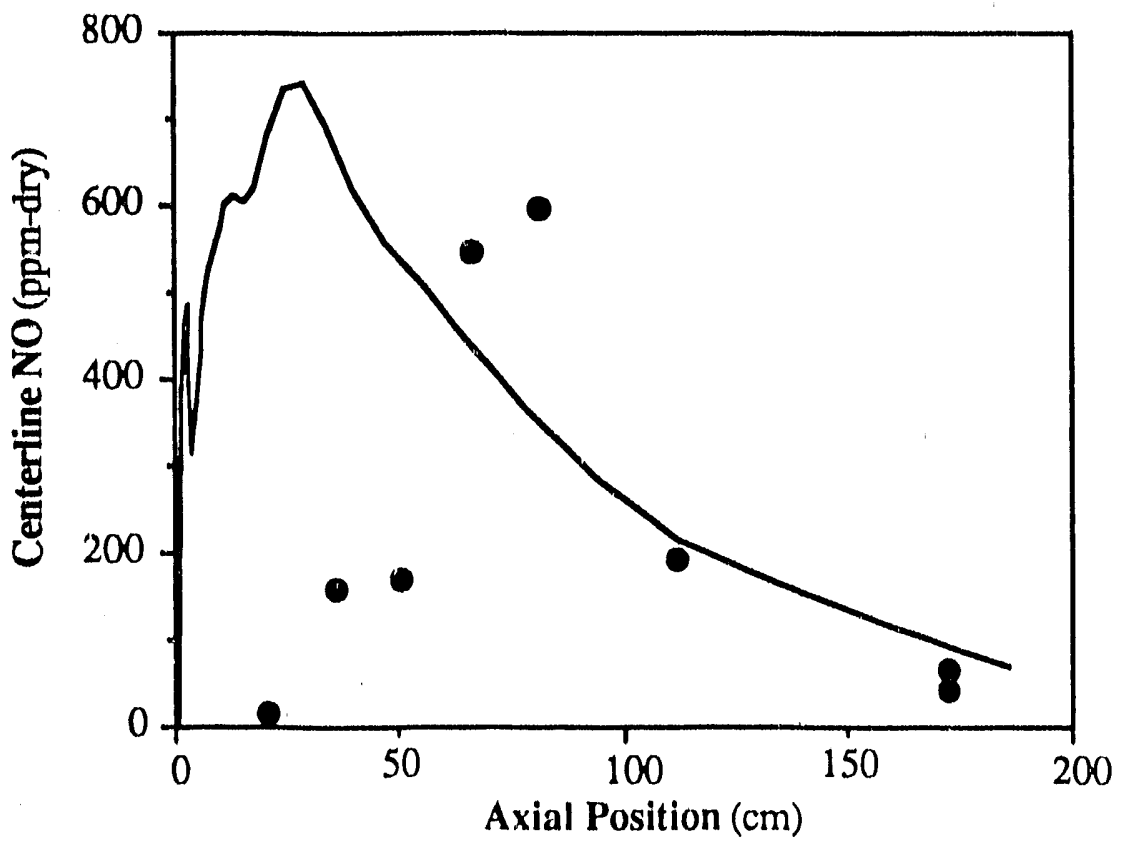

Figure II.G-6 (cont'd). Comparison between predicted and measured No centerline profiles with delayed release of volatile North Dakota lignite nitrogen and equal partitioning between HCN and $\mathrm{NH}_{3}$. Data are from Brown (1985).

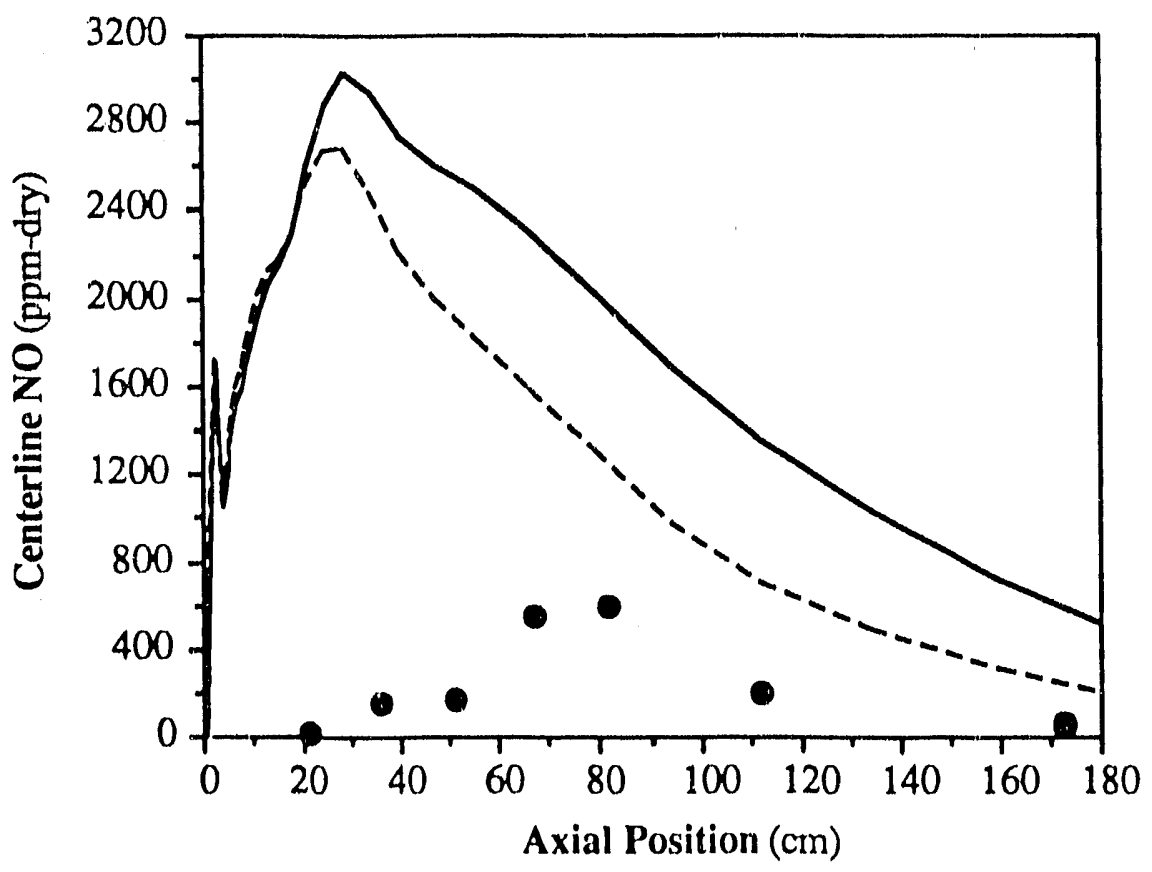

Fig.II.G-7. Comparison between predicted and measured nitrogen pollutant centerline profiles for North Dakota lignite gasification using the alternative fuel No mechanism with the global rate correlation of Bose et al., (1988). Upper curve assumes all coal nitrogen is released as HCN. Lower curve assumes 50 percent of coal nitrogen is released as $\mathrm{NH}_{3}$. Data are from Brown (1985). 
NOx concentrations exceeding 8000 ppm were predicted in the proximity of the burner for the North Dakota lignite case. These concentrations rapidly decayed to negligible quantities.

\section{Summary of Fuel NO Mesihantsms Evaluations}

The results of this study show that No concentrations can be viably predicted using the improved fuel No mechantsm (Figure II.G-1a). The 1ignite gasification case was more favorably predicted when nitrogen release rate was delayed and nitrogen volatiles were partitioned between $\mathrm{HCN}$ and $\mathrm{NH}_{3}$. Based on the model predictions. $\mathrm{NH}_{3}$ appears to be important in the early volatile products.

The alternative fuel No mechanism gave mixed results. The global kinetic expression reported by Bose et al. (1988) appears to give favorable predictions if $\mathrm{OH}$ concentrations can be correctly estimated. Predictions with the kinetics of Mitchell and Tarbell (1982) did not successfully match nitrogen pollutant proflles for either combustion or gasiflcation cases.

Until methods or models are available to predict $0 H$ concentrations, the improved fuel NO mechanism (Figure II.G-Ia) appears to be the most reliable choice for predicting fuel No formation during pulverized coal combustion and gasification. If $\mathrm{OH}$ concentrations can be estimated, the alternative fuel-NO mechanism (Figure II.G-1b) would provide a useful method for predicting No concentrations, thus increasing the power of the No model as a design tool.

\section{Joint Thermal and Fuel NO Predictions}

Thermal NO Formation During Coal Combustion - When the thermal NO mechanism was jointly solved with the fuel NO mechanism, the impact on total NO concentrations was less that the sum of the individual mechanisms. Thermal NO concentrations in excess of $25 \mathrm{ppm}$ were predicted for the wyoming subbituminous cases when the fuel no mechanism was not included in the calculations. An incremental difference of less than $10 \mathrm{ppm}$ NO was predicted when the thermal No and fuel No were jointiy predicted (see Figure II.G-8). The primary reason for this result is the decay of thermal No by fuel nitrogen intermediates but also includes competition for oxygen concentrations. This finding matches the observation of Pershing and Wendt (19\%6) who showed that thermal No concentrations in their laboratory-scale combustor were less than 5 percent at reactor temperatures below $2200 \mathrm{~K}$. 


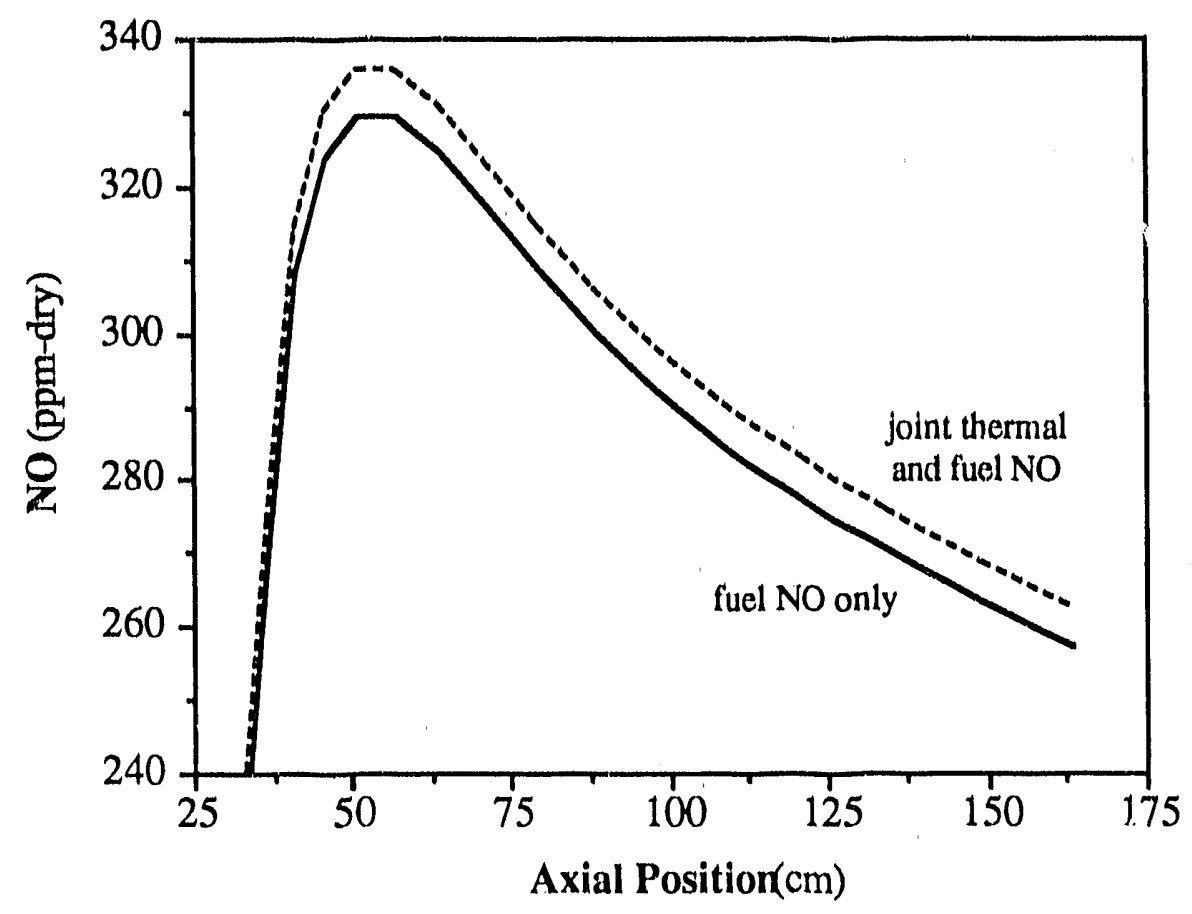

Figure II.G-8. Joint thermal and fuel No mechanism prediction of NO concentrations for Wyoming coal combustion case. Thermal NO calculations assume radical oxygen concentrations are in quasi-equilibrium with molecular oxygen

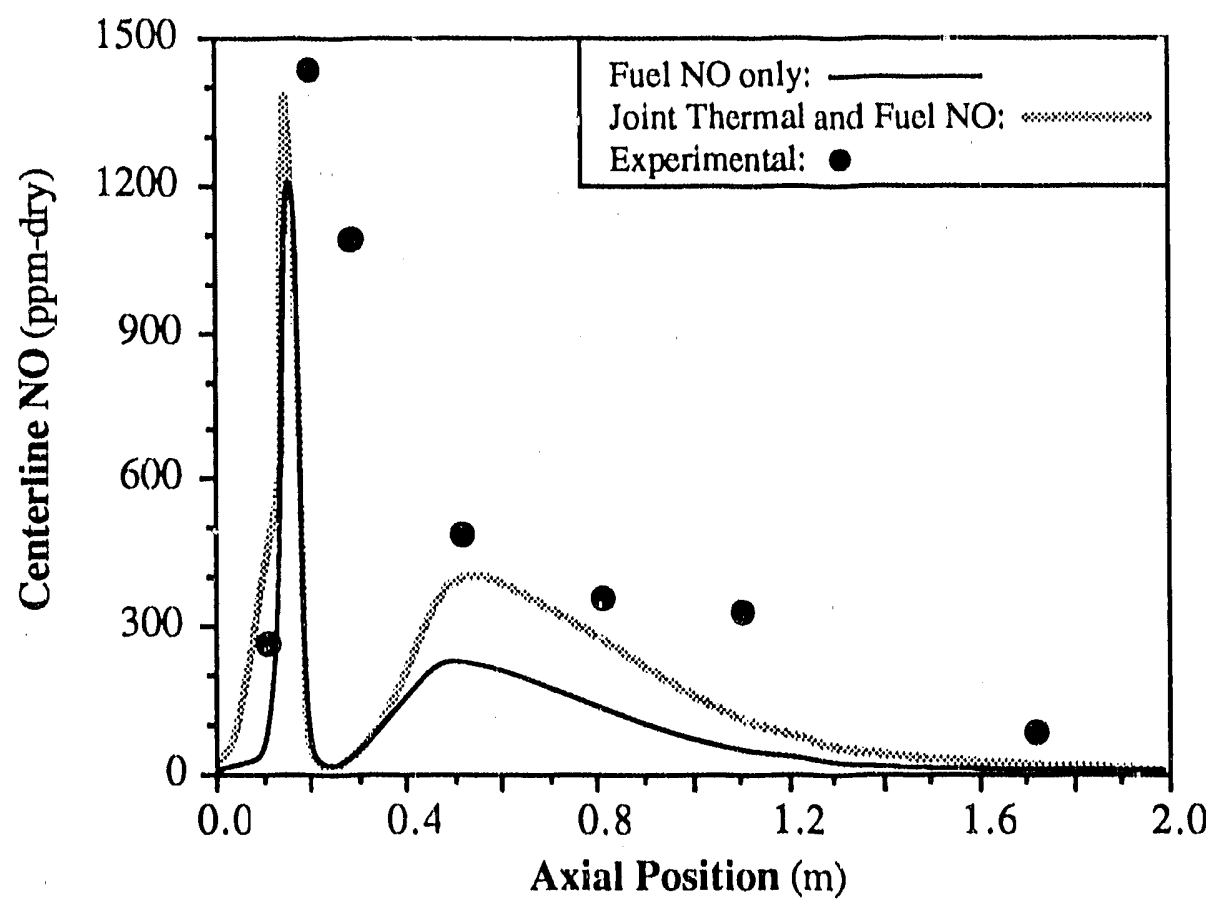

Figure II.G-9. Comparison between measured and predicted NO centerline concentrations for gasification of utah bituminous coal at 1 atm. Predicted curves made with and without the thermal No mechanism included in the calculation. Data are from Brown (1985). 
The value of separately predicting fuel and thermal NO contributions is the power to identify appropriate $\mathrm{NO}_{x}$ abatement strategies. For instance, thermal NO may or may not be significant when over-fire air registers are employed in a combustor. If thermal NO is found to be important in the staging air. then strategic placement of he air registers could reduce total NO emissions.

Thermal NO Formation During Coal Gasification - The potential for thermal No formation is reduced in the absence of oxidizing air and purge nitrogen. In order for thermal NO to form. $N_{2}$ must first build up as a result of fuel nitrogen decay. Even when all of the nitrogen in the coal is converted to gaseous $\mathrm{N}_{2}$, the predicted amount of thermal $\mathrm{NO}$ formed was only a few ppm during North Dakota lignite gasification. The addition of window purge nitrogen, however, can lead to appreciable thermal No formation. Figure II.G-9 shows the relative contribution of thermal NO during the gasification of Utah bituminous coal when a small amount of purge nitrogen $(<10$ mole percent) was added to the secondary stream inlet. The predicted incremental contribution of thermal $N O$ is $20 \%$ where the NO concentration is maximum. In the aft section of the gasifier, thermal No brings the predicted profile up to the level of the measured data. Hence, the inclusion of the thermal No mechanism into the model substantially improved the agreement between predicted and measured NO values when nitrogen was included in the inlet feed.

\section{NO Submodel User Guidelines}

User instructions for running the revised $N O$ submodel have been written (Bodrdman. 1990). In this document, a description of the input flags which govern the optional mechanisms and rate expression that are used to calculate No formation and destruction is given. The logical sequencing of the code is discussed. A discussion about convergence parameters is also provided to aid 1:5ers in achieving converged solutions.

\section{$\mathrm{SO}_{x}$-Sorbent Particle Reaction Submodel}

Iracking the Sorbent Particles - Work was initiated under Subtask 3.c to modify PCGC-2 to track reacting sorbent particles and account for their effects on the gas. 
Sulfur/Serbent Reaction - Sorbent capture of sulfur species will be predicted using a simplified version of the grain model of Silcox (1985). This model accounts for diffusion of reactants through the porous structure of the particle, diffusion through the product $\mathrm{CaSO}_{4}$, and reaction at the $\mathrm{CaO}$. $\mathrm{CaSO}_{4}$ interface. The grains are assumed to react by the shrinking core model. The reaction rate of $\mathrm{SO}_{2}$ and $\mathrm{H}_{2} \mathrm{~S}$ will be correlated to experimental data available in the open literature. The governing equation for silcox's model is a partial differential equation to determine the concentration profile in a sorbent particle. Thus, the solution of the model is not trivial and will require the development of an efficient subroutine and solver. Gaseous $\mathrm{SO}_{2}$ and $\mathrm{H}_{2} \mathrm{~S}$ concentrations will determined by solving species continuity for each species.

SO-Sorbent Reaction Submodel Evaluat, un - Prediction of gaseous sulfur species has been presented in previous quarterly reports. In addition to these cases, the data measured in the BYU gasifier by Huber (1989) under Subtask 2.h will be used to evaluate the $\mathrm{SO}_{\mathrm{x}}$-sorbent reaction submodel.

\section{Plans}

Work on the sorbent reactions submodel will continue. 


\section{SECTION III. TASK 3. COMPREHENSIVE MODEL DEVELOPMENT AND EVALUATION}

\section{Objectives}

The objective of this task is to integrate advanced chemistry and physics submodels into a comprehensive two-dimensional model of entrained-flow reactors (PCGC-2) and to evaluate the model by comparing with data from well-documented experiments. Approaches for the comprehensive modeling of fixed-bed reactors wi11 also be reviewed and evaluated and an initial framework for a comprehensive fixed-bed code will be employed after submission of a detailed test plan (Subtask 3.b).

\section{Task outline}

This task is being performed in three subtasks. The first covers the full 60 months of the program and is devoted to the development of the entrained-bed code. The second subtask is for fixed-bed reactors and is divided into two parts. The first part (12 months) was devoted to reviewing the state-of-theart in fixed-bed reactors. This led to the development of the research plan for fixed-bed reactors, which was approved. The code development is being done in the remaining 45 months of the program. The third subtask is to generalize the entrained-bed code to fuels other than dry pulverized coal and will be performed during the last 24 months of the program. 


\title{
III.A. SUBTASK 3.A. - INTEGRATION OF ADVANCED SUBMODELS \\ INTO ENTRAINED-FLOW CODE, WITH EVALUATION AND DOCUMENTATION
}

\author{
Senior Investigators - B. Scott Brewster and L. Douglas Smoot \\ Brigham Young University \\ Provo, UT 84602 \\ (801) $378-6240$ and 4326
}

Research Assistant - Susana K. Berrondo

\section{Objectives}

The objectives of this subtask are 1) to integrate the FG-DVC submodel into PCGC-2, 2) incorporate additional submodels and improvements developed under Task 2, 3) validate the improved code, 4) improve user-friendliness and robustness, and 5 ) document the code.

\section{Accomplishments}

Work continued on modeling the transparent wall reactor for code validation and on developing a graphical, user-friendly interface. Accomplishments are described below.

\section{Iransparent Wall Reactor}

Data are available for non-reacting flow and for three coal flames in the AFR transparent wall reactor. Reasonable results have been achieved for the simulation of the non-reacting flow case and the "fast-flow" Rosebud coal flame. These results were obtained by assuming a coal-carrier stream inlet diameter of $2 \mathrm{~mm}$ at the nozzle exit. consistent with visual observation.

Simulation Results - Temperature profiles at several axial locations are shown in Figure III.A-1 for gas flow without particles. The data were obtained with an unshielded thermocouple and subsequently corrected for heat loss. The inlet radial profile has a low-temperature core (coal carrier gas) surrounded by hot air which is surrounded by cold (room) air. As the gas progresses up the reactor. the core heats up by diffusion and convection induced by buoyancy, and the gradient between the hot air and room air becomes less steep. Finally, a point is reached where the depression in the core disappears entirely, and the profile become peaked at the center. The 
a)

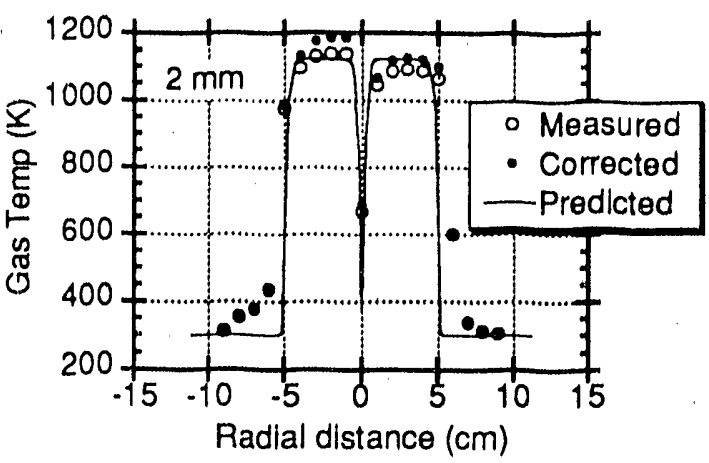

b)

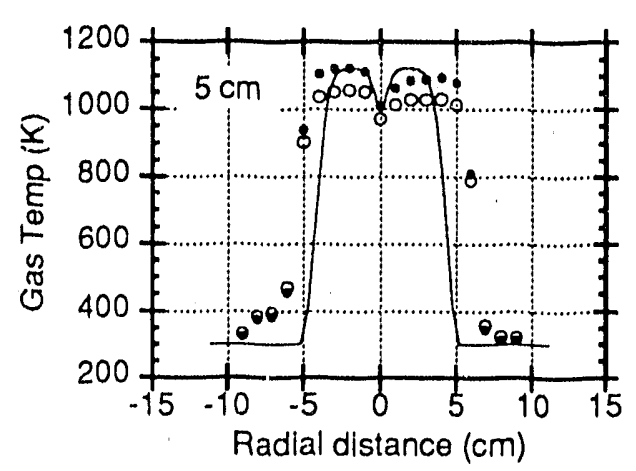

c)

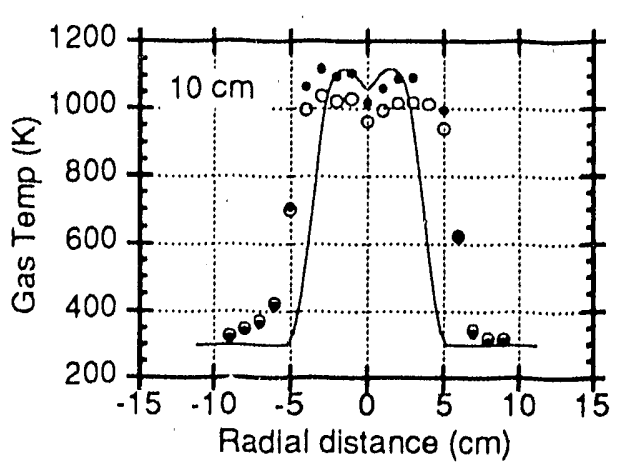

d)

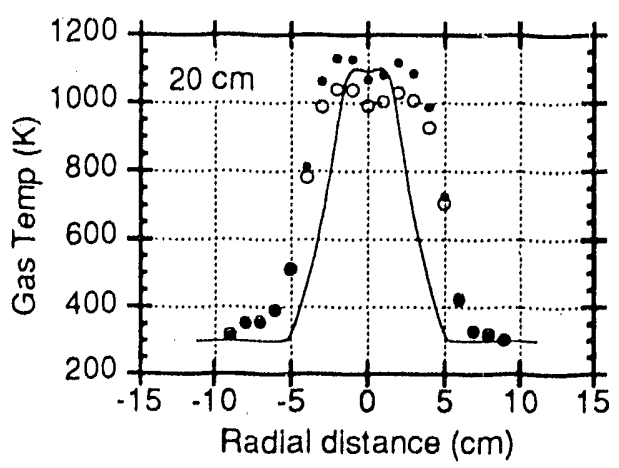

e)

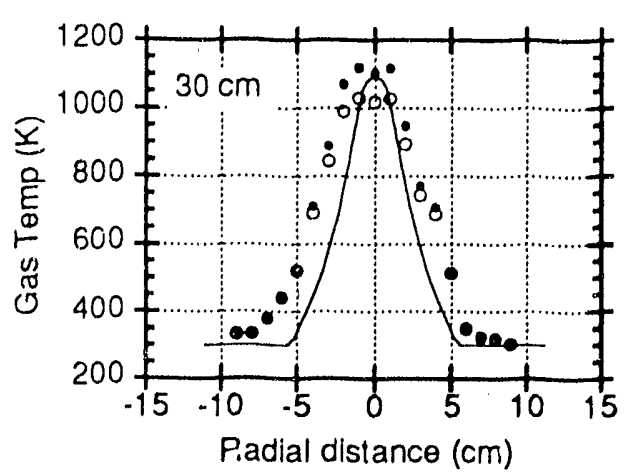

f)

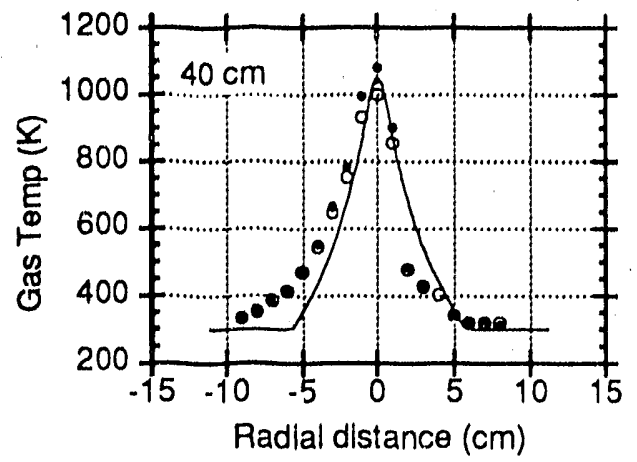

g)

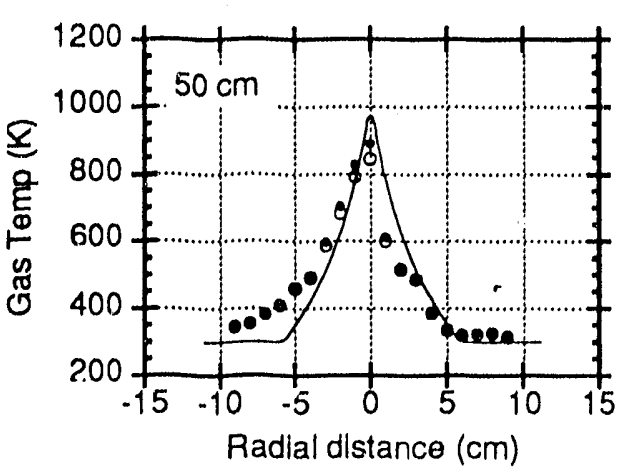

h)

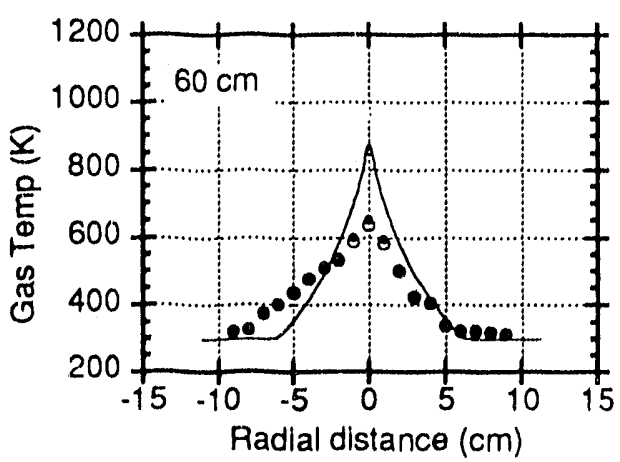

i)

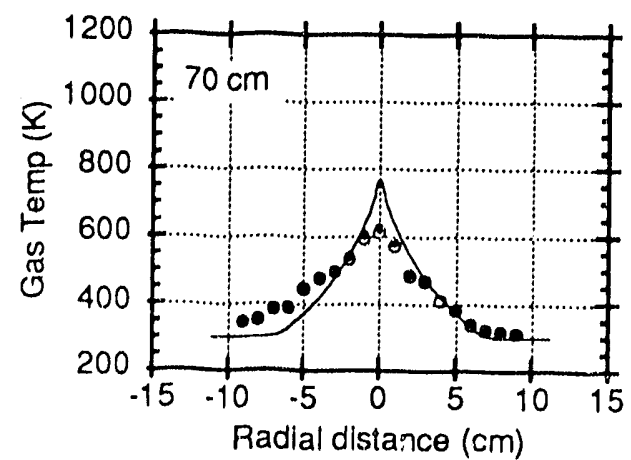

Figure III.A-1. Radial gas temperature profile data measured with a thermocouple and corrected for heat loss compared with with predictions for non-reacting flow (air only) in the TWR. 
peakedness is caused by the convection toward the centerline induced by buoyancy. Overall, the agreement with the data is quite good. The thermocouple measurements near the screen $(2 \mathrm{~mm}$ ) at a radius greater than $5 \mathrm{~cm}$ are too high, probably due to radiation from the hot screen, although the corrections don't seem to be much of an improvement. The mixing rate between the hot air and room air seems to be overpredicted. This could also be a result of overpredicting buoyancy forces. The transition from cold core to a peak at the centerline is accurately predicted.

Similar data for the coal flame are presented in Figure III.A-2. When particles are present, there is an immediate rise in temperature at the core following ignition. In this flame, ignition occurred at $10 \mathrm{~cm}$. The peaked nature of the profile is enhanced by the more dominant buoyancy forces compared to the gas-only case. due to the higher temperature in the core caused by the flame. Again the overall prediction of trends in the shape of the profile seem to be predicted fairly well. Interestingly, the uncorrected thermocouple measurements seem to agree better with the predictions than the corrected values. Heat-loss corrections in coal flames are quite uncertain owing to the effects of gas and soot radiation in the flame and coating of the thermocouple with soot.

Computed particle trajectories are shown in Figure III.A-3. Figure III.A-3a shows the complete trajectories. Figure III.A-3b shows only the portion of each trajectory where the particle temperature exceeds $1000 \mathrm{~K}$ and the particle is not completely burned out. The particles ignite at from 5 to $9 \mathrm{~cm}$ above the exit of the nozzle. The particles near the outer edge of the stream ignite first, as expected. since they are the first to mix with the preheated air. They also react the most quickly and burn out first, causing the width of the glowing particle stream to reach a maximum and then taper in toward the center of the reactor. The width of the particle stream also undergoes a rapid expansion at the ignition point as hot gases generated by combustion suddenly force the particle stream outward.

Measured and predicted particle velocities are compared in Figure III.A4. These measurements were obtained from the length of streaks recorded with a video camera. Calculations for two particle sizes and two starting locations are shown. The outer-edge particles accelerate more quickly than the centerline particles due to the sudden expansion of the gas as it enters the flow domain. The centerline particles don't accelerate until after ignition, at which time buoyancy forces and expansion due to heating cause the 
a)

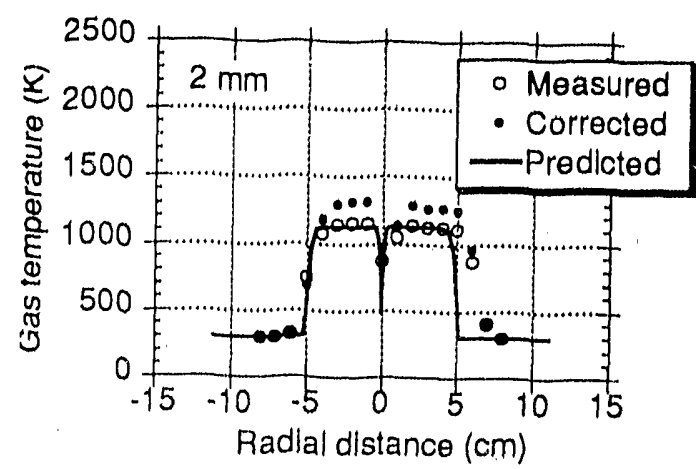

b)

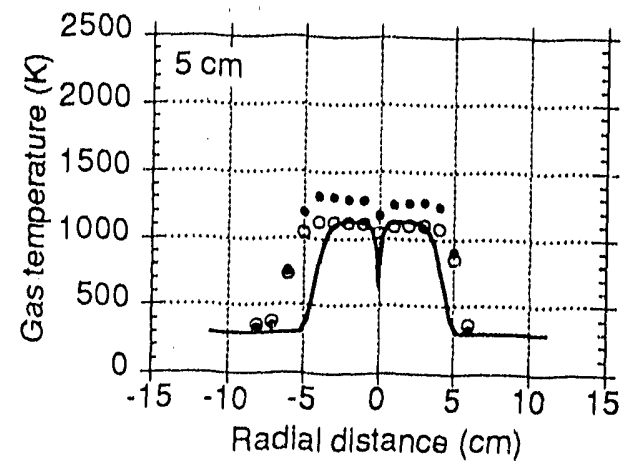

c)

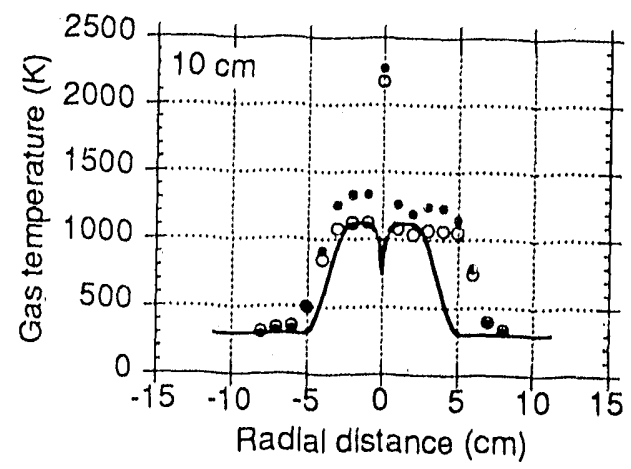

d)

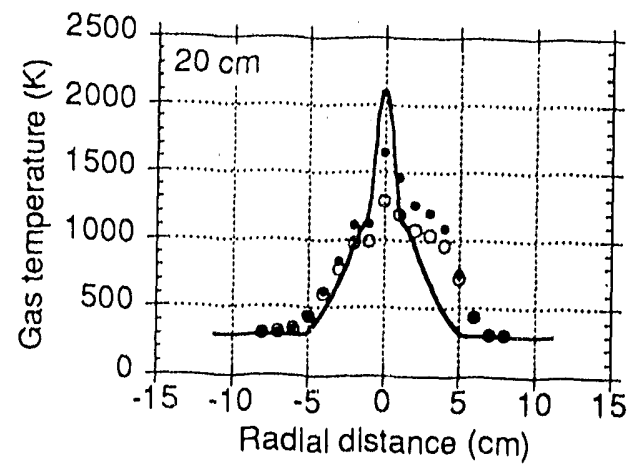

e)

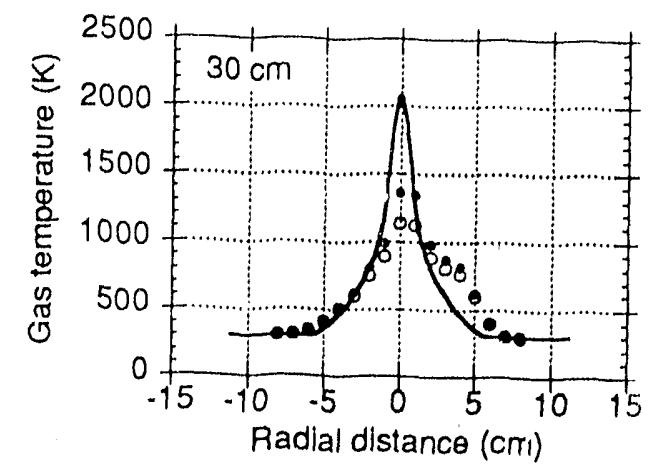

f)

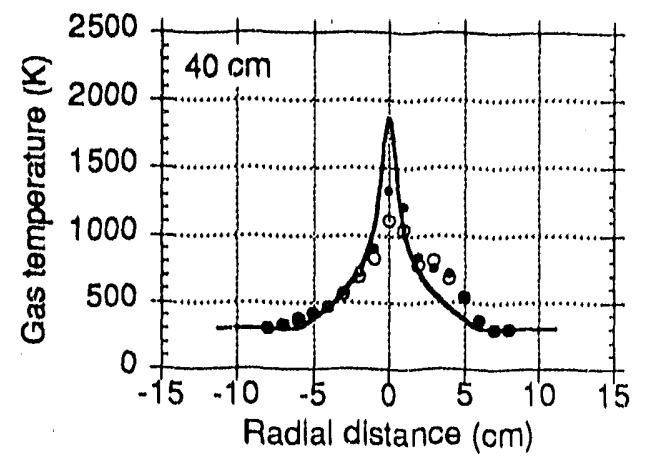

g)

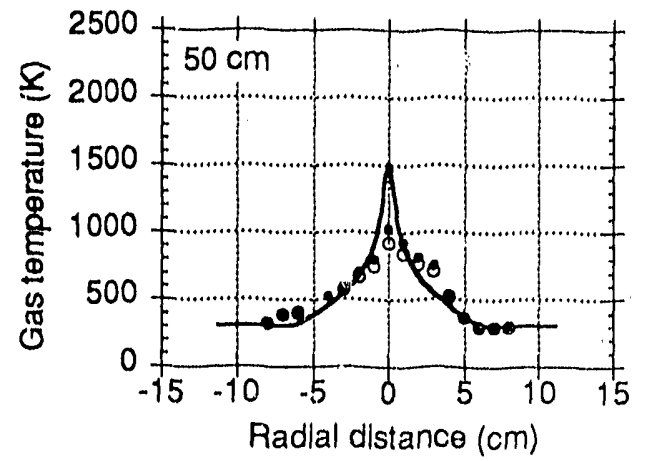

h)

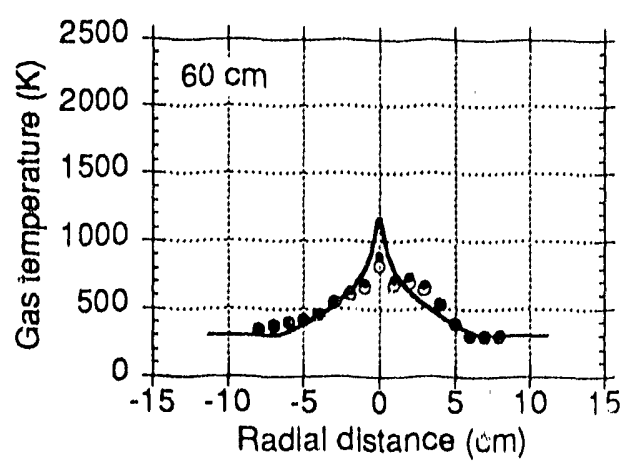

i)

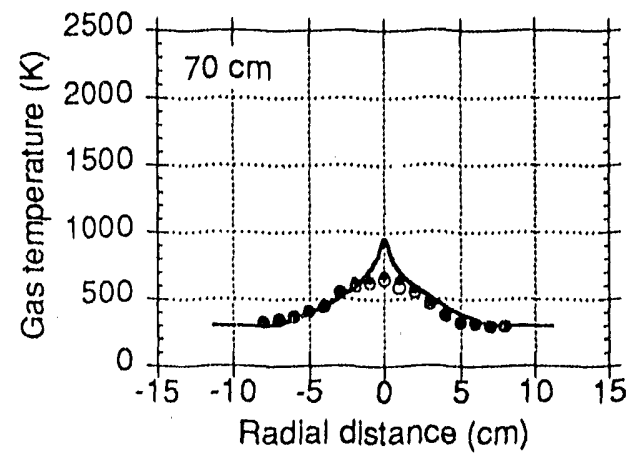

Figure III.A-2. Radial gas temperature profile data measured with a thermocouple and corrected for heat loss compared with with predictions for Rosebud subbituminous coal flame in the TWR. 
a) Complete trajectories

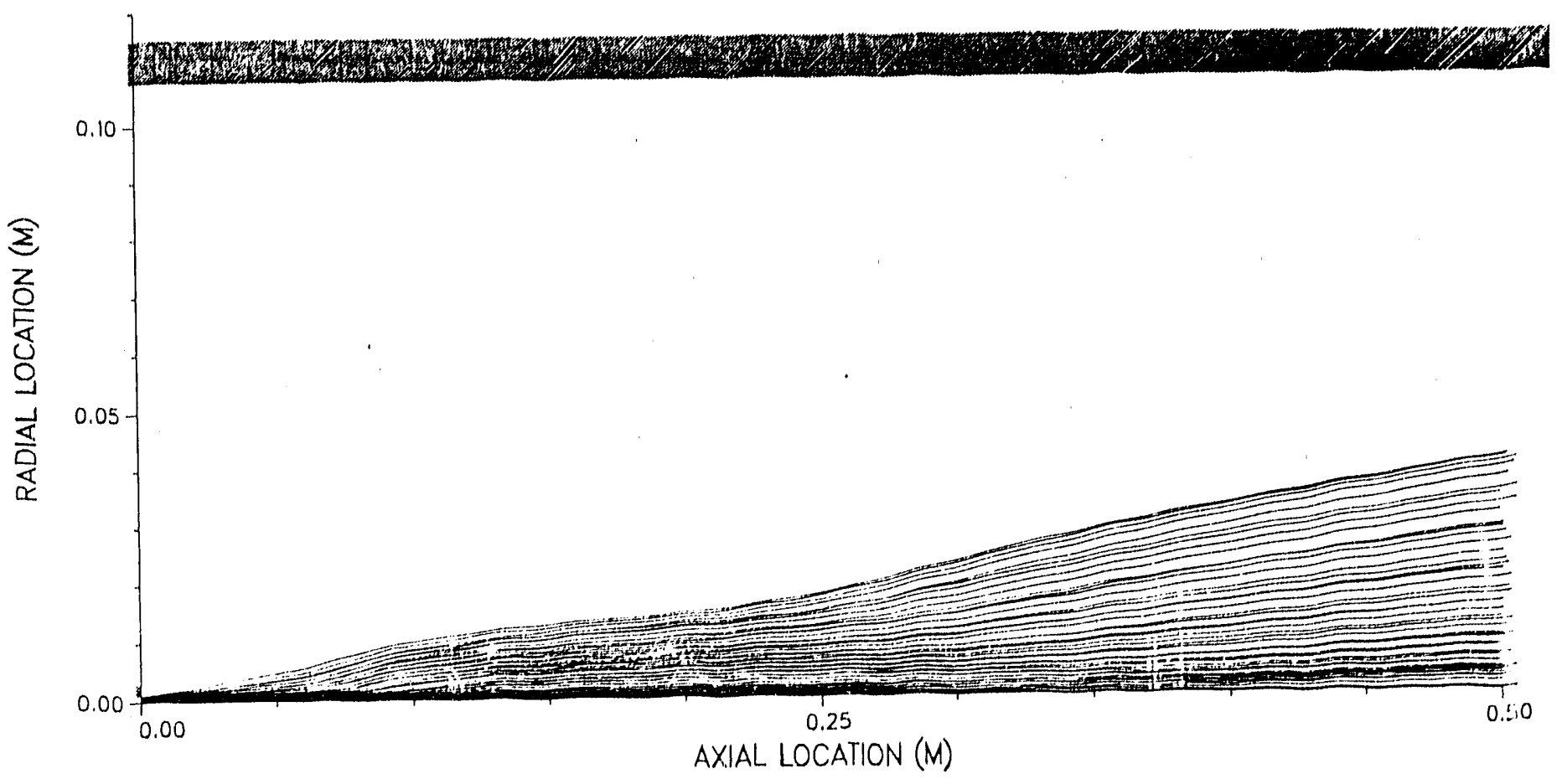

b) Trajectories of ignited particles

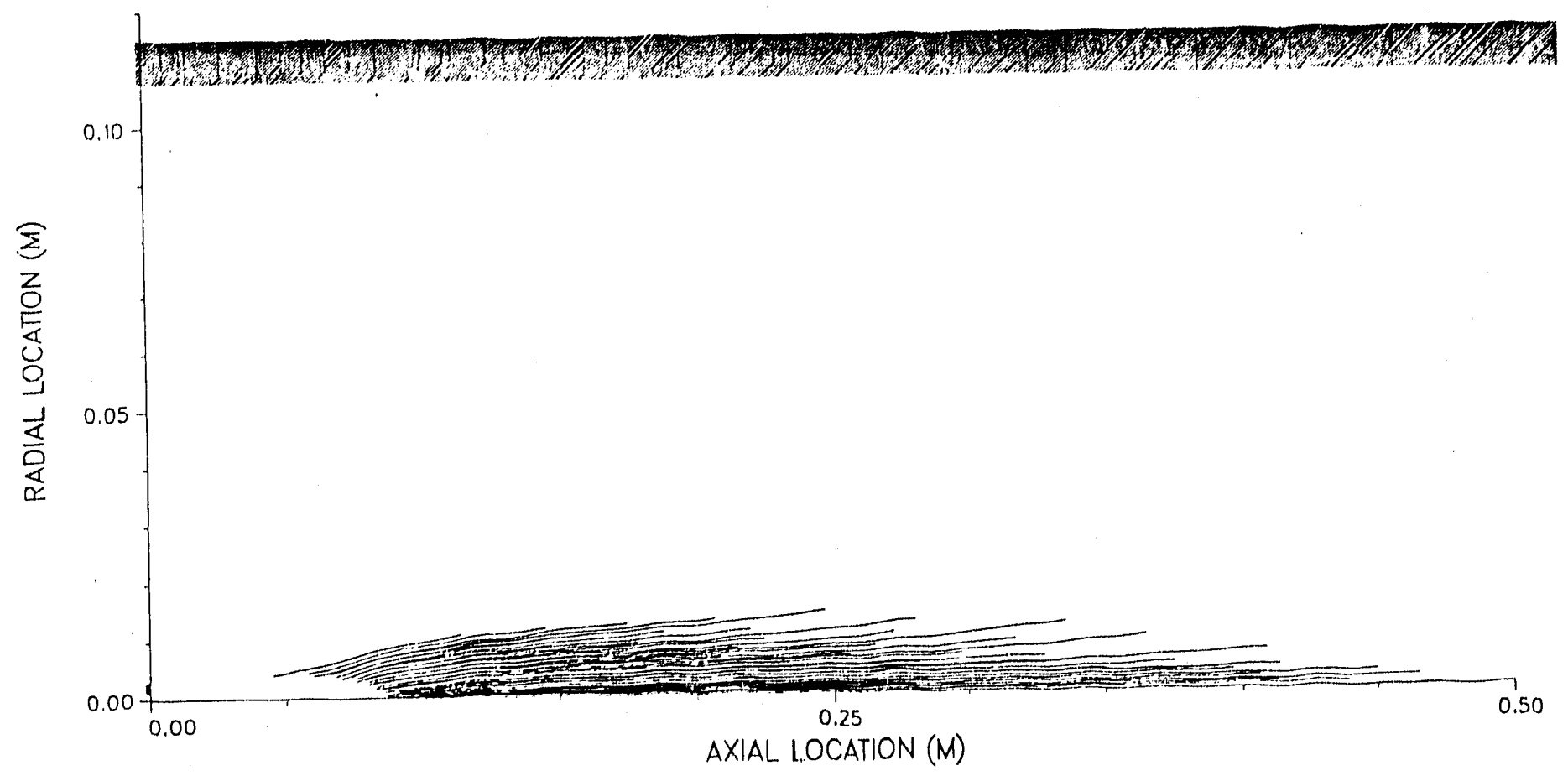

Figure III.A-3. Computed particle trajectories for Montana Rosebud coal flame in the TWR. 


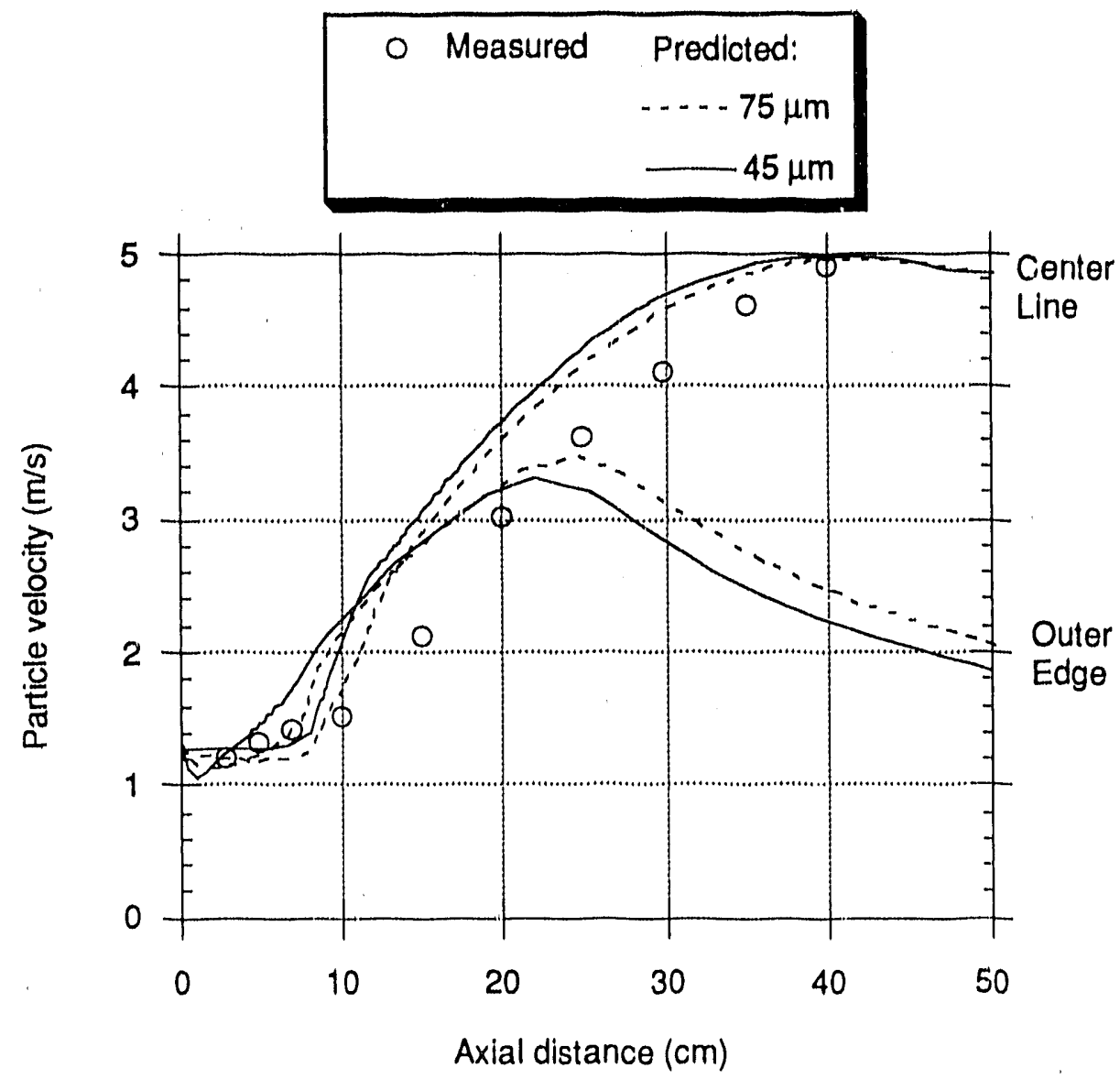

Figure III.A-4. Particle velocity determined from streaks on a video recording compared with predictions for $45 \mu \mathrm{m}$ and $75 \mu \mathrm{m}$ particles at the centerline and at the outer edge of the coal particle stream for a Rosebud subbituminous coal flame in the TWR.

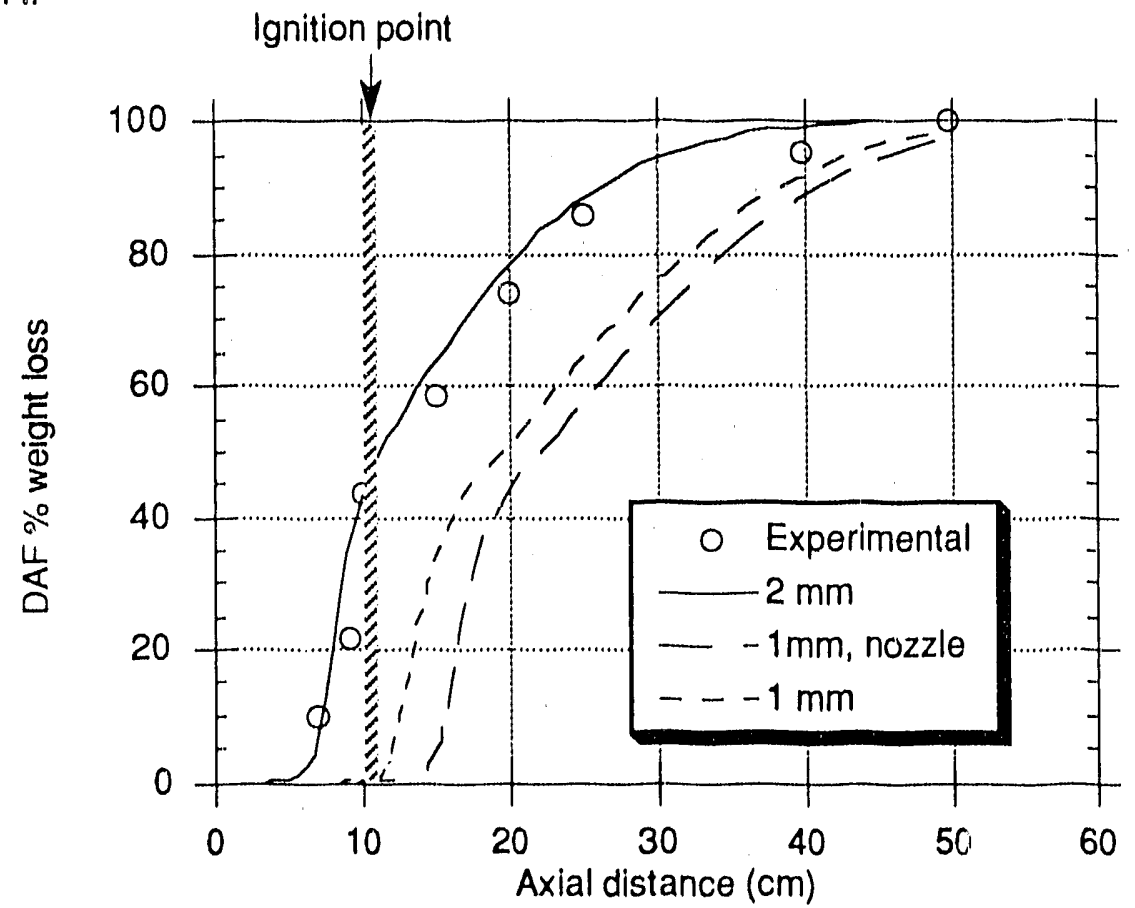

Figure III.A-5. Radially integrated particle burnout determined by the ash tracer method compared with predicted burnout for three cases for a Rosebud subbituminous coal flame in the TWR. The three cases are a 1- and 2-mm-diameter coal stream with the nozzle excluded from the calculational domain and a 1-mm-diameter coal stream with the nozzle included. 
gas velocity to increase near the center of the reactor. The centerline particles continue to accelerate until the radial velocity proflle begins to flatten due to the effects of diffusion. The outer edge particles. on the other hand, accelerate with the centerline particles, but then decelerate as they spread away from the centerline where the velocity is lower. These particles are, however, burned out (see Fig. III.A-3b) and so are not seen in the video recording. Predicted particle velocity is quite independent of particle size. It is a lso fairly independent of starting location in the preand early-flame regions, but then becomes a strong function of particle position. Predicted velocity exceeds the measured values up to the point where it becomes a strong function of particle position. The predicted velocity for the visible trajectories agrees fairly well with the measured values.

Particle burnout is shown in figure III.A-5. Three cases are shown: a l-mm-diameter coal stream at the nozzle exit (nozzle excluded from the calculational domain), a 2 -mm-diameter coal stream at the nozzle exit, and 1mm-diameter coal stream at the nozzle entrance (nozzle included in the calculational domain). The coal stream enters the reactor through a 1 -mmdiameter tube, which expands into a 5-mm-diameter nozzle. As shown, the burnout curve is predicted very well for the inlet condition of a $2 \cdot \mathrm{mm}$ diameter coal stream at the nozzle exit. which is consistent with visual observation of the stream as it exits the nozzle. The curve is shifted to the right for the $1 \mathrm{~mm}$ case (nozzle excluded) because of the increased velocity. The $1-\mathrm{mm}$ case with nozzle included was apparently unable to resolve the complex flow in the nozzle with the current grid spacing. Detailed simulation of the nozzle revealed the presence of recirculation zones which extended beyond the nozzle exit into the reactor. The slight "knee" in the curve at 40 percent burnout is due to the iransition from devolatilization to heterogeneous oxidation of the residual char. The shape of the burnout curve is fairly insensitive to the assumed coal stream inlet diameter and particle velocity, but the curve (and ignition point) can be shifted several centimeters to the right or left by varying the particle inlet assumptions.

Tomography data and predictions are shown in Figs. III.A-6 to 8 . Figure III.A-6 presents the particle and gas temperatures. A symbol is shown for the temperature of each particle trajectory as it crosses the indicated axial distance. At $6 \mathrm{~cm}$, the particles are being heated by the gas and lag the gas temperature. At the edge of the particle stream, it appears that one of the smallest particles $(45 \mu \mathrm{m})$ is ignited. Measurements indicate the presence of 
a)

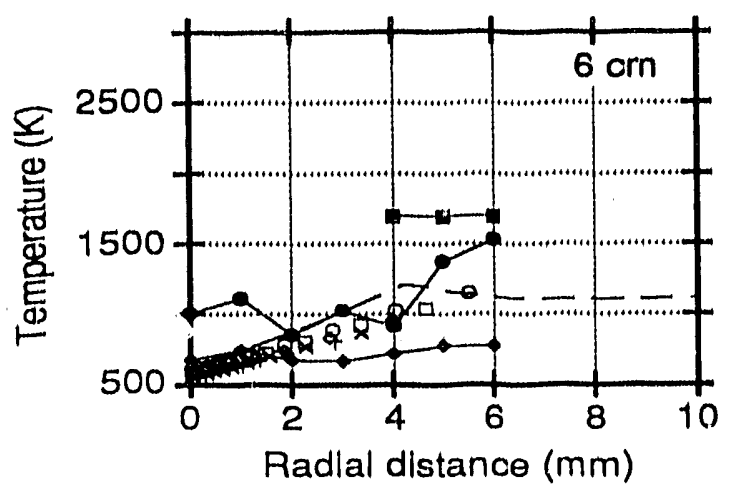

b)

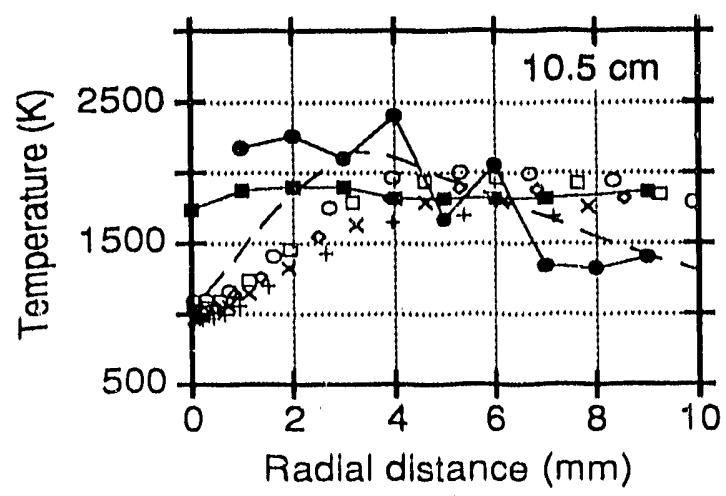

c)

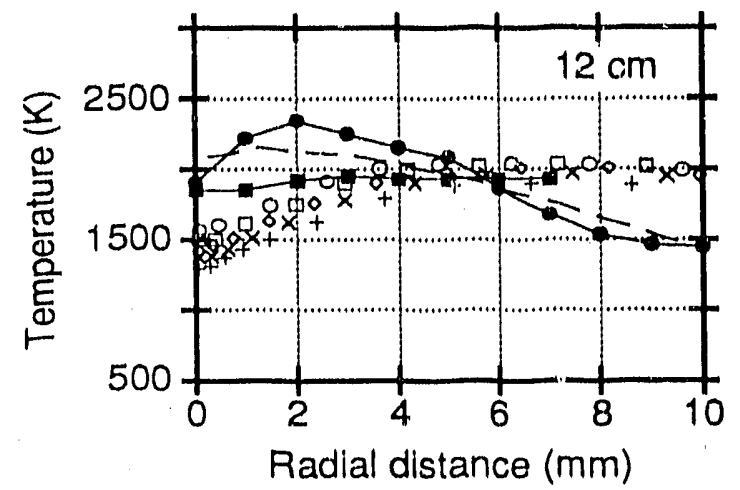

d)

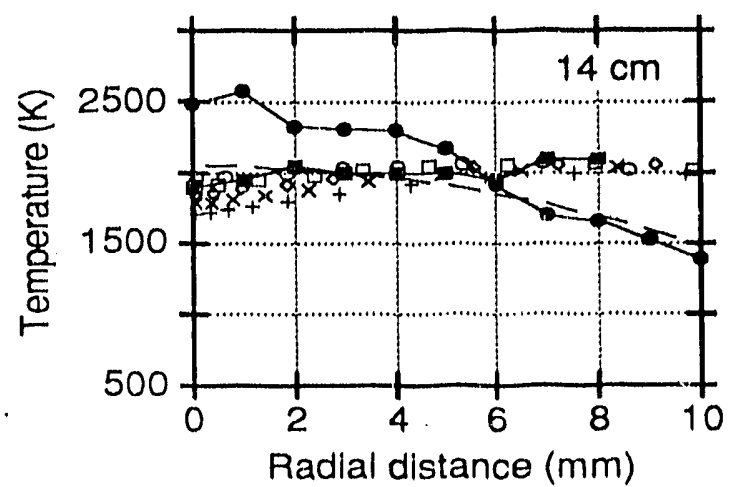

Tomography:

Predloted:

$-\mathrm{CO}_{2}$

$\rightarrow$ Unlgnited partlules

- -Gas

- 45. $\mu \mathrm{m}$ partloles

- $52.5-\mu \mathrm{m}$ partioles

- 60- $4 \mathrm{~m}$ partloles

$\times 67,5-\mu \mathrm{m}$ partloles

$+75-\mu \mathrm{m}$ partloles ө)

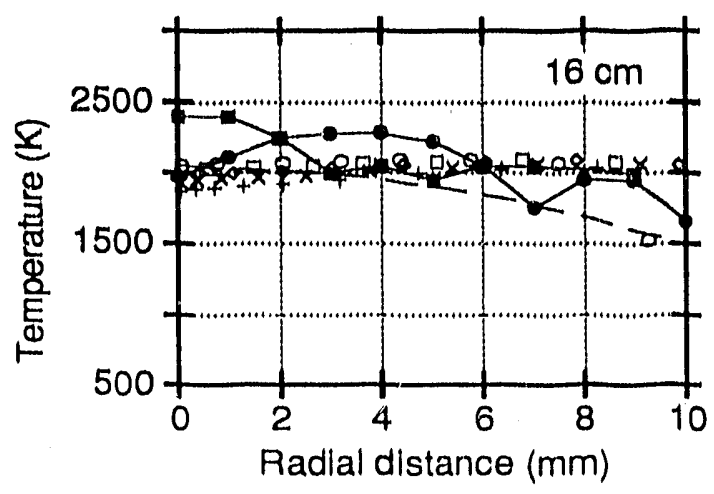

f)

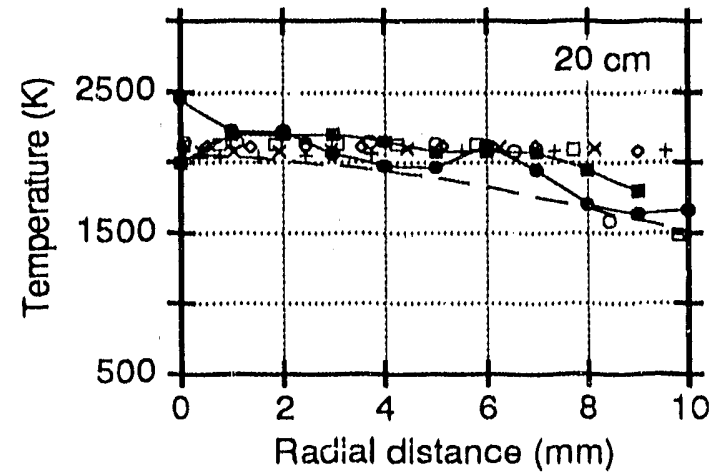

g)

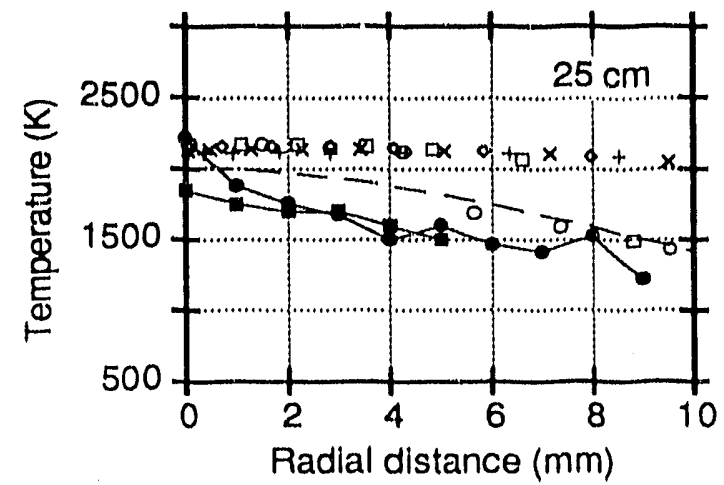

Figure III.A-6. Radial $\mathrm{CO}_{2}$ and particle temperature profiles determined from tomographic reconstruction of FT-IR emission/transmission spectra compared with predicted gas and particle temperature for a Rosebud subbituminous coal flame in the TWR. 
both ignited and urifgnited particles near the outer edge. consistent with the predictions. However, the predicted particles heat more slowly than the measured particles near the edge of the stream and the ignited particles, have a higher temperature than predicted. The higher temperature of ignited particles is probably due to not having the correct $\mathrm{CO}_{2} / \mathrm{CO}$ ratio at the particle surface as discussed below. Also, the measured $\mathrm{CO}_{2}$ temperature is usually higher than the predicted average gas temperature where tgnition occurs, since the combustion energy is first going to heat the $\mathrm{CO}_{2}$ which subsequently heats the other gases.

At $10.5 \mathrm{~cm}$, the core is still fairly cool while many mure particles have ignited at the outer edge. The predictions don't show the $20 \%$ of the high temperature particles which are observed to be ignited on the centerline. This may be due to the feedback of the energy to the particle from co combustion not being modeled properly. For these calculations, it was assumed that the oxidation of the particle produces $c 0$ and $a 11$ the energy from the $\mathrm{CO} \rightarrow \mathrm{CO}_{2}$ oxidation goes into the gas phase. This assumption is not in agreement with the measurements of Mitchell et a1. (1988) or Tognotti et al. (1990). The assumption on the amount of $\mathrm{CO}_{2}$ produced in the partfcle can be varied to test the predictions.

At $12 \mathrm{~cm}$, the gas temperature leads the particle temperature by approxiriutely $600 \mathrm{~K}$, as oxygen diffuses from the surrounding air and reacts with the volatiles and co produced by heterogeneous reaction. The latter is assumed in the model to react to $\mathrm{CO}_{2}$ in the bulk gas, away from the particle surface. After the volatiles have reacted, the burning char particles continue to rise in temperature and exceed the temperature of the gas, even in the core. At $16 \mathrm{~cm}$ and higher. some particles near the outer edge have burned out and dropped in temperature to that of the gas. It is the smallest particles $(45 \mu \mathrm{m})$ which burn out first. The predicted temperatures are higher than measured at $25 \mathrm{~cm}$. This may be a problem with the reduction of reactivity at high extents of burnout.

Figure III.A-7 presents the measured height of the continuum blockage determined for soot from the transmittance spectra as percent of the incident IR beam compared with the predicted mole fraction of condensed carbon. Figure III.A-7a shows the radial profiles at $10.5 \mathrm{~cm}$, the location of highest measured soot concentration. and Fig. III.A-7b shows the axial centerline profiles. As shown, the peak concentration of condensed carbon occurs at approximately $10 \mathrm{~cm}$, and this coincides with the highest measured 
a) Radial proflle at $10.5 \mathrm{~cm}$ :

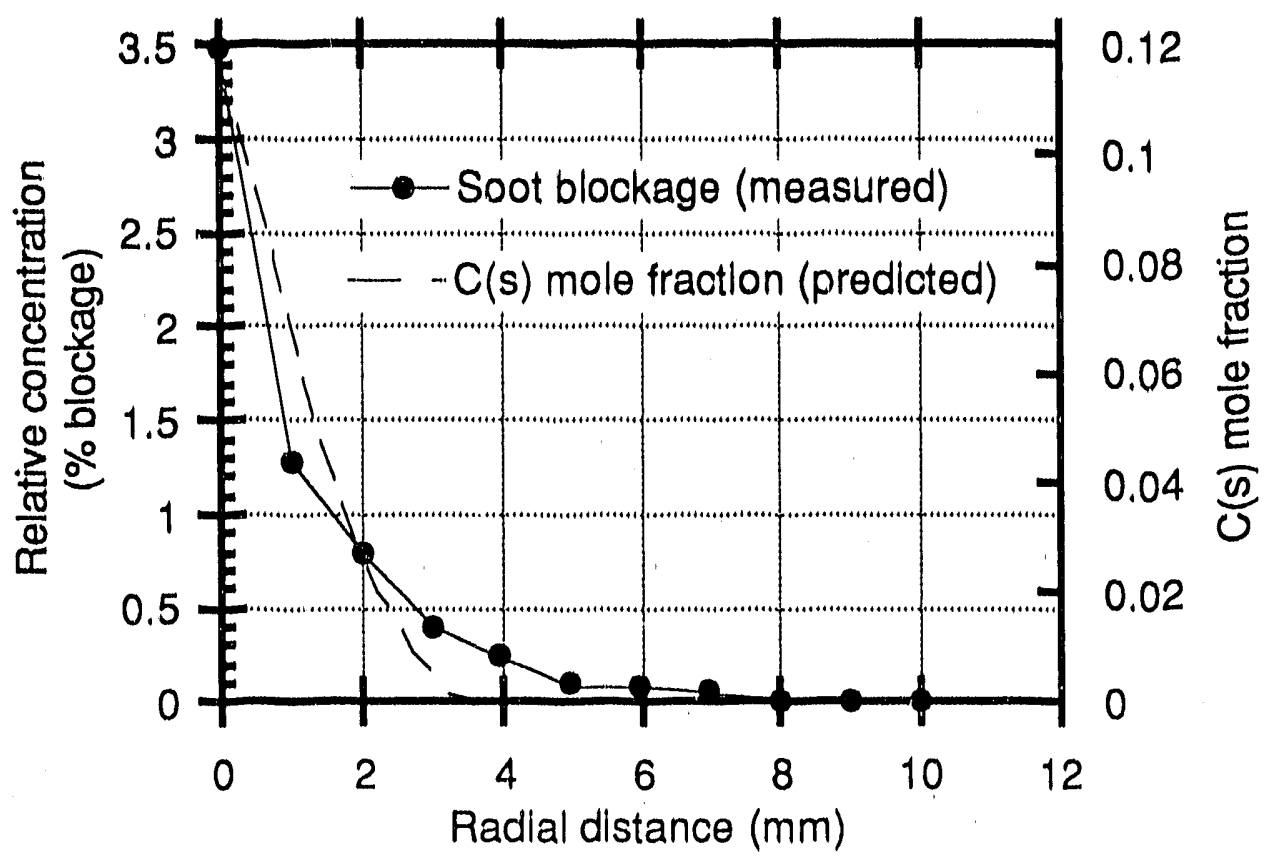

b) Axial profile at the centerline:

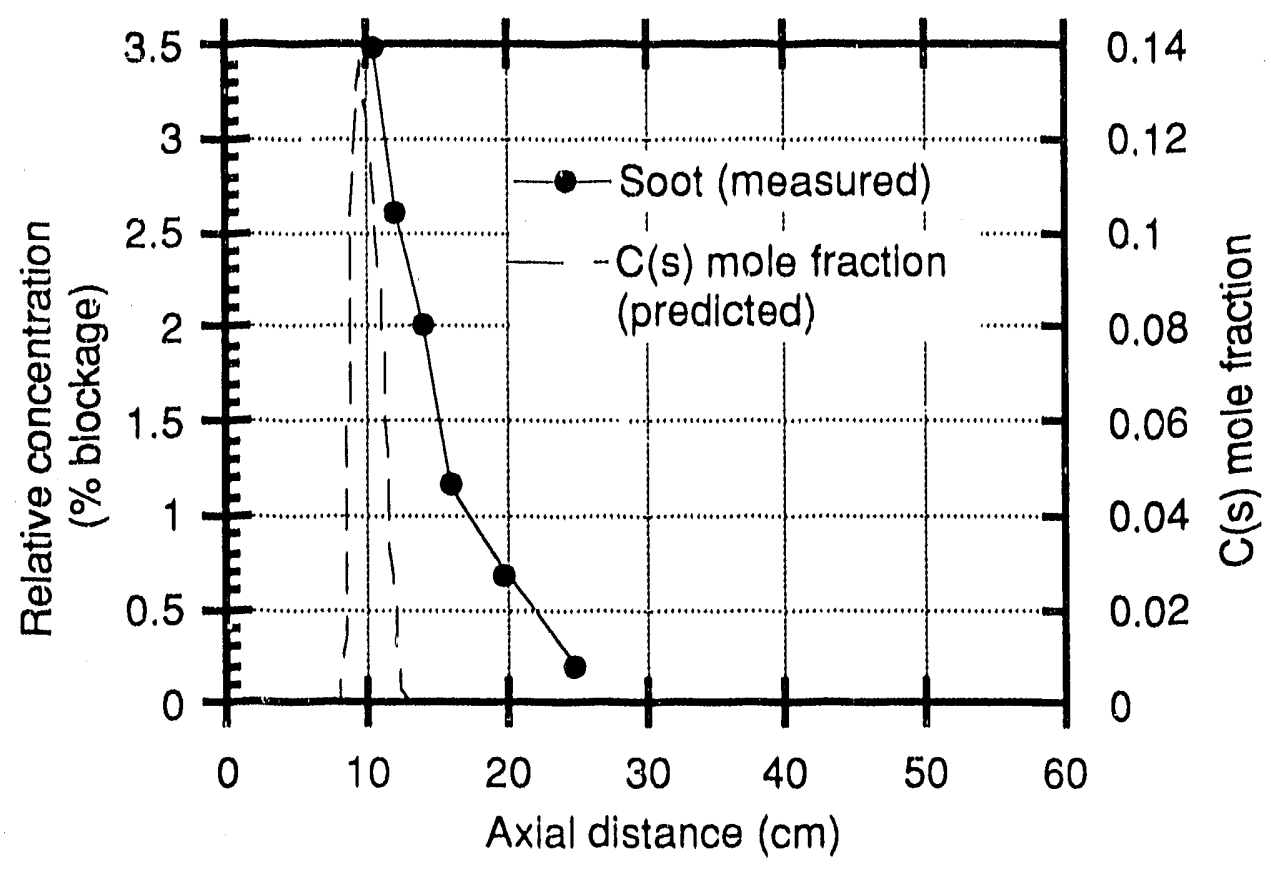

Figure III.A-7. Relative soot concentration determined by tomographic reconstruction of FT-IR emlssion/transmission spectra from a Rosebud coal flame in the TWR compared with predicted concentration of condensed carbon. 
concentration of soot. The predicted radtal profile at $10.5 \mathrm{~cm}$ has approximately the same shape as the measured profile. However, the decay of soot. once formed. seems to be kinetically controlled, as the predicted centeritine concentration of condensed carbon falls off much more rapidly than the measured soot concentration.

Figure III.A-8 shows the measured and predicted $\mathrm{CO}_{2}$ concentrations. The absolute values cannot be compared, because the measured values are given in absorbance units, which have not been calibrated. However, the relative magnitudes and trends show reasonable agreement. Prior to ignition, the measured and predicted concentration is 10w. Both measured and predicted values are higher at the centerline after ignition and remain fairly constant to a distance of $25 \mathrm{~cm}$.

Conclusions - After modifying for up-firing, gas buoyancy, and laminarization, the computer model for two-dimensional, turbulent combustion of pulverized coa1. PCGC-2, has been used to successfully model the laminar coal flame in the transparent wall reactor. Key flame properties, such as ignition point, burnout profile, and gas and particle temperature, have been reasonably well predicted. Complex flow patterns at the nozzle promote particle dispersion, and were not adequately resolved with current grid spacing. Code predictions are sensitive to inlet boundary conditions for the coal stream at the nozzle exit, and detailed characterization of this boundary condition is needed. Soot formation seems to correlate with equilibrium concentration of condensed carbon, but decays more slowiy than predicted from equilibrium. The energy feedback to particles or the $\mathrm{CO}_{2} / \mathrm{CO}$ ratio produced at the particle is not adequately predicted.

\section{Graphic Interface}

Work continued on the development of a graphical user interface (GUi) for PCGC-2 on the Sun workstation. A window was added for specifying the composition and temperature of the inlet streams. The thermodynamic input file can now be gencrated automatically using information in the main data file and a database cuntaining data for approximately 200 species. Work was also initiated to apply two graphical programs that have been developed under independent funding, a pre- and a post-processor, to PCGC-2. The relationship of these two programs and the GUI to PCGC-2 is shown in Figure iII.A-9. As shown, the pre-processor generates a computational grid and the post-processor presents code results. The format of the grid file used by PCGC-2 differs 
a)

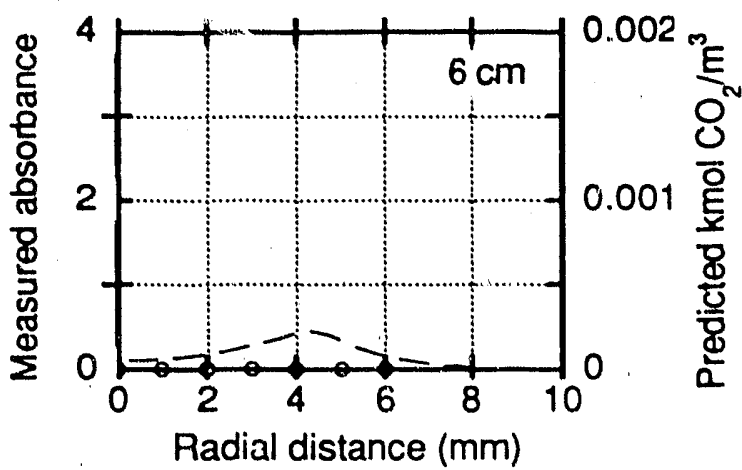

b)

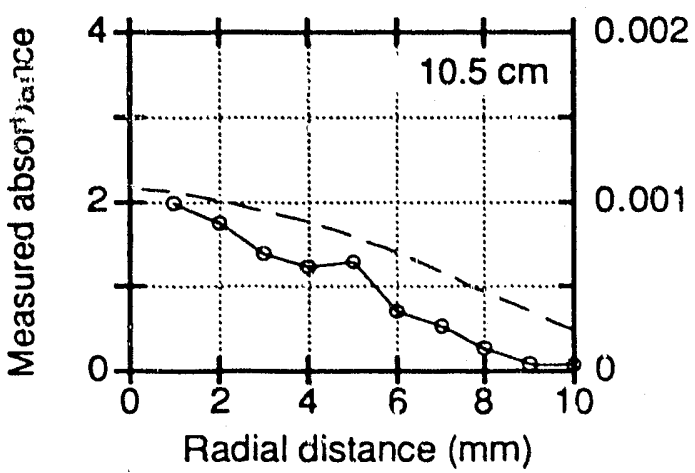

c)

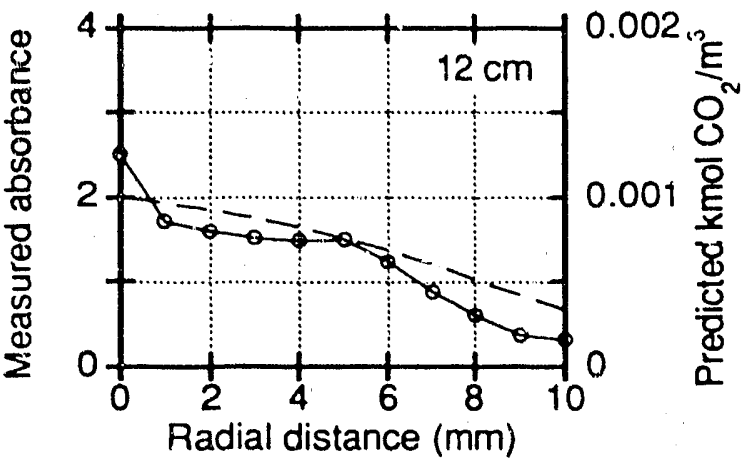

d)

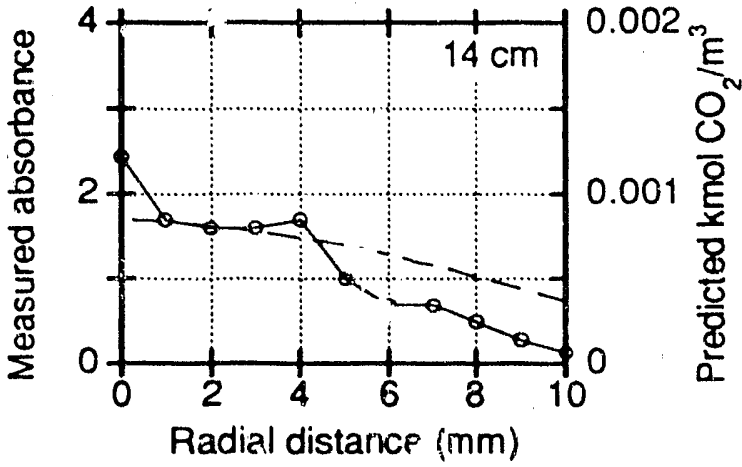

- Measured

- -Predicted e)

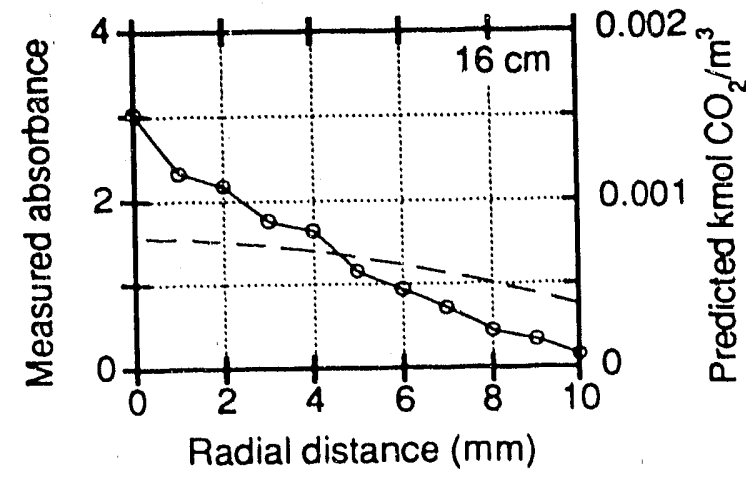

f)

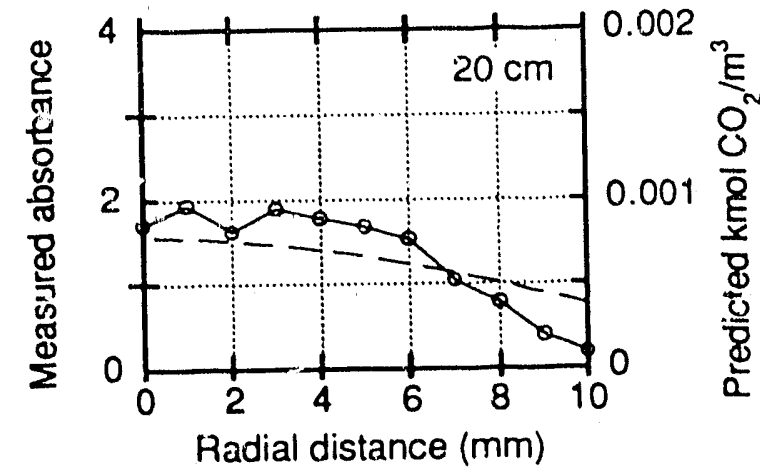

g)

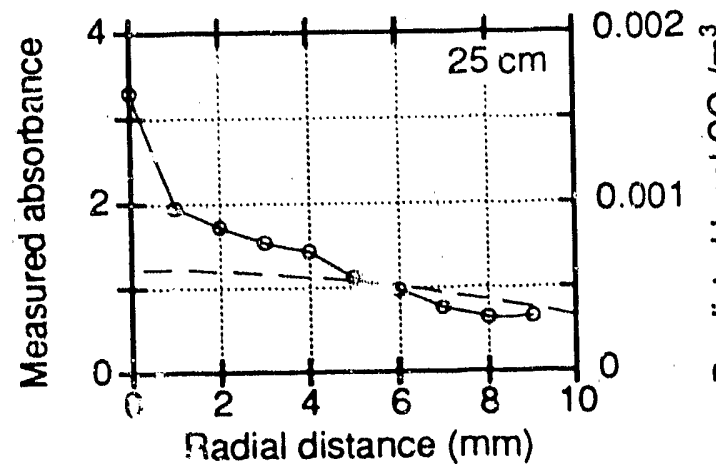

Figure III.A-8. Radial $\mathrm{CO}_{2}$ absorbance profiles deterr: 'ned from tom.ographic reconst' ution of FT-IR emission/transmission spectra compared with predic.. concentration for " Rosebud subbituminous coal flame in the TWR. 
from that used by the pre-processor, and a program was written for converting files between the two formats. A subroutine was modified and added to PCGC-2 for writing the plotting file needed by the post-processor.

Both the pre- and post-processors have been applied to the TWR simulation described above. Figure III.A-10a shows the graphical representation of the computatiulal grid, and Figure III.A-10b shows the computed gas temperature. The vertical lines in the grid are the radial node locations and the horizontal lines are the axial nodes. The reactor centerline is to the left, where the radial nodes are more closely spaced. The light blue strip on the right side of the grid represents the reactor wal1. The cells representing the coal feed tube are at the lower, left-hand corner. They are color-coded, but can'l, be seen in this figure. The cells representing the preheated air inlet are the cells colored red at the bottom. The cells colored green represent the room air inlet. The buttons along the top and right-hand side of the window allow the user to select different code options to construct and modify the grid.

The color-fringe plot in Figure III.A-10b is on its side, with the reactor inlet on the left and the gas flowing to the right. The centerline is at the bottom and the wall is at the top. The yellow and red regions indicate the location of the flame and hot combustion gajes. The coal inlet stream can be seen at the lower, left-hand corner. The postprocessor also has buttons across the top (not visible in this figure) and down the right-hand side of the window to allow the user to interact with the program.

\section{Plans}

Early in the next quarter, work will be completed on modeling of the TWR reactor flames. Work will continue on extending the graphical user interface. A major effort will be initiated toward development of the final integration of PCGC-2 and FG-DVC, including user-friendliness, robustness, and the user's manual. The first version of the graphical interface will be completed for gas, and consideration will be given to extending to particles. A poster paper entitled "Structure of a Near-Laminar Coal Jet Diffusion Flame" will be presented at the 23 rd Symposium (International) on Combustion to be held in orléans, France, on july $22-27$. 
a) Computational grid (pre-processor)

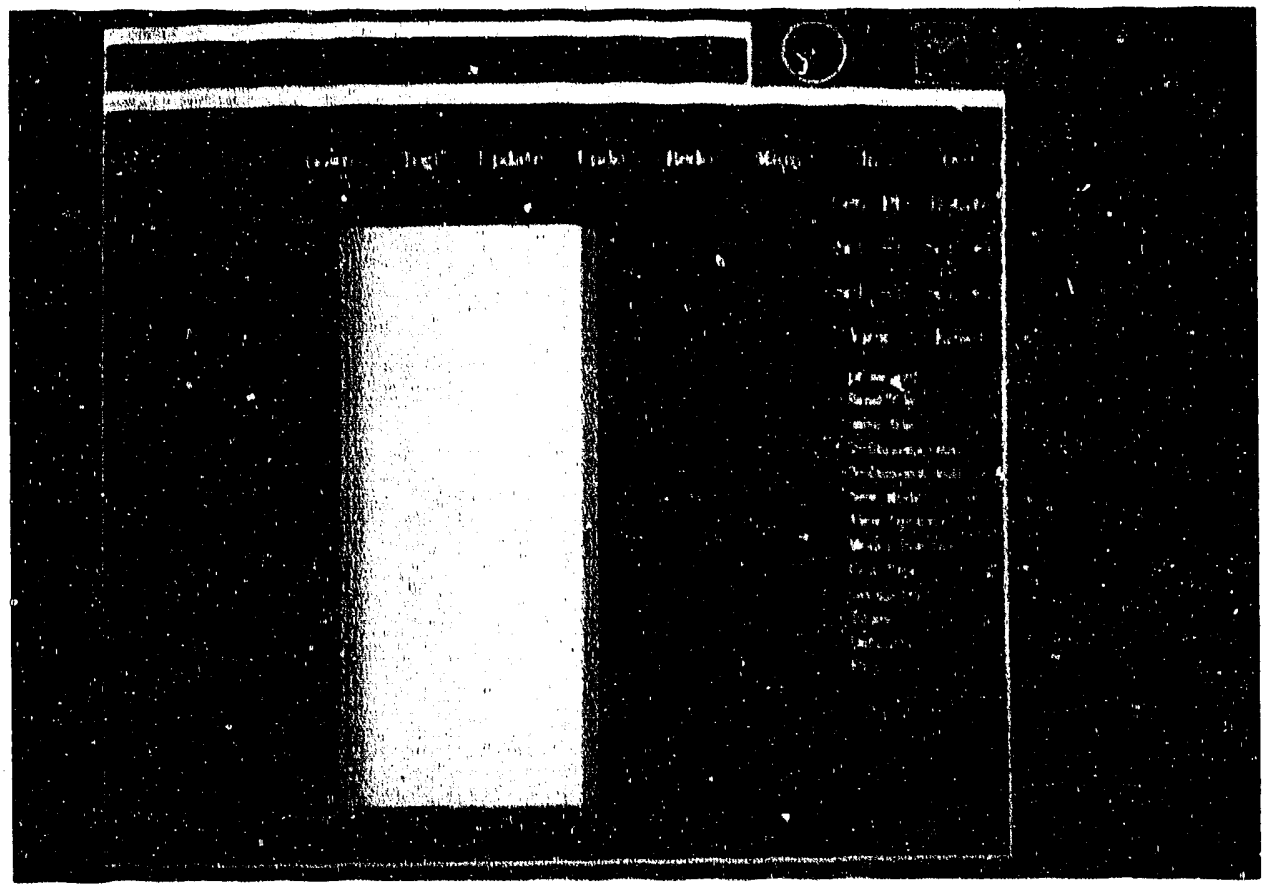

b) Predicted temperature field (post-processor)

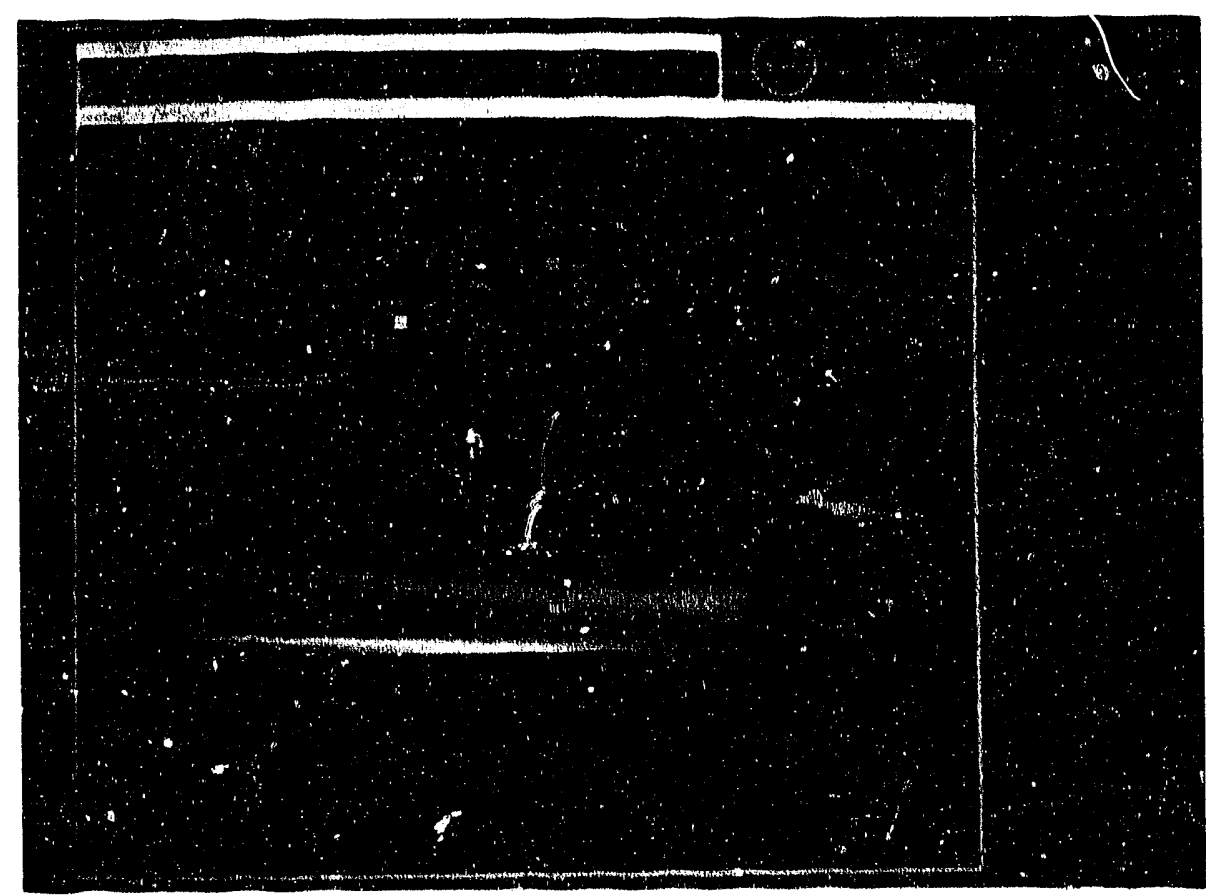

Figure III.A-10. Computational grid and predicted temperature field as rendered by the pre- and post-processors on a Sun workstation for the PCGC-2 simulation of the Montana Rusebud subbituminous coal flame in the transparent wall reactor. 


\title{
III.B. SUBTASK 3.B. - COMPREHENSIVE FIXED-BED MODELING REVIEW. DEVELOPMENT, EVALUATION. AND IMPLEMENTATION
}

\author{
Senior Investigators - Predrag T. Radulovic and L. Douglas Smoot \\ Brigham Young University \\ Provo, Utah 84602 \\ (801) $378-3097$ and (801)378-4326
}

Graduate Research Assistant - Michael L. Hobbs

\section{Objectives}

The objectives of this subtask are 1 ) to develop an advanced fixed-bed model incorporating the advanced submodels being developed under Task 2 , particularly the large-particle submodel (Subtask 2.e.). and 2) to evaluate the advanced model.

\section{Accomplishments}

During the last quarter, work continued on reviewing, coding, and validating submodels. To enhance user-friendliness, the input file has been rewritten to segregate input parameters for the two-zone submodel and the onedimensional submodel. Also, the fixed-bed code has been rewritten in a modular fashion with extensive comment statements. The two-zone submodel has been improved to accommodate user-specified burnout. Also, two heat transfer zones were added to the well-mixed model to account for heat loss in the freeboard region and heat transfer between solid and gas in the ash zone of the reactor. The ash enthalpy calculation was improved. The heat capacily of the ash is calculated with the Kopp-Neumann rule which is based on the various constituents of the ash. Melting is assumed to occur at the measured ash fluid temperature, and the associated enthalpy of fusion is assumed to be 230 $\mathrm{J} / \mathrm{g}$ (Mills and Rhine, 1989).

The fixed-bed code was evaluated by parametric sensitivity analysis. Sensitivity runs were divided into model options, model parameters and operational parameters. Model options include tar vapor reaction equilibrium. volatile mass transport, char ash layer formation, and combustion product distribution. Hodel parameters include the solid-to-gas heat transfer coefficient, effective diffusivity, bed-to-wall heat transfer, potential tarforming fraction. functiorial group composition (coal rank), and oxidation and 
gasification kinetics. Operational parameters include the temperature of the feed gas, reactor pressure, coal mass flow rate, steam mass flow rate, air mass flow rate. while coal and bed properties include proximate ash content of the feed coal, proximate moisture content of the feed coal, particle diameter. and bed void fraction.

Calculations have been conducted for twelve coal types which range from lignite to bituminous. The availability of experimental profiles within laboratory-scale or commercial-scale fixed-bed gasifiers is limited. Temperature and pressure profiles have been measured by Thimsen et a1. (1984) during coal gasification in a Wellman-Galusha gasifier. True density. particle density, bulk (bed) density, bed void fraction, porosity, particle diameter, and carbon conversion for feed coal and exit ash were determined from available experimental data and correlations provided in Elliott (1981).

\section{Improved Two-Zone Submodel}

The two-zone submodel was refined by adding two heat transfer zones to account for heat loss in the freeboard region and heat transfer between solid and gas in the ash zone of the reactor. In the ash zone, the solid and gas temperatures are close and, therefore, a reasonable assumption is to assume them equal. However, this assumption has little effect on calculated effluent results since the ash mass flow rates are typically small in fixed-bed reactors.

\section{Improved Ash Enthalpy}

The specific heat of the ash, $C p_{a}\left(\frac{J}{k_{g} \cdot K}\right)$. can be determined from (Merrick. 1983):

$$
C p_{a}=754+0.586 t
$$

where $t\left({ }^{\circ} \mathrm{C}\right)$ is the ash temperature. The Kopp-Neumann rule also gives reliable estimates of the ash heat capacity if the various constituents of the ash are known (Milis and Rhine, 1989):

$$
C p_{a}=\frac{1000 \cdot \sum_{i=1}^{n} x_{i} C p_{i}}{\overline{\mathbf{M}}_{w}}
$$

where $x_{i}, C p_{i}\left(\frac{J}{\operatorname{miok}}\right)$, and $\bar{M}_{w}$ represent the mole fraction of the $i$ th ash constituent, partial molar heat capacity of the pure $i$ th component, and the weight-average molecular weight of the ash or slag. The temperature 
dependence of $C_{p}$ is frequently expressed as $C_{p}=a+b T-c T^{-2}$ and values of $a, b$, and $C$ for $s$ lag constituents used herein are given in Table III.B-1. Equation III.B-2 can also be used to determine the heat capacity of the liquid slag. Melting is assumed to occur at the measured ash fluid temperature, and the associated enthalpy of fusion is assumed to be $230 \frac{\mathrm{J}}{8}$ (Mills and Rhine, 1989).

Sensitivity Analisisl

The one-dimensional model sensitivity analysis is divided into three major sections: 1) model options, 2) model parameters, and 3) operational and coal parameters. Details regarding each option and input parameters are available in Hobbs (1990). The base case is gasification of Jetson bituminous coal in an atmospheric, air-fired, Wellman-Galusha gasifier. Four model options are briefly discussed herein. The model options include tar vapor reaction equilibrium, volatiles mass transport, char ash layer formation, and combustion product distribution. Three model parameters are also discussed: solid-to-gas heat transfer, effective diffusivity, and bed-to-wall heat transfer. Six operational and coal parameters are discussed: potential tarforming fraction (relates to coal rank), feed gas temperature, reactor pressure, feed coal flow rate, particle size, and bed void fraction.

The sensitivity analysis reported in this section is taken from approximately 300 simulations. Only 38 of these simulations are given in Figures III.B-1 and III.B-2. The extra simulations were performed to determine the most appropriate set of realistic fixed-bed parameters. Additional information and details regarding the fixed-bed sensitivity can be fo!nd in Hobbs (1990).

Iar Vapor Reaction Equilibrium - The one-dimensional, fixed-bed model has two options for treating tar vapor chemistry: 1) the tar is allowed to react in the gas phase to completion (chemical equilibrium assumption) or 2) the tar vapor is nonreactive (i.e.. in thermal equilibrium, but "frozen" chemica17y). "Condensed-phase" tar is included in the char. If option 1 is chosen, all gases including tar are assumed io be in cheillical equilibrium. If option 2 is crosen, all gases except tar are assumed to be in chemical equilibrium.

The predicted sensitivity of the axial solid temperature profile to the tar gas phase equilibrium assumption is shown in Figure III.B-1a. Use of the equilibrium assumption causes the temperature peak to shift closer to the 
Table III.B-1. Partial molar heat capacity of slag components used in Kopp-Neumann rule.

\begin{tabular}{|c|c|c|c|c|c|}
\hline Slag & $M_{w}$ & & $D_{i}\left(\frac{J}{m o l K}\right)=a+$ & $C T^{-2}$ & $\bar{C} p$ (liquid) \\
\hline Component & $\frac{k_{g}}{k m o l}$ & $a$ & $b$ & $c$ & $\frac{J}{\operatorname{molK}}$ \\
\hline $\mathrm{SiO}_{2}$ & 60.09 & 53.591 & $1.8715 \times 10^{-2}$ & $1.2644 \times 10^{6}$ & 87.0 \\
\hline $\mathrm{CaO}$ & 56.08 & 41.868 & $2.0264 \times 10^{-2}$ & $4.5217 \times 10^{5}$ & 80.8 \\
\hline $\mathrm{Al}_{2} \mathrm{O}_{3}$ & 101.96 & 92.445 & $3.7560 \times 10^{-2}$ & $2.1876 \times 10^{6}$ & 146.4 \\
\hline $\mathrm{MgO}$ & 40.31 & 45.469 & $5.0116 \times 10^{-3}$ & $8.7379 \times 10^{5}$ & 90.4 \\
\hline $\mathrm{K}_{2} \mathrm{O}^{\ddagger}$ & 94.2 & 65.700 & $2.2600 \times 10^{-2}$ & 0.0 & 74.0 \\
\hline $\mathrm{Na}_{2} \mathrm{O}^{\ddagger}$ & 61.98 & 65.700 & $2.2600 \times 10^{-2}$ & 0.0 & 92.0 \\
\hline $\mathrm{TiO}_{2}$ & 79.9 & 49.446 & $3.1568 \times 10^{-2}$ & $1.7543 \times 10^{5}$ & 111.7 \\
\hline $\mathrm{MnO}$ & 70.94 & 31.108 & $4.3459 \times 10^{-2}$ & $5.5156 \times 10^{-5}$ & 79.9 \\
\hline $\mathrm{FeO}$ & 71.85 & 52.84 & $6.2470 \times 10^{-3}$ & $3.1903 \times 10^{5}$ & 76.6 \\
\hline $\mathrm{Fe}_{2} \mathrm{O}_{3}$ & 159.7 & 103.50 & $6.7156 \times 10^{-2}$ & $1.7727 \times 10^{6}$ & 191.2 \\
\hline$F e^{\ddagger}$ & 55.85 & 12.72 & $3.1710 \times 10^{-2}$ & $-2.5100 \times 10^{5}$ & 43.9 \\
\hline $\mathrm{P}_{2} \mathrm{O}_{5}^{\ddagger}$ & 141.91 & 182.5 & $4.6400 \times 10^{-2}$ & $4.5440 \times 10^{6}$ & 242.7 \\
\hline $\mathrm{CaF}_{2}^{\ddagger}$ & 78.08 & 59.83 & $3.045 \times 10^{-2}$ & $-1.9600 \times 10^{5}$ & 96.2 \\
\hline $\mathrm{SO}_{3} \neq$ & 80.06 & 70.2 & $9.774 \times 10^{-2}$ & 0.0 & 175.7 \\
\hline
\end{tabular}

$\S$ All solid heat capacity coefficients obtained from Perry's Handbook (1973 page 3-119) except as noted. All liquid heat capacity values are obtained from Mills and Rhine (1989).

‡ Solid heat capacity coefficients obtained from Mills and Rhine correcting b and $\mathrm{c}$ by $10^{-3}$ and $10^{5}$, respectively. 


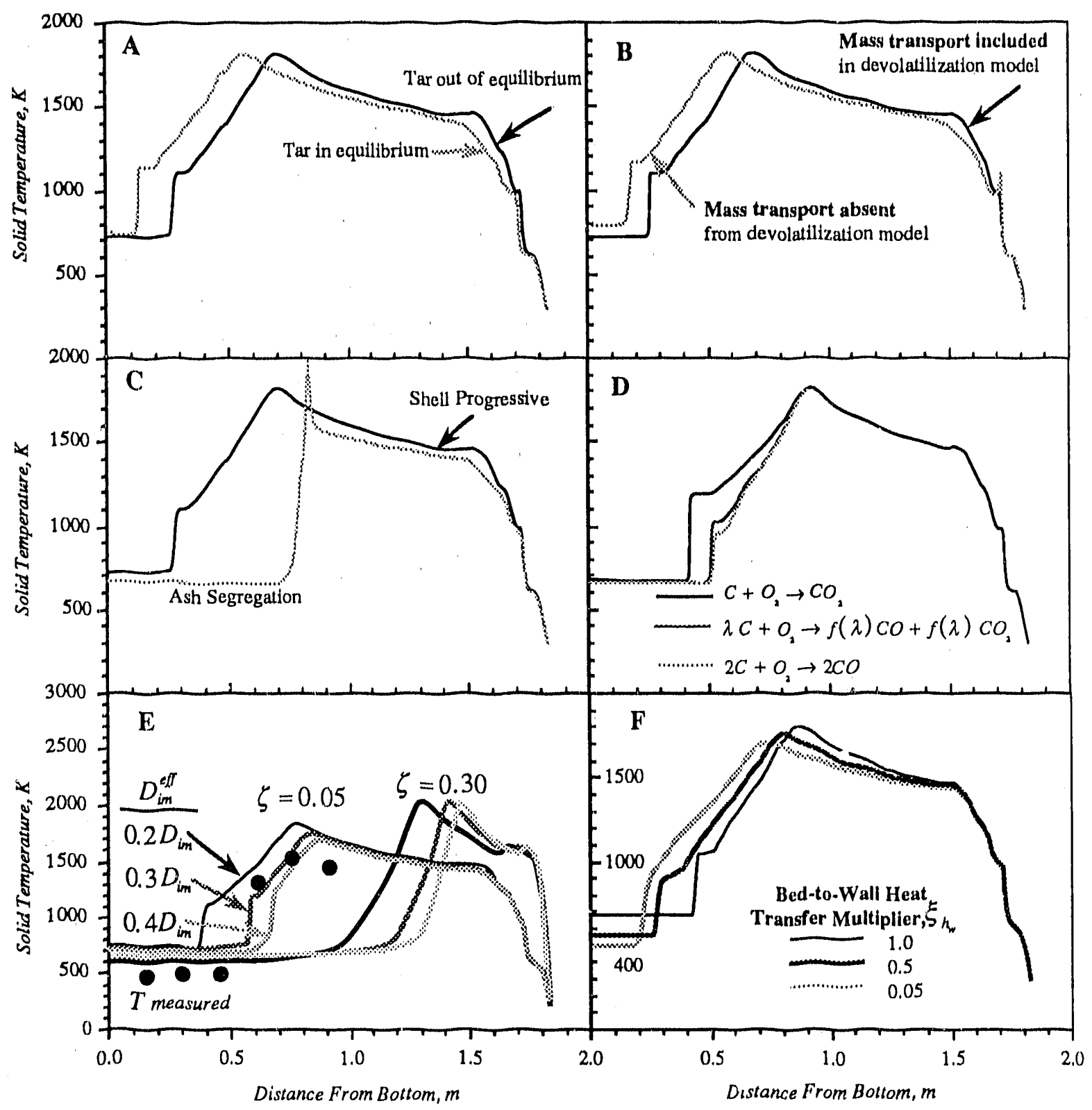

Figure III.B-1 Predicted sensitivity of axial solid temperature to A) tar gas phase equilibrium assumption, B) the devolatilization mass transport option, C) char model ash assumption, D) combustion product distribution assumption E) solid-to-gas heat transfer correction factor, $\zeta$, and effective diffusivity and F) bed-to-wall heat transfer multiplier. These results are for the Wellman-Galusha gasifier and Jetson bituminous coal. Complete input conditions can be found in Hobbs (1990). 


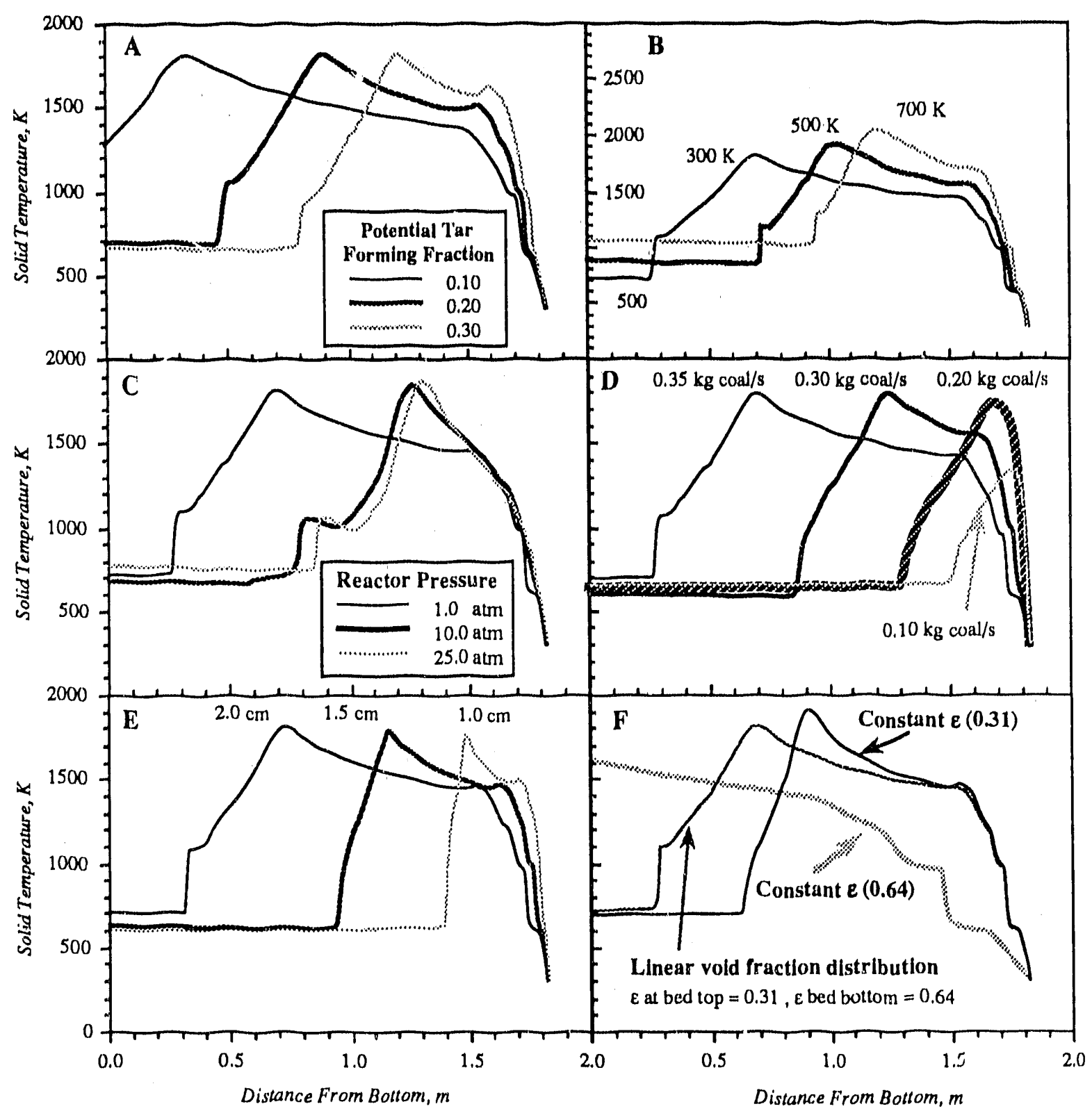

Figure III.B-2 I redicted sensitivity of axial solid temperature to A) potential tar forming fraction, B) feed gas temperature, C) pressure, D) feed coal mass flow rate, E) particle diameter, and F) Bed void fraction. These results are for the Wellman-Galusha gasifier and Jetson bituminous coal. Complete input conditions can be found in Hobbs (1990). 
bottom of the reactor. This shift can be explained by noting that the gasifier is fuel-rich near the top. When the tar is allowed to react to equilibrium in the drying and devolatilization zones, the gas phase becomes more fuel-rich. which causes the temperature to decrease sightiy. This decrease in temperature leads to an increased devolatilization zone length which consequently causes the entire temperature profile to shift downward. The transition between the devolatilization and gasification zones is more gradual when the tar is allowed to react to equilibrium. Again, the gradual transition is attributed to lower temperatures.

Velatiles Mass Iranspert - Two options regarding volatiles mass transport were investigated: 1) mass transport is included via transport resistances through the film and particle similar to char oxidation and gasification or 2) mass transport is not included. The predicted sensitivity of axial solid temperature to the volatile mass transport is shown in figure III.B-1b. When mass transport is not considered during devolatilization, a temperature spike occurs in the devolatilization zone which is attributed to the rapid release of volatile matter into the gas phase. The temperature shift in the overall solid temperature curve can be explained in a manner which is similar to the sensitivity analysis of the tar vapor reaction equilibrium assumption. The rapid release of volatile matter near the reactor top causes the gas phase to become more fuel-rich which causes the temperature to decrease. The decreased temperature in the devolatilization zone causes the zone length to increase which causes the location of the maximum temperature to move toward the bottom of the reactor.

Char Ash Layer Formation - The ash in the shell progressive (SP) char oxidation submodel is assumed to remain intact, surrounding the unreacted char core. The oxidant is required to diffuse through the gas film and ash layers. The ash in the ash segregation (AS) model is assumed to be removed instantaneously and fall away from the char particle with the oxidant requirea only to diffuse through the film boundary layer. The predicted sensitivity of axial solid temperature to the SP and AS ash assumptions is shown in Figure III.B-1C. The shape of the solid temperature profile using the AS model is sharp compared to the broad peak predicted by using the SP model. Also. the maximum temperature is higher when the AS model option is chosen. Furthermore, the devolatilization zone temperature is lower for the AS model option. 
Increasing the equivalence ratio in a fuel-rich zone, such as in the drying, devolatilization, or gasiffcation zones, causes the temperature to decrease. Conversely. in a fuel-lean zone, such as the oxtdation zone, increasing the equivalence ratio will cause the temperature to increase. Both an increase and decrease in temperature in fuel-lean and fuel-rich regions in the gasifier can be observed in Figure III.B-1C. The AS submodel option results in an increased rate of carbon being added to the gas phase, which causes the gas phase to become more fuel-rich. In the drying. devolatilization, and gasification zones, a decrease in temperature is observed. Typically, lower devolatilization temperatures cause the location of the maximum temperature to shift downward. However, the location of the maximum temperature in Figure III.B-IC shifts toward the top of the reactor. The shift upward is attributed to a significantly shorter oxidation zone caused by increased carbon release into the fuel-lean gas phase The two models should represent extremes in possible ash behavior, althe $h$ the $S P$ model is expected to be closer to actual ash behavior. This conclusion is based on comparing predicted temperature profiles to measured profiles, and is discussed in more detail in the validation sections of this chapter.

Combustion Product Distribution. The oxidation of carbon produces both $\mathrm{CO}$ and $\mathrm{CO}_{2}$ as primary products. Carbon monoxide may be favored at higher temperatures if $\mathrm{CO}$ is formed at carbon edges and $\mathrm{CO}_{2}$ is formed at inorganic sites. Lower temperatures may favor $\mathrm{CO}_{2}$ due to catalytic activity (Laurendeau, 1978).

Predicted sensitivity of axial solid temperature to the distribution of $\mathrm{CO}$ and $\mathrm{CO}_{2}$ is shown in Figure III.B-1d. Three assumptions are shown: 1$) \mathrm{CO}_{2}$ as the sole primary combustion product, 2) $C O$ as the sole primary combustion product, and 3 ) a distribution of $\mathrm{CO}_{2}$ and $\mathrm{CO}$ combustion products that depends on solid temperature. As expected, only the oxidation zone is affected by the combustion product distribution assumption. The different temperatures are attributed to the energy exchange at the particle-to-gas interface die to reaction. Comparison between the sole $\mathrm{CO}$ distribution and the $\mathrm{CO} / \mathrm{CO}_{2}$ distribution indicates that carbon monoxide may be assumed to be the primary product at typical combustion teriperatures. Laurendeau (1978) makes lris same conclusion.

Solid-to-Gas Heat Transfer Coefficient - The solid-to-gas heat transfer coefficient for a nonreacting system ma be ten to fifty times higher than for 
a reacting system (Lowry, 1963). Dzhaphyev et al. (1986) attribute the difference in computed values to unsteady heat transfer. Vigorous reactions as well as nonspherfcity may also contribute to this discrepancy. The solid temperature is sensttive to the ratio of reactive to non-reactive heat transfer coefficients, $\zeta$, which ranges between 1.0 and 0.02 . Predicted sensitivity of axial solid temperature to solid-to-gas heat transfer correction factor., $\zeta$, is shown in Figure III.B-le.

This solid-to-gas heat transfer correction factor ( $\zeta$ ) has a dramatic effect on the location of the maximum solid temperature. Small values of $\zeta$ cause the location of the maximum temperature to shift toward the bottom of the reactor. By limiting the heat exchange between solid and gas at the top of the reactor, the solid temperature decreases in the devolatilization zone. which increases the length of the devolatilization zone. The increased size of the devolatilization zone causes the entire temperature profile to shift toward the bottom of the reactor. Also, the magnitude of the maximum temperature decreases as $\zeta$ is decreased. The decrease in maximum temperature is attributed to a redistribution of solid enthalpy.

Effective Diffusivity. - The oxidation and gasification rates are globally modeled by using an effective diffusivity which is based on the molecular diffusivity multiplied by a constant $\left(D_{\text {aff }}=\phi D_{m}\right)$. The constant, $\phi$. is based on the porosity of the developing ash layer. Thorsness and kang (1985) used 0.35 for $\phi$. Laurerideau (1978) showed that $\phi$ can be estimated by the ash porosity divided by two. The value two is an estimate of the tortuosity squared. Wang and Wen (1972) have measured porosity of a fire clay ash which varied from 0.4 to 0.8 . Using Wang and Wen's values for the ash porosity $(0.4$ to 0.8$), \phi$ should range between 0.2 and 0.4 .

Although the ash porosity for the sensitivity analysis is assumed to range between 0.4 and 0.8 , the ash porosity should not be 1 imited to these values. The ash porosity car be determined by using extrapolated values of pore volume (E1 liott, 1981, page 1520. Figure 23.14). The ash porosities for the for high-pressure, fixed-bed gasification may range between 0.1 and 0.3 (with corresponding $\phi$ ranging between 0.05 and 0.15 ) which implies significant compaction for the fixed-bed ash compared to the measurements of wang and Wen (1972).

The predicted sensitivity of the axial solid temperature profile to the effective diffusivity is shown in Figure III.B-le. The effective diffusivity 
affects the location of the maximum solid temperature, the magnitude of the maximum solid temperature and the shape of the solid temperature proftle. Lower values of $\phi$ cause the location of the maximum solid temperature to shift toward the bottom of the reactor and the slze of the oxidation zone to increase. The impact of the effective diffusivity on solid temperature may be a consequence of the size and shape of the reactant. For example, the molecular diffusivity for oxygen is smaller than the molecular diffusivity for steam. In other words, the oxygen diffusive resistance is greater than the steam diffusive resistance. Thus, smalier values of $\phi$ influence the steam gasification reaction less than the oxidation reaction. Therefore, the endothermic oxidation reaction is favored for lower values of $\phi$ which may explain the higher maximum solid temperature.

Bed-to-Wall Heat Transfer - The sensitivity of solid axial temperature to the bed-to-wall heat transfer calculation is shown in figure III.B-If. For the calculations, the effective bed-to-wall heat transfer coefficient was multiplied by a constant. $\zeta_{\text {hw }}$, to see the effect of lowering bed-to-wall heat transfer. Lower values of $\zeta_{\text {hw }}$ caused the overall axial solid temperature to decrease in the gasification and oxidation regions of the gasifier. The opposite effect is shown in the oxidation zone where solid temperature increases. The shift in location of the maximum solid temperature and the change in the shape of the curve is attributed to a redistribution of solid enthalpy.

Petential Tar-Forming Fraction - The potential tar forming fraction, $x^{o}$, represents the maximum possible tar yield of a given coal. However, the maximuin tar yield is never achieved due to competition from light gas evolution. Predicted sensitivity of axial solid temperature to the potential tar-forming fraction is shown in Figure III.B-2a. As the potential tar fraction is increased, the ultimate volatile yield increases and the corresponding ultimate char yield decreases. which results in a larger devoiatilization zone and a smaller gasification/oxidation zone. The shift in the location of the maximum solid temperature can be attributed to the smaller oxidation and gasification zones.

Lemperature of Feed Gas - The predicted sensitivity of axial solid temperature and axial gas composition to feed gas temperature is shown in Figure I1:.B-2b. The location of the maximum temperature and the magritude of the maximum temperature are affected by feed gas temperature. As expected, the maximum temperature is lower when the feed gas temperatures are lower. 
The location of the maximum temperature at steady operating conditions shifts toward the bottom of the reactor when the feed gas temperature is lowered. The lower feed gas temperature causes the effluent gas temperature to decrease. The lower effluent gas temperature results in less sensible energy to preheat and dry the feed coal. Thus, both the drying and devolatilization zone lengths are increased. Which causes the location of the maximum temperature to move toward the bottom of the reactor as shown in Figure 11I.B. $2 b$.

Beactor Pressure - The predicted sensitivity of axial solid temperature and gas concentrations to reactor pressure is shown in Figure III.B-2C. The nonlinear effect of pressure results in the formation of a duel peak in the oxidation zone. The "duel" peak also was observed during the validation simulations of the high pressure dryash Lurgi gasffiers (Hobbs, 1990). Increasing pressure causes the location of the maximum temperature to shift toward the top of the reactor. The shift caused by pressure is very nonlinear. In fact, simulations at 50 and 100 atmospheres were close to the 25-atmosphere simulation plotted in Figure III.B-2C. The small peak near the bottom of the reactor is attributed to competition between the highly exothermic oxidation reaction and the endothermic steam gasification reaction.

Once the solid temperature is sufficiently high for the oxidation reaction to begin, the oxidation reaction is very rapid. The rapid oxidation of carbon causes the solid temperature to increase dramatically. Once the temperature reaches about $1000 \mathrm{~K}$, the steam reaction begins. Although the steam reaction is not as fast as the oxidation reaction, the concentration of steam is significantly higher than the oxygen concentration. The carbon cinsumption associated with the steam reaction approaches carbon consumption associated with the oxidation reaction. The endothermic steam gasification reaction quenches the rapid increase in solid temperature and causes a sudden increase in the solid temperature profile which is observed in the low. pressure case in Figure III.B-2C.

When pressure is increased, the partial pressure of the water increases. Although the partial pressure of oxygen is also increased, the greater abundance of steam causes an increase in the steam gasification reaction when compared to the oxidation reaction. The effect is to magnify the competition between the endothermic and exothermic reactions, producing a small peak. Also, the diffusivity of water is greater than that of oxygen. In other words, the oxygen mass diffusive resistance is greater than the steam diffusive resistance. Changes in pressure have a greater effect on the 
oxidation reaction than on the steam gasification reaction. Therefore, the steam gasification reaction is amplified at higher pressures.

Coal Mass Flow Rate - The predicted sensitivity of axial solid temperature to coal mass flow rate is shown in Figure III.B-2d. All parameters in these simulations were held constant except the coal mass flow rate. The shift in the location of the maximum temperature is attributed to a decrease in time required to completely consume all of the organic matter in the coal. It is interesting to note that the low coal mass flow rates actually correspond to combustion occurring at the top of the gasifier. Thus. both combustion and gasification runs are also depicted in Figure III.B-2d.

Particle Diameter - The predicted sensitivity of axial solid temperature to feed coal particle diameter is shown in Figure III.B-2e. The small particles heat up faster than the larger particles. The increased solid temperature promotes devolatilization. which is completed more quickly than for the larger particles. Also, mass transport limitations are not as pronounced for the smaller particles.

The particle size effect seems to be approximately linear as shown in the temperature profile in Figure III.B-2e. Hovever, the influence of a distribution of particles may $r$ difficult to determine. Not only are heat and mass transport processes affected significantly. but also the bed void fraction may change dramaticiily as discussed in the following section. Wide particle size distributions tend to decrease the bed void fraction.

Bed Void Fraction - The predicted sensitivity of axial solid tenperature to bed void fraction is shown in Figure III.B-2f. The void fraction significantly affects the particle number density which in turn affects the overall bed consumption rate. Increasing void fraction causes a decrease in the overall bed reaction rate. Drying, devolatilization, gasification and oxidation rates are decreased significantly when the void fraction is increased. Thus, all prominent reaction zones increase with increasing bed void fraction and the location of the maximum temperature moves toward the bottom of the reactor.

The abrupt changes taking place in the solid temperature profile are magnified in the case where the void fraction is assumed to be constant at 0.64 in Figure III.B-2f. The initial increase in temperature is attributed to evolution of loose functional groups. The sudderi increase in solid 
temperature at the reactor top is attributed to a rapid release of tar. Finally, the tight functional groups evolve slowly until devolatilization is complete.

\section{Model Evaluation}

This section treats evaluation of the one-dimensional, fixed-bed model by comparing predictions with experimental data and modeling results of other investigators. Unfortunately, the availability of experimental profiles within laboratory scale or commercial scale fixed-bed gasifiers is limited. Temperature and pressure profiles have been measured by Thimsen et a1. (1984) during coal gasification in a Wellman-Galusha gasifier.

Thimsen (1990) suggests that the Weliman-Galusha measured temperature profiles be used only for qualitative comparisons since the temperature probe. a $1 / 2$-inch schedule 40304 SS pipe with six sheathed type $k$ thermocouples placed six inches apart. was rotracted from the gasifier when any junction approached $1600 \mathrm{k}$. The rod was retracted for protection from high temperature. Typically, the temperature probe was allowed ten minutes to reach a steady state (Thimsen et al.. 1984). However, the temperature profiles may represent transient conditions if the probes were retracted due to high temperatures.

Lurgi simulation - Predicted temperature, pressure drop, gas concentration. carbon consumption, burnout, and particle diameter for gasification cf Illinois 非 coal in a high-pressure, oxygen-fired Lurgi gasifier are shown in Figure III.B-3. Input conditions, including true. particle and bulk densities, bed void fraction, porosity, particle ciameter and carbon conversion for feed coal and exit ash can be found in Hobbs (1990).

The high-pressure, oxygen-fired Lurgi cases produce a siymoid or' $S$ shaped $\mathrm{CO}_{2}$ concentration profile. The shape of the carbon dioxide profile can be explained by the low temperature of the solid in the gasification section of the gasifier. The low temperature is a result of large quantities of steam in the feed gas stream. The temperature is low enough that the only significant heterogeneous reaction in this section of the gasifier is the steam gasification reaction. Gasification with carbon dioxide is essentially quenched due to low temperatures. With only hydrogen arid carbon monoxide being produced in the gasification section, the hydrogen and carbon monoxide profiles should correspond. However, gas phase reactions such as the water- 


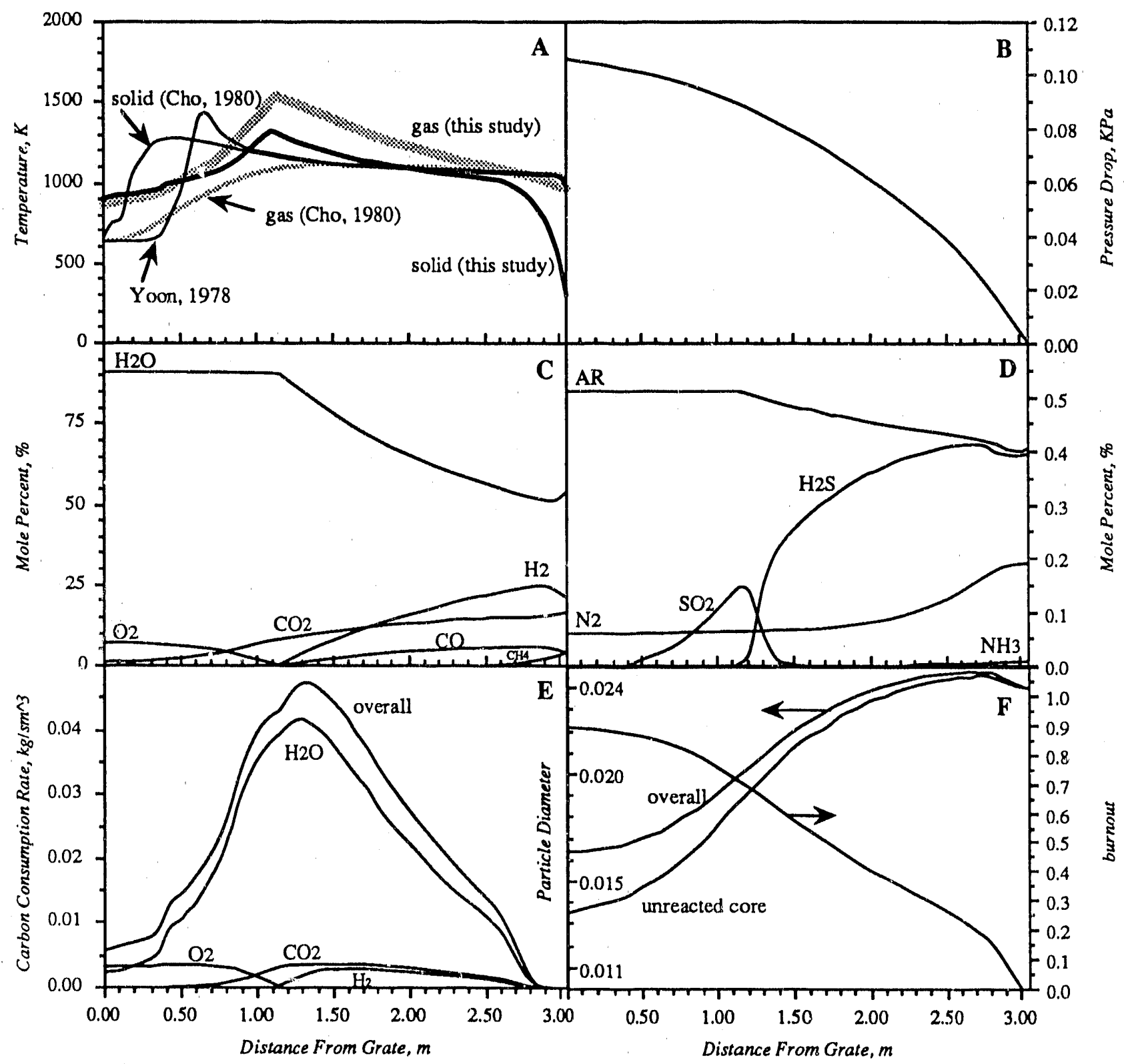

Figure III.B-3 Predicted temperature, pressure drop, gas concentration, carbon consumption due to oxidation and gasification, burnout, and particle diameter for gasification of Illinois \#6 bituminous coal in high pressure gasifier with oxygen (Elgin and Perks, 1974): A) solid and gas temperature profile, B) pressure drop, C) major species concentration profile, D) minor gas species concentration profile, $\mathbf{E}$ ) volumetric solid carbon consumption rate due to oxidation and gasification reactions, and F) burnout, overall and unreacted particle diameter throughout reactor. Input conditions can be found in Hobbs (1990). Part A shows results from the homogeneous model of Yoon (1979) and the heterogeneous model of Cho (1980). Yoon and Cho report that the input conditions for the cases shown in Part A are for gasification of Illinois \#6 in the high pressure Lurgi gasifier at Westfield. However, the input conditions are slightly different from that reported by Elgin and Perks (1974). 
gas-shift reaction produce a slight increase in carbon dioxide concentration, creating a sigmoid profile.

Predictions from two one-dimensional models from the literature are also shown in Figure III.B-3a. Yoon assumed equal solid and gas temperature, instantaneous devolatilization with a fixed composition, and assumed that the water-gas-shift reaction determines the gas phase concentration. Cho essentially extended the model of Yoon to include separate solid and gas temperatures. The sharp spike predicted by yoon probably results from noncompeting endothermic and exothermic reactions. Also, the average solid and gas temperatures of Cho do not correspond to the predictions of Yoon. Cho's gas temperatures are less than the solid temperature in the oxidation zone. Steam gasification produces $\mathrm{H}_{2}$ and $\mathrm{CO}$ in the oxidation zone. Also, CO is produced from oxidation. In the presence of oxygen, the homogeneous reactions of $\mathrm{H}_{2}$ and $\mathrm{CO}$ with $\mathrm{O}_{2}$ react to produce $\mathrm{H}_{2} \mathrm{O}, \mathrm{CO}_{2}$ and heat. These exothermic gas phase reactions inevitably cause a dramatic increase in gas temperature, as shown in the predictions presented in this study.

Since there are no measurements of axial temperature or concentration profiles in the Lurgi gasifiers, it is difficult to conclude which simulations are correct. Al1 models seem to predict reasonable effluent properties even though the profiles are significantly different.

Wellman-Galusha Simulation - Predicted temperature, pressure drop, gas concentration, carbon consumption, burnout, and particle diameter for gasification of Utah Blind Canyon bituminous coal in an atmospheric, air-fired Wellman-Galusha gasifier are shown in Figure III.B-4. Input conditions including true particle and bulk densities, bed void fraction, porosity. particle diameter and carbon conversion for feed coal and exit ash can be found in Hobbs (1990).

Qualitative agreement was obtained for both the temperature profile and the pressure profile. The low measured pressure drop near the top of the reactor appears to be due to channeling near the bed top. The measured temperature profile indicates a drying and devolatilization zone length of approximately 0.5 meters which corresponds directly with the predicted drying and devolatilization zone length of 0.5 meters.

The Wellman-Galusha gas phase concentration profile can be explained by following the solid temperature profile, starting at the bottom of the 


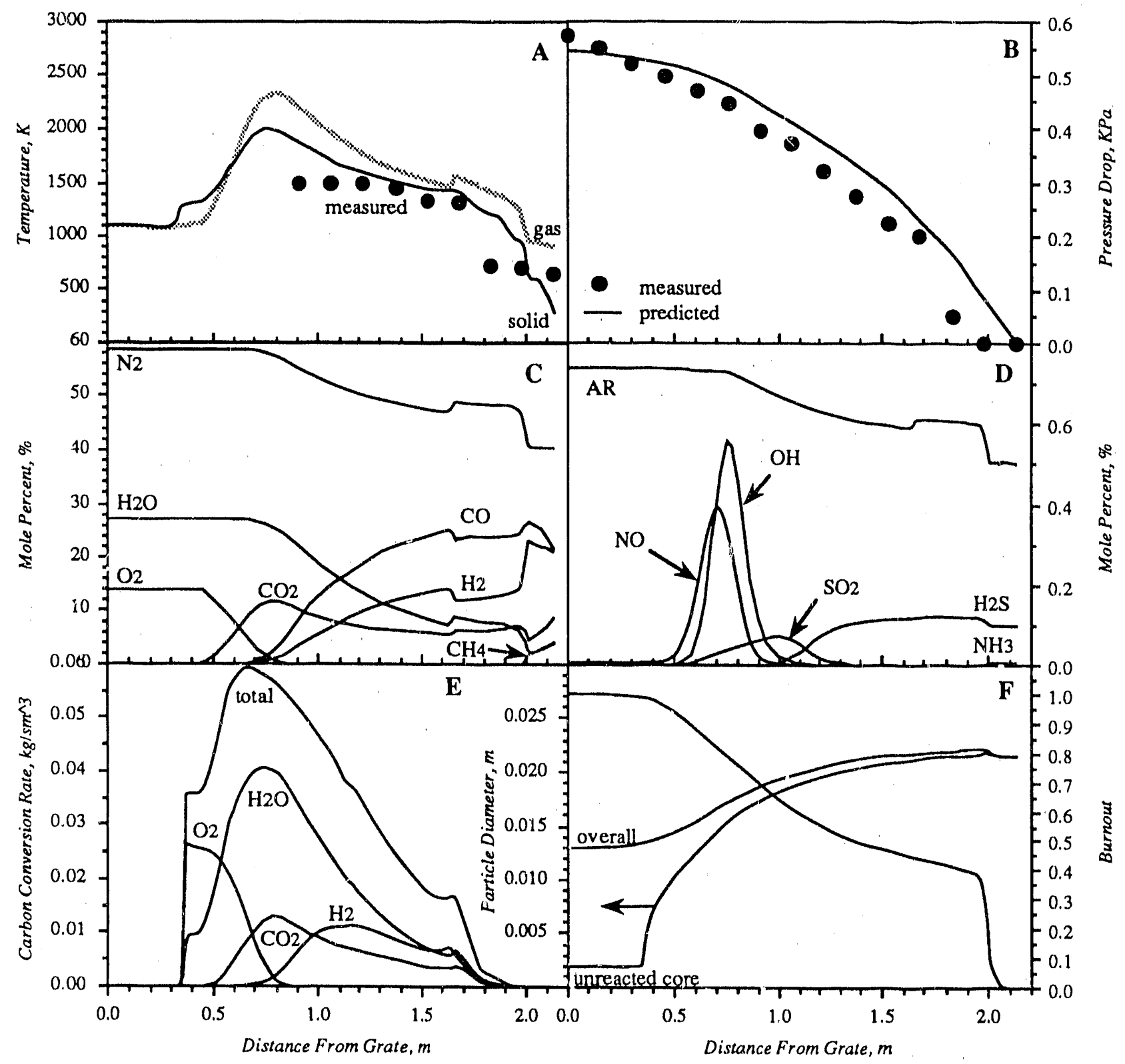

Figure III.B-4 Predicted temperature, pressure drop, gas concentration, carbon consumption due to oxidation and gasification, burnout, and particle diameter for gasification of Utah Blind Canyon bituminous coal in an atmospheric gasifier with air (Thimson et al., 1985; Vol 13, page L3): A) measured and predicted temperature profile, B) measured and predicted pressure drop, $\mathbf{C}$ ) predicted major species concentration profile, $\mathbf{D})$ predicted minor gas species concentration profile, E) predicted volumetric solid carbon consumption rate due to oxidation and gasification reactions F) predicted burnout, overall and unreacted particle diameter throughout reactor. Input conditions can be found in Hobbs (1990). 
reactor. At the reactor bottom, primarily ash is present which exchanges energy with the countercurrent gas stream. As the solid increases in temperature, oxygen in the feed gas reacts heterogeneously with the solid carbon to form gaseous carbon monoxide and carbon dioxide. The carbon moroxide reacts homogeneously in the gas phase to form carbon dioxide. Steam also reacts with the solid carbon to form hydrogen and carbon monoxide. If oxygen is present in the gas phase, the hydrogen and carbon monoxide react homogeneously with oxygen to form steam and carbon dioxide. Thus, no depletion of steam is apparent until all gas phase oxygen is depleted. Furthermore, only carbon dioxide is shown to increase in the presence of homogeneous oxygen. Although both steam and carbon dioxide react heterogeneously with the solid carbon. the gasi,ication products from both reactions are oxidized to form carbon dioxide in the presence of oxygen.

Comparison of Temperature Profiles at Different Conditions - Several of the Wellman-Galusha experimental test cases included temperature profiles at different operating conditions. Predicted temperature profiles are compared to measurements for the Elkhorn bituminous case, the Jetson bituminous case. the Leucite Hills subbituminous case and the Utah Blind Canyon bitumirous case in Figs. III.B-5 and 6. Input conditions can be found in Hobbs (1990) or Thimsen et a 1. (1984).

The Elkhorn case shows a shift in the measured temperature profile near the top of the reactor as shown in Figure III.B-5a. The predictions are in agreement with the direction of the temperature shift. The Jetson case depicted in Figure III.B-5b shows the effect of varying operational parameters in the oxidation zone, which gives a definite indication of the change in location of the maximum temperature. Again, the direction of shift is predicted by the one-dimensional model.

The one-dimensional model is in agreement with the experimental data for the Leucite Hills subbituminous coal shown in Figure III.B-6a. The increase in coal flow rate and steam flow rate causes the location of the maximum temperature to shift toward the bottom of the reactor for the Leucite Hills case. The Utah Blind Canyon case depicted in Figure III.B-6b also shows the effect of increased coal and gas throughputs. Trends in measured and predicted profiles are in agreement. The temperature measurements were taken for two time periods. For the first one, the measurements were repeated on two separate days; but only one set of operational data was reported for this time 


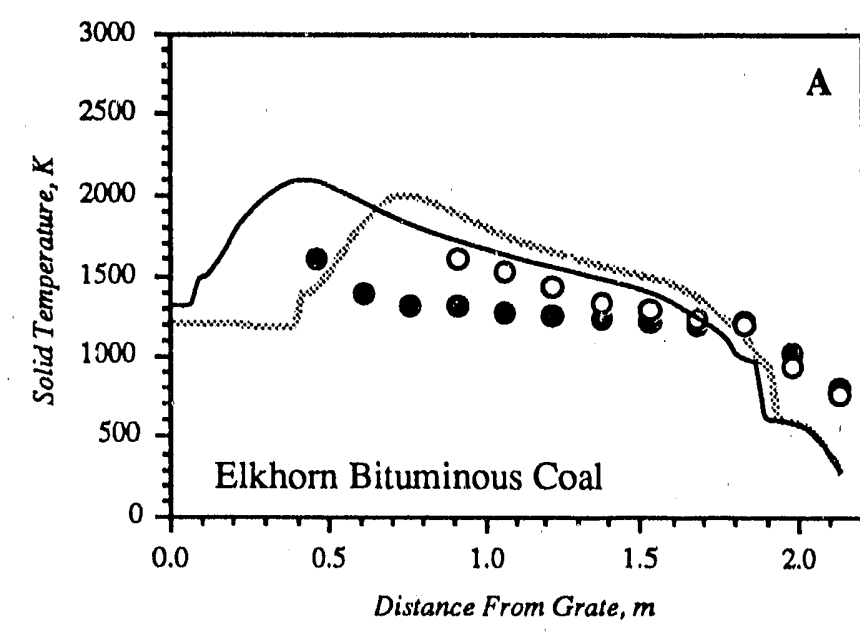

Predicted (date of measurements: 10/6/83)

Coal mass flow $0.292 \mathrm{~kg} / \mathrm{s}$

air mass flow $\quad 0.754 \mathrm{~kg} / \mathrm{s}$

steam mass flow $0.122 \mathrm{~kg} / \mathrm{s}$

Predicted (date of meisurements: 9/18/83)

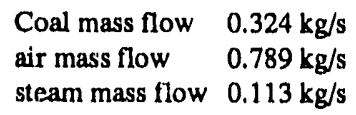

O Measured: $10 / 6 / 83$

Measured: $9 / 18 / 83$

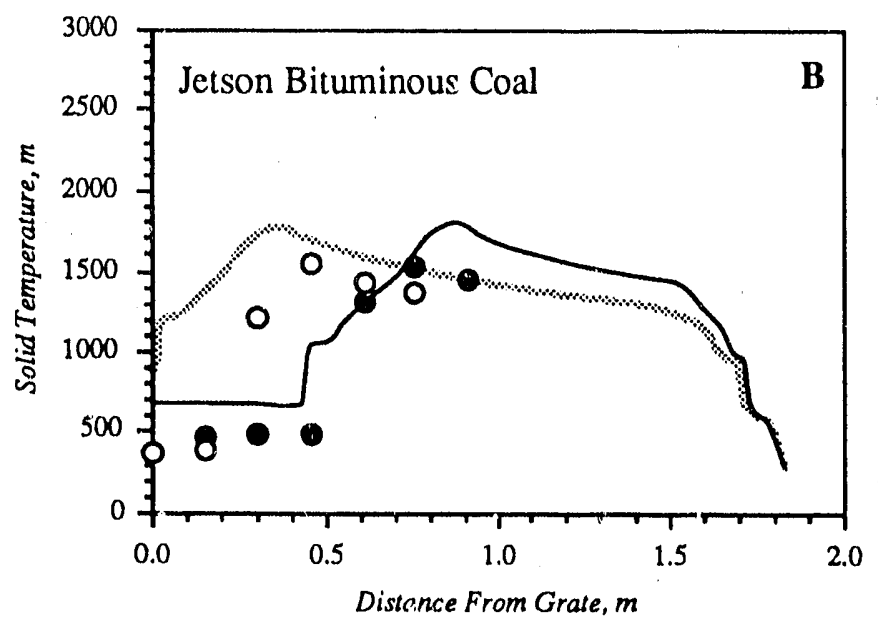

Predicted (date of measurements: 8/23/82)

Coal mass flow $0.279 \mathrm{~kg} / \mathrm{s}$

air mass flow $\quad 0.649 \mathrm{~kg} / \mathrm{s}$

steam mass flow $0.116 \mathrm{~kg} / \mathrm{s}$

Predicted (date of measurements: 8/30/82)

Coal mass flow $0.352 \mathrm{~kg} / \mathrm{s}$

air mass flow $\quad 0.948 \mathrm{~kg} / \mathrm{s}$

steam mass flow $0.156 \mathrm{~kg} / \mathrm{s}$

Measured: $8 / 23 / 82$

Measured: $10 / 30 / 82$

Figure III.B-5 Comparison of measured and predicted solid temperature for several operating conditions for gasification of A) Elkhorn bituminous coal and B) Jetson bituminous coal in an air-fired, low pressure Wellman-Galusha gasifier. Experimental data can be found in Thimsen et al., 1984. Input parameters can be found in Hobbs (1990). 


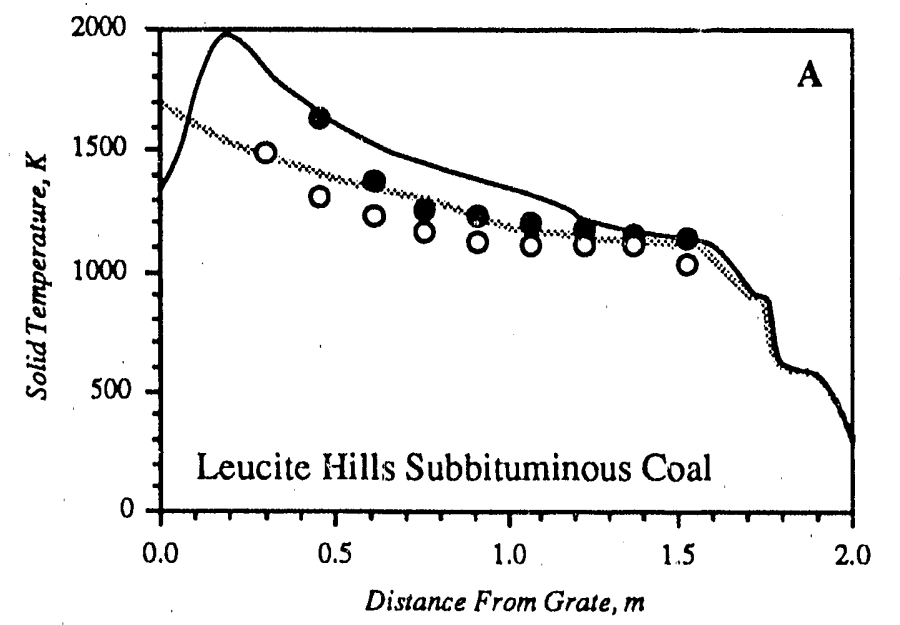

Predicted (date of measurements: 4/16/83)

Coal mass flow $0.300 \mathrm{~kg} / \mathrm{s}$ air mass flow $\quad 0.528 \mathrm{~kg} / \mathrm{s}$ steam mass flow $0.098 \mathrm{~kg} / \mathrm{s}$

Predicted (date of measurements: 4/17/83) $\begin{array}{ll}\text { Coal mass flow } & 0.293 \mathrm{~kg} / \mathrm{s} \\ \text { air mass flow } & 0.532 \mathrm{~kg} / \mathrm{s} \\ \text { steam mass flow } & 0.088 \mathrm{~kg} / \mathrm{s}\end{array}$

O Measured: $4 / 16 / 83$

Measured: $4 / 17 / 83$

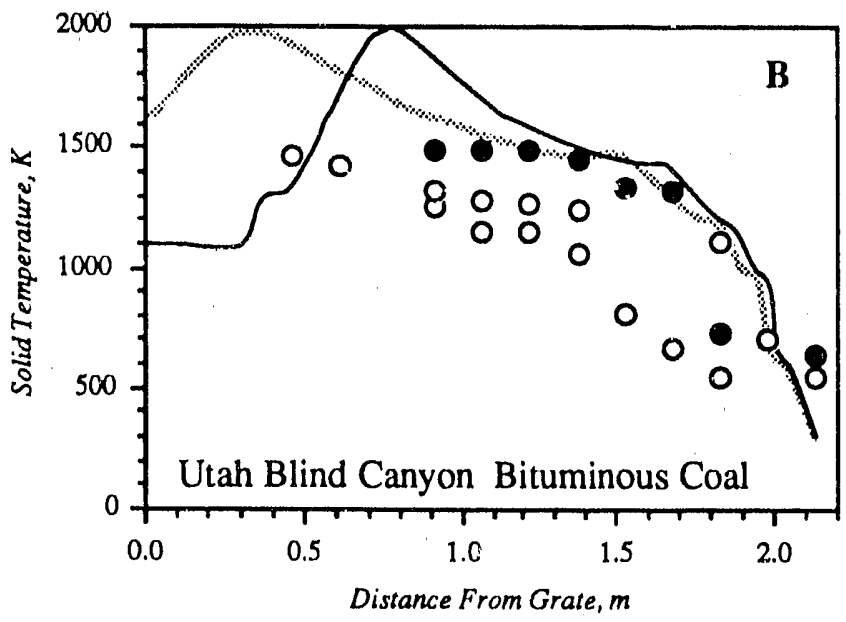

Predicted (date of measurements: 8/9-10/84)

Coal mass flow $0.464 \mathrm{~kg} / \mathrm{s}$ air mass flow $0.969 \mathrm{~kg} / \mathrm{s}$ steam mass flow $0.178 \mathrm{~kg} / \mathrm{s}$

Predicted (date of measurements: $8 / 4 / 84$ ) $\begin{array}{ll}\text { Coal mass flow } & 0.337 \mathrm{~kg} / \mathrm{s} \\ \text { air mass flow } & 0.673 \mathrm{~kg} / \mathrm{s} \\ \text { steam mass flow } & 0.119 \mathrm{~kg} / \mathrm{s}\end{array}$

O Measured: $8 / 9-10 / 84$

- Measured: $8 / 4 / 84$

Figure III.B-6 Comparison of measured and predicted solid temperature for several operating conditions for gasilication of A) Leucite Hills subbituminous coal and B) Utah Blind Canyon bituminous coal in an air-fired, low pressure Wellman-Galusha gasifier. Experimental data can be found in Thimsen et al., 1984. Input parameters can be found in Hobbs (1990). 
period (Thimsen et al.. 1984). The spread in experimental data indicates the variability in the experimental data.

\section{Plans}

The development of the fixed-bed code will continue next quarter. The two-sigma FG-DVC model will be implemented into the one-dimensional fixed-bed model when available from AFR. Further validation of the one-dimensional fixed-bed model will be necessary after full integration of the FG-DVC slibmodel. A poster paper entitled "Fixed-Bed Coal Gasification Modeling" will be presented at the 23 rd Symposium (International) on Combustion to be held on July 22-27 in Orléans, France. 


\author{
III.C. SUBTASK 3.C. * GENERALIZED FUELS FEEDSTOCK SUBMODEL \\ Senior Investigators - B. Scott Brewster and L. Douglas Smoot \\ Brigham Young University \\ Provo, UT 84602 \\ (801) $378-5240$ and 4326
}

\title{
Objective
}

The original objective of this subtask was to generalize PCGC-2 to include several types of solid feed, liquid feed and solid-liquid feedstocks. Since there are no sutmodels being developed in Task 2 that are specifically applicable to liquid-based feedstocks, and since a sulfur/sorbent submodel is being deve?oped under subtask 2.g. it seemed a more reasonable approach to fulfill the terms of the contract for a generalized feedstocks submodel by generalizing PCGC-2 to include sorbent injection rather than liquid and solidliquid fuel feedstocks. This approach was outlined in the Phase II Research Plan. An official modification to the work statement for Subtask 3.c was requested from AFR during the last quarter to bring it in line with the above approach.

\section{Accomplishments}

Following the approach outlined in the Phase II Plan, work was initiated to extend PCGC-2 to accommodate sorbent injection. The particles will be tracked in a Lagrangian reference frame, similar to the coal. only one particle size will be allowed. Calcination will be assumed instantaneous, and the $\mathrm{CO}_{2}$ released during calcination will be added to the carrier gas. Since sorbent particles are small $(<10 \mu \mathrm{m})$ and the loading is light, the effect of sorbent on the gas velocity field, temperature, and major gas species will be neglected. Reaction source terms will be provided by the sorbent reactions submodel being developed under subtask 2.g. The source terms will be used to correct the gas sulfur species concentrations to account for capture by the sorbent.

\section{Plans}

Continue modification of PCGC-2 to allow sorbent injection. 


\section{SECTION IV. TASK 4. APPLICATION OF INTEGRATED CODES}

\section{Objective}

The objectives of this task are to evaluate the integrated comprehensive codes for pulverized coal and fixed-bed reactors and to apply the codes to selected cases of interest to METC.

\section{Task outline}

This task will be accomplished in two subtasks, one for the entrained-bed lasting 45 months and one for the fixed-bed lasting 36 months. Each of these subtasks will consists of three components: 1) Simulation of demonstration cases on BYU computers; 2) Implementation on a work station at AFR; and 3) Simulation of demonstration cases on the workstation. 
IV.A. SUBTASK 4.A. - APPLICATION OF GENERALIZED, PULVERIZED-COAL COMPREHENSIVE CODE

\author{
Senior Investigators - B. Scott Brewster and L. Douglas Smoot \\ Brigham Young University \\ Provo, UT 84602 \\ (801) $378-6240$ and 4326
}

\begin{abstract}
Objectives
The objectives of this subtisk are 1 ) to simulate reactors of interest to METC and 2) to implement the comprehensive entrained-bed code at METC.

\section{Accomplishments}

This subtask has not been initiated.

\title{
Plans
}

No work is planned on this subtask during the next quarter. 


\section{IV.B. SUBTASK 4.B. - APPLICATION OF FIXED-BED CODE}

Senior Investigators - Predrag T. Radulovic and L. Douglas Smoot Brigham Young University

Provo. Utah 84602

(801) $378-3097$ and (801) $378-4326$

Graduate Research Assistant - Michael L. Hobbs

\section{Objective}

The objective of this subtask is to apply the advanced fixed-bed code developed in Subtask :.b. to simulate fixed-bed gasifiers of interes': to METC.

\section{Accomplishments}

During the last quarter, work continued on collecting fixed-bed design and test data from organizations and individuals involved in fixed-or movingbed gasification or combustion research or in research on non-reacting fixedor moving-beds. Work also continued on collecting fixed-bed experimenta? data from the open literature.

\section{Fixed-bed code application}

The advanced fixed-bed code, developed, tested and validated under subtask III.B. was applied to seven riew test cases under this subtask. The test cases included the dry-ash Lurgi gasifier, the Wellman-Galusha gasifier, the METC gasifier, and the slagging BGC-Lurgi gasifier. A presentation was given at the joint METC/AFR/BYU project review meeting and discussions were held with AFR concerning the 1-D fixed-bed code deveiopment.

Lurgi Dry Ash Gasifier - Predicted temperature, pressure drop, gas concentration, carbon consumption, burnout, and particle diameter for gasification of Illinois 非, Pittsburgh 非, and Rosebud coals in a highpressure, oxygen-fired Lurgi gasifier at Westfield. Scotland are shown in Figures IV.B-1 through 3. Complete input files for these cases are presented in Hobbs (1990).

The sensitivity analysis was presented previously for a low-pressure, air-fired Wellman-Galusha gasifier. The most obvious differences between the 


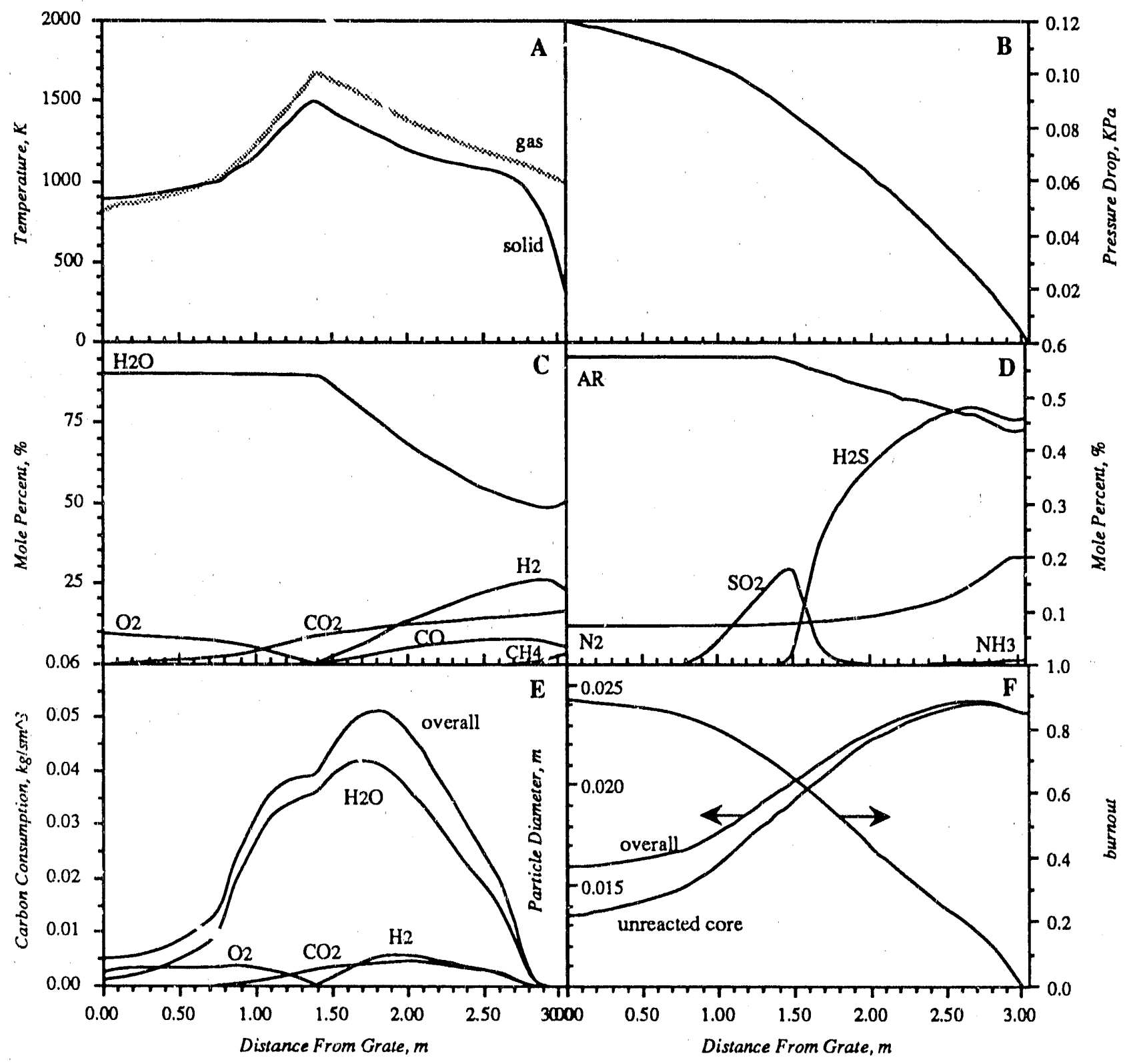

Figure IV.B-1 Predicted temperature, pressure drop, gas concentration, carbon consurption due to oxidation and gasification, burnout, and particle diameter for gasification of Illinois 'A'5 bituminous coal in high pressure gasifier with oxygen (Elgin and Perks, 1974): A) solid and gas temperature profile, B) pressure drop, C) majo: species concentration profile, D) minor gas species concentration profile, E) volumetric solid carbon consumption rate due to oxidation and gasification reactions, and F') burnout, overall and unreacted particle diameter throughout reactor. Input conditions can be found in Hobbs (1990). 


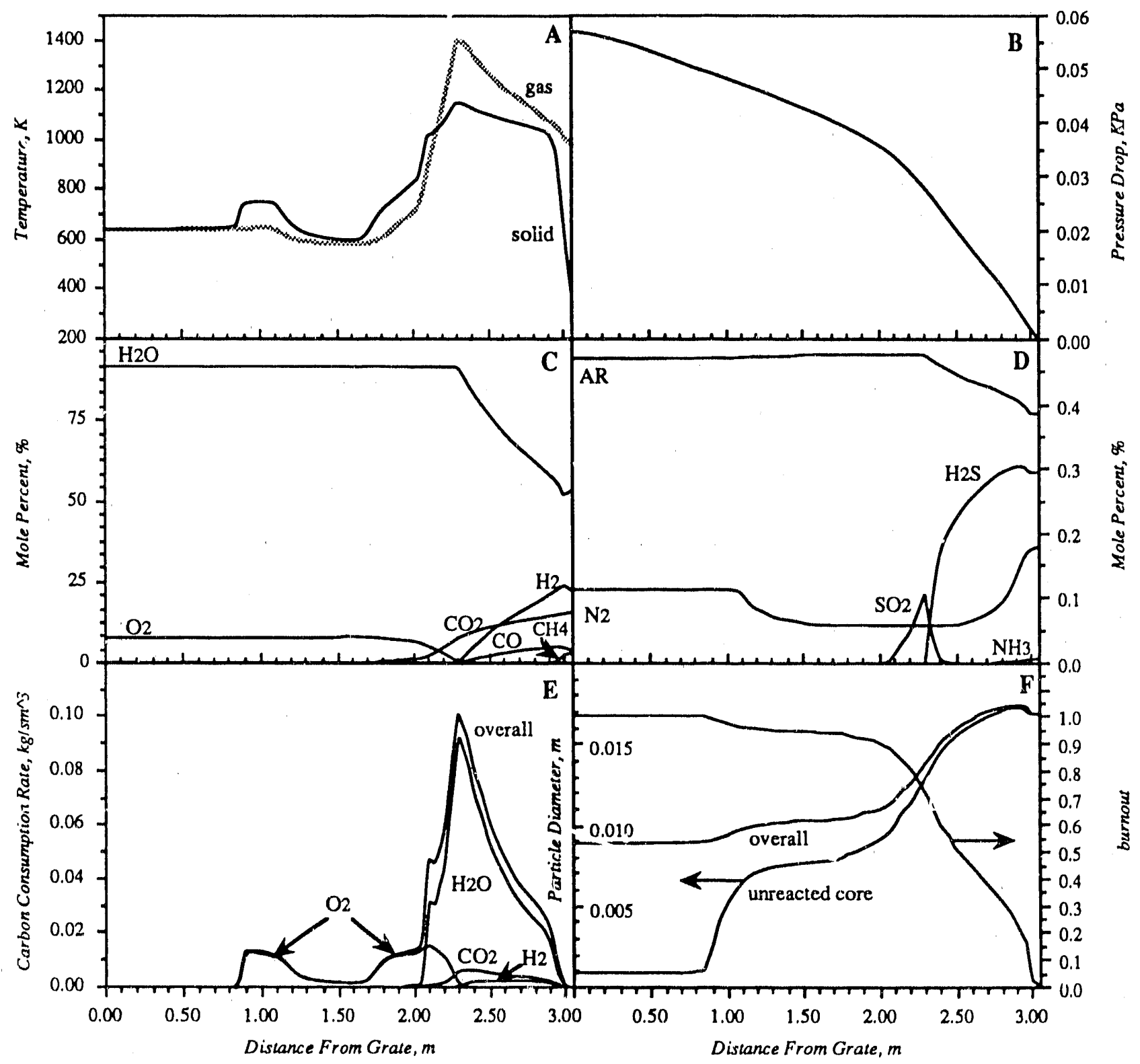

Figure IV.B-2 Predicted temperature, pressure drop, gas concentration, carbon consumption due to oxidation and gasification, burnout, and particle diameter for gasification of Pittsburgh \#8 bituminous coal in high pressure gasifier with oxygen (Elgin and Perks, 1974): A) solid and gas temperature profile, B) pressure drop, C) major species concentration profile, D) minor gas species concentration profile, E) volumetric solid carbon consumption rate due to oxidation and gasification reactions, and F) burnout and overall and unreacted particle diameter throughout reactor. Input conditions can be found in Hobbs (1990). 


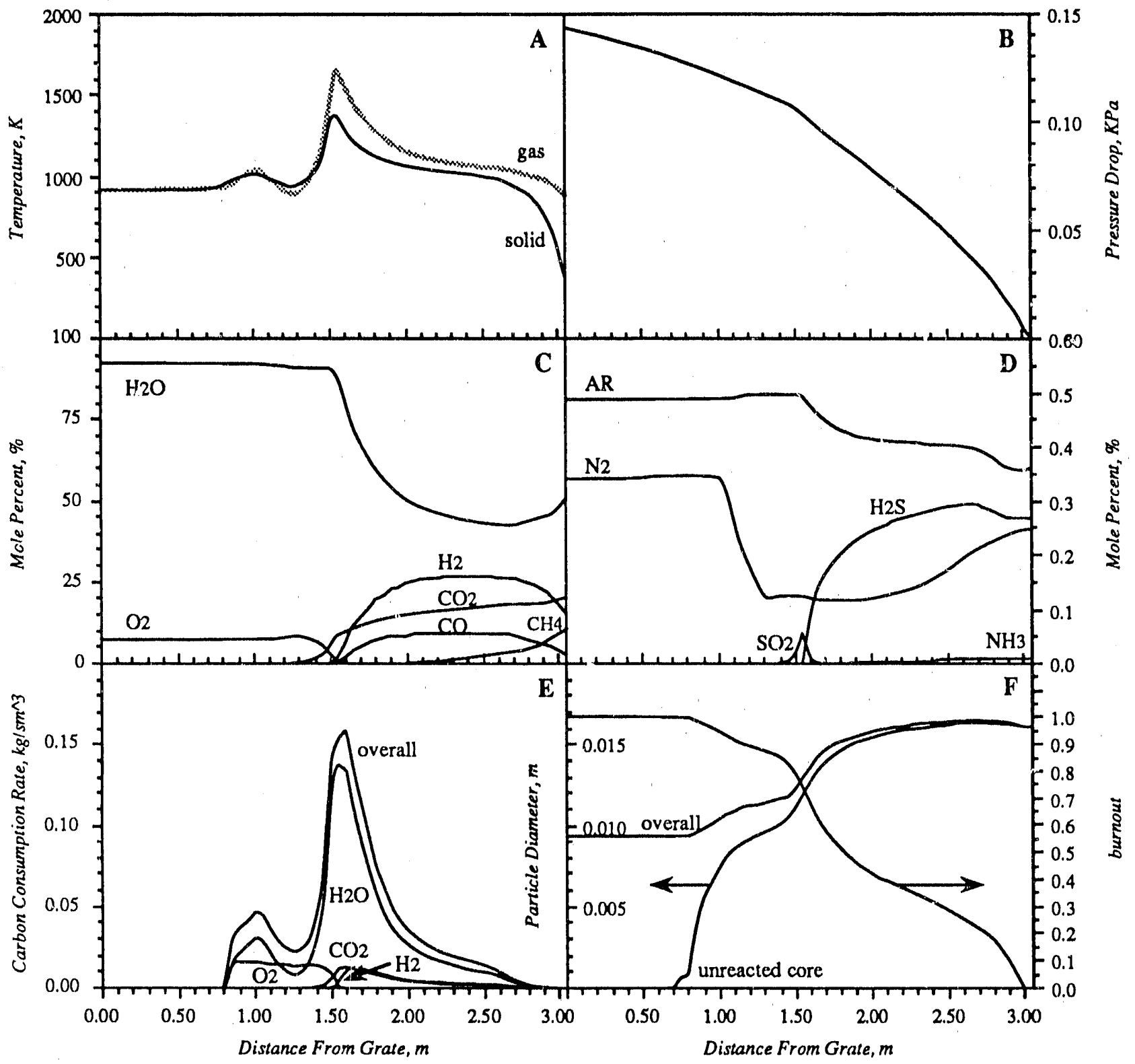

Figure IV.B-3 Predicted temperature, pressure drop, gas concentration, carbon consumption due to oxidation and gasification, burnout, and particle diameter for gasification of Rosebud subbituminous coal in a high pressure gasifier with oxygen (Elgin and Perks, 1974): A) solid and gas temperature profile, B) pressure drop, C) major species concentration profile, D) minor gas species concentration profile, E) volumetric solid carbon consumption rate due to oxidation and gasification reactions, and F) burnout, overall and unreacted particle diameter throughout reactor. Input conditions can be found in Hobbs (1990). 
Wellman-Galusha cases and the Westfield cases are the absence of the carbon dioxide peak during high pressure gasification and the appearance of dual temperature peaks in the Pittsburgh and Rosebud Westfield simulations as shown in Figure IV.B-2 and IV.B-3. The dual peaks may be attributed to high pressure operation as discussed in detail in Section III.B.

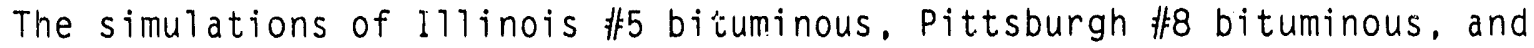
Rosebud subbituminous coals in the Lurgi gasifier are shown in Figures IV.B-1 through IV.B-3, respectively. No experimental temperature or pressure profiles were reported for these cuses. The predicted profiles seem reasonable and similar to the Illinois 非 bituminous case, which has been discussed in Section III.B.

Weliman-Galusha Dry Ash Gasifier - Predicted temperature, pressure drop, gas concentration, carbon consumption, burnout, and particle diameter for gasification of Illinois 非 bituminous and Rosebud subbituminous (weathered) coals in ar atmospheric, air-fired Weliman-Galusha gasifier (Thimsen et al.. 1984) are shown in Figures IV.B-4 and IV.B-5. Complete input files for these cases can also be found in (Hobbs, 1990).

Experimental data from runs that gasified poorly were difficult to simulate. Poor gasification refers to significant distribution problems such as channeling or clinker formation which leads to questionable reported operational conditions. The one-dimensional code is very sensitive to input conditions as discussed in the sensitivity analysis. For example, if the selected values for the bed void fraction were significantly in error, the devolatilization zone could potentially exist throughout the entire reactor with no gasification or oxidation taking place. The Illinois 非 bituminous case was easy to simulate while the weathered Rosebud subbituminous case was difficult. The low-rank coal cases required more adjustment of parameters such as the bed vid fraction, the solid-to-gas heat transfer coefficient, and the effective diffusivity, to match experimental data.

The simulation of Illinois 非 bituminous coal in the Wellman-Galusha gasifier is shown in Figure IV.B-4. No experimental temperature profiles or pressure profiles were reported for this case. The predicted profiles seem reasonable and similar to the jetson bituminous coal case, which has experimental data and has been discussed in chapter III.B. 


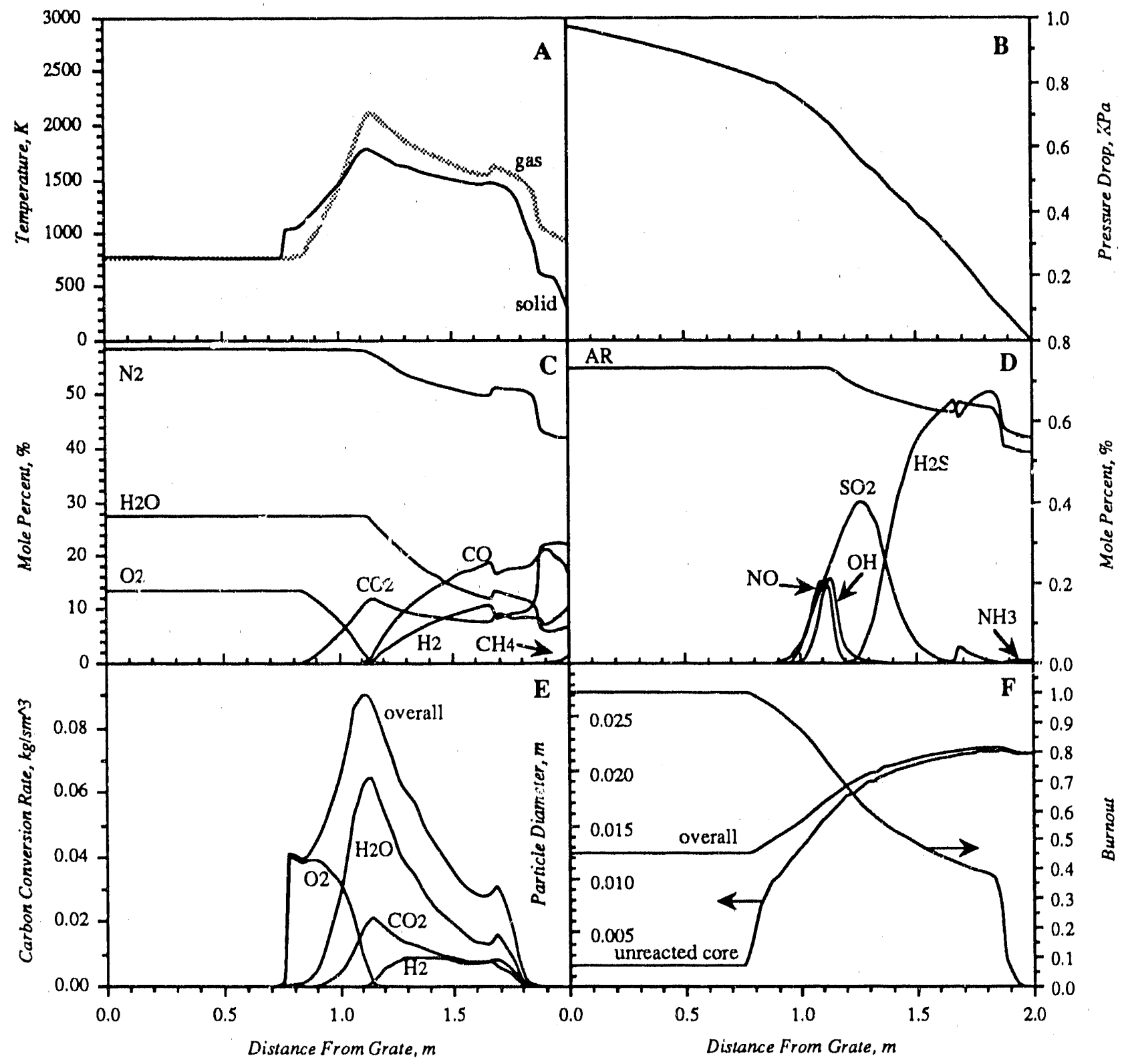

Figure IV.B-4 Predicted temperature, pressure drop, gas concentration, carbon consumption due to oxidation and gasification, burnout, and particle diameter for gasification of Illinois \#6 bituminous coal in an atmospheric gasifier with air (Thimson et al., 1984; Vol 8, page 68): A) predicted gas and solid temperature profile, B) predicted pressure drop, C) predicted major species concentration profile, D) predicted minor gas species concentration profile, E) predicted volumetric solid carbon consumption rate due to oxidation and gasification reactions $F$ ) predicted burnout, overall and unreacted particle diameter throughout reactor. Input conditions can be found ir Hobbs (1990). 


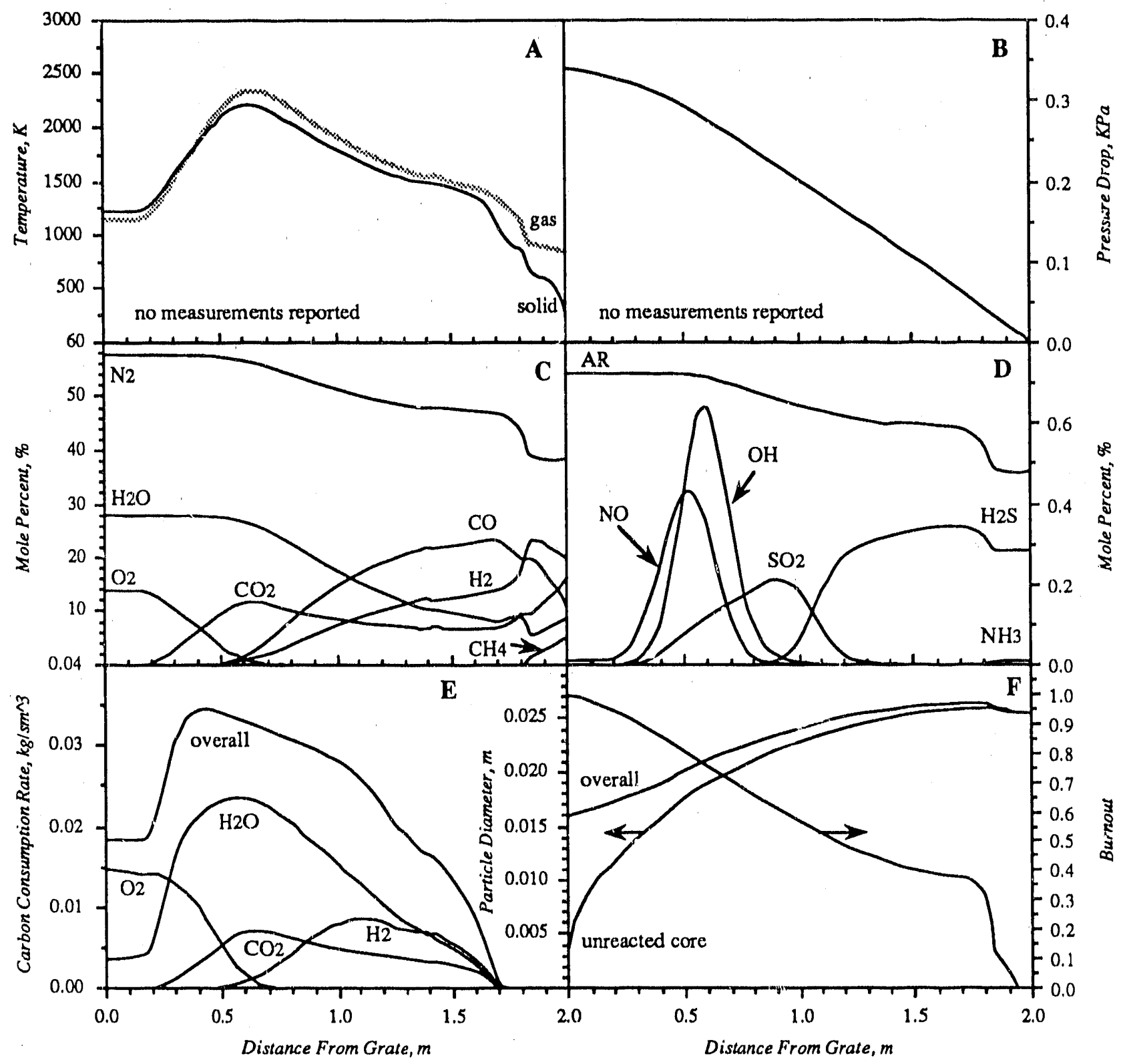

Figure IV.B-5 Predicted temperature, pressure drop, gas concentrati, 1 , carbon consumption due to oxidation and gasification, burnout, and particle diameter for gasification of Rosebud subbituminous coal in an atmospheric gasifier with air (Thimson et al., 1985; Vol 3, page 63): A) predicted gas and solid temperature profile, B) predicted pressure drop, C) predicted major species concentration profile, D) predicted minor gas species concentration profile, E) predicted volumetric solid carbon consumption rate due to oxidation and gasification reactions F) predicted burnout, overall and unreacted particle diameter throughout reactor. Input conditions can be found in Hobbs (1990). 
The simulation of the weathered Rosebud subbituminous coal in the Wellman-Galusha gasifier is shown in Figure IV.B-5. This simulation was similar to the fresh Rosebud case, which has experimental data (Hobbs, 1990).

METC Gasifier - A comparison of solid and gas temperature profiles and selected gas species profiles for gasification of Arkwright bituminous coal in the air-fired, METC gasifier operated at 6.4 atmospheres (absolute) is shown in Figure IV.B-6. The input conditions for this case were found in Desai and Wen (1978). The solid and gas temperature profiles predicted by Desai and Wen are indistinguishable. Desai and Wen believed that the prediction was the average of the gas and solid temperature. However, the sample calculation in the Appendix of Desai and Wen (1978) indicates that the solid and gas temperatures were indeed equal. It is assumed that Desai and Wen did not account for the difference between the nonreacting solid-to-gas heat transfer coefficients and the reacting solid-to-gas heat transfer coefficients. In other words, they assumed that $\zeta$ was equal to 1 . which would give equal solid and gas temperatures as indicated by the sensitivity analysis on $\zeta$. The concentration profiles show the instantaneous devolatilization assumption made by Desai and Wen. Also the lack of a peak in the $\mathrm{CO}_{2}$ profile indicates simplified assumptions regarding the gas-phase chemistry.

BGC-Lurgi Slagging Gasifier - Predicted temperature, pressure drop, gas concentration, carbon consumption, burnout, and particle diameter for gasification of pittsburgh 非 bituminous coal in a high-pressure, slagging gasifier with oxygen (Scott, 1981) are shown in Figure IV.B-7. The coal flow rate is 2-3 times larger than for dry-ash gasifiers. The temperature is higher to promote slagging of the ash. The predicted temperature of the ash zone is low. A possible explanation could be inadequacy of the plug flow assumption for the ash flow rate. The BGC-Lurgi slagging case is presented to show the possibility of simulating the slagging gasifier.

\section{Plans}

During the next quarter, work will continue on collecting fixed-bed design and test data. The fixed-bed design and test data will be collected both from the open literature and from organizations and individuals involved in fixed-or moving-bed gasification or combustion research or in research on non-reacting fixed-or moving-beds. Efforts will continue to identify additional test cases for simulation. The code will be applied to these additional test cases. 


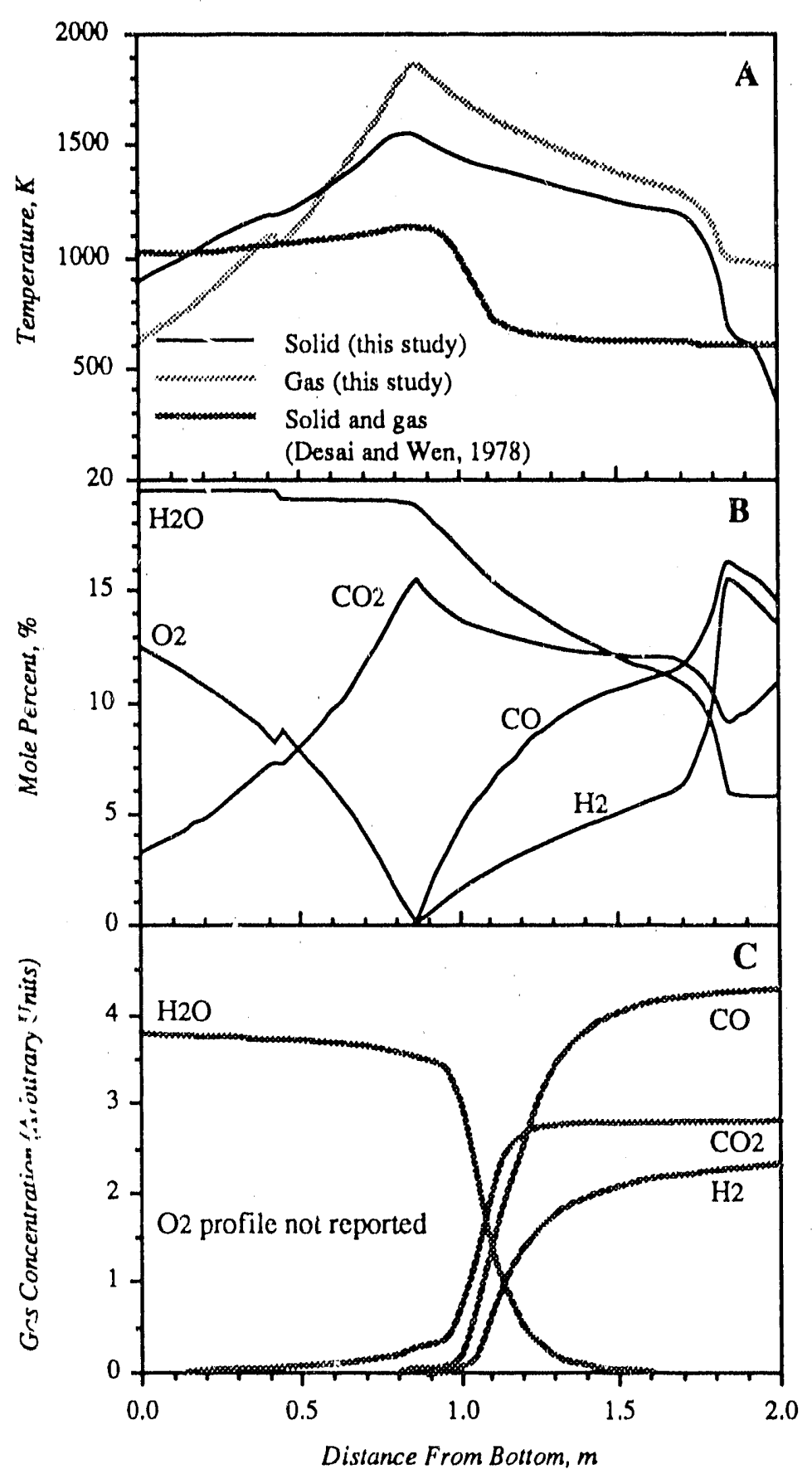

Figure IV.B-6 Comparison of A) solid and gas temperature profiles, and B) selected gas species profiles for gasification from this study and C) Desai and Wen (1978) of Arkwright bituminous coal in the air-fired METC gasifier operated at 6.4 atmospheres (absolute). Input conditions and model predictions from Desai and Wen (1978). Input file for MBED-1D can be found in Hobbs (1990). Coal, air, and steam mass flow rate are $0.138,0.518$, and 0.063 . $\mathrm{kg} / \mathrm{s}$, respectively. 


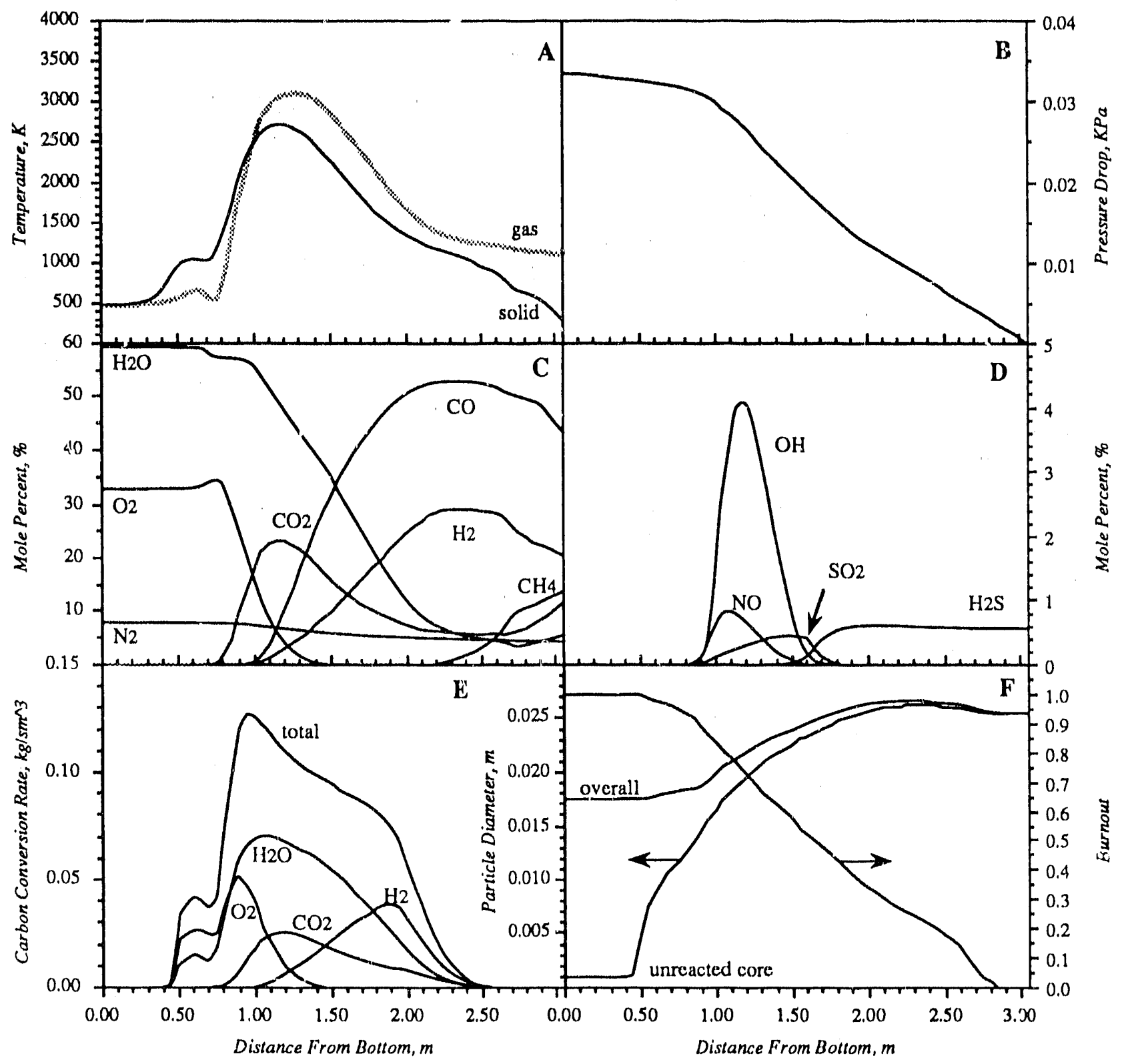

Figure IV.B-7 Predicted temperature, pressure drop, gas concentration, carbon consumption due to oxidation and gasification, burnout, particle diameter for gasification of Pittsburgh \#8 bituminous coal in a high-pressure slagging gasifier with oxygen (Scott, 1981; page E-50): A) predicted solid and gas temperature profile, B) predicted pressure drop, C) predicted major species concentration profile, D) predicted minor gas specie concentration profile, E) predicted volumetric solid carbon consumption rate due to oxidation and gasification reactions, and F) predicted burnout, overall and unreacted particle diameter throughout the reactur. Reactor geometry is the same as the Westfield Lurgi cases. Coal, oxidizer and steam mass flow rates are 2.793, 1.6329, and $0.9464 \mathrm{~kg} / \mathrm{s}$, respectively. Complete input file can be found in Hobbs (1990). 


\section{REFERENCES}

Bae, J.H., "A Simple Thermogravimetric Apparatus for Pressures up to 70 Atmospheres", The Review of Scientific Instruments, 43, 983-985, (1972).

Barton, W.A. and Lynch, L.J., Energy \& Fuels, 3, 402, (1989).

Boardman, R.D., "Further Evaluation of a Predictive Model for Nitric Oxide Formation During Pulverized Coal Combustion", Master's Thesis, Brigham Young University, Provo, UT, (1987).

Boardman, R.D., "Measurement and Prediction of Nitric Oxide in Stationary Combustors", Ph.D. Dissertation, Brigham Young University, Provo, UT, in Preparation, (1990).

Boardman, R.D. and Smoot, L.D., "Prediction of Nitric Oxide in Advanced Combustion Systems", AIChE J., 34, 1573, (1988).

Bose, A.C., Dannecker, K.M., and Wendt, J.0.L., "Coal Domposition Effects on Mechamisms Governing the Destruction of NO and Other Nitrogenous Species During Fuel-Rich Combustion", Energy \& Fueis, 2, 301, (1988).

Castellan, G.W., Physical Chemistry, (F.T Bonner, Ed.), Addison-Wesley Publishing Company, 1971, 2nd Edition.

Chen, S.L., Pershing, D.W., and Martin, G.B., "Influence of Coal Composition on the Fate of Folatile and Char Nitrogen During Combustion", 19th Symposium (Int) on Combustion. The Combustion Institute, Pittsburgh, PA, $1271,(1982)$.

de Soëte, G.G., "Overall Reaction Rates of $N O$ and $\mathrm{N}_{2}$ from Fuel Nitrogen", 15th Symposium (Int) on Combustion, The Combustion Institute, Pittsburgh, PA, 1093, (1975).

de Soëte, G.G., Personal Communication, (1987).

DeSai, P.R. and Wen, C.Y., Computer Modeling of the MERC Fixed-Bed Gasifier, Report MERC/CR-78/3, Morgantown Energy Technology Center, Morgantown, WV, (1978).

Dobner, S., Kan, G., Graff, R.A., and Squires, A.M., "A Thermobalance for High Pressure Process Studies", Thermochimica Acta, 16, 251-265, (1976).

Dzhapbyev, K., Miropol'skii, A.L., and Mal'Kovskii, V.J., "Investigation of Usteady Heat Transfer in a Packed Bed of Spheres Swept by Gas", Thermal Engineering, 33, 159, (1986).

Elliott, M.A., Chemistry of Coal Utilization, Second Supplementary Volume, John Wiley, New York, (1981).

Fletcher, T.H., "Yime-Resolved Particle Temperature and Mass Loss Measurements of a Bituminous Coal During Devolatilization", Combustion and Flame, 78, 223-236, (1989a). 
Fletcher, T.H., "Time-Resolved Temperature Meas'irements of Individual Coal Particles During Devolatilization", Comb. Sci. Tech., 63, 89-105, (1989b).

Forgac, J.M. and Angus, J.C., "A Pressurized Thermobalance for Use at Extreme Conditions", Ind. Eng. Chem. Fund., 18, 416-418, (1979).

Ghodsi, M., Derie, R., and Lempereur, J.P., "Construction of an Isothermal Balance with Two Symmetrical Pans for Operation Under Pressure", Thermoctimica Acta, 28, 259-264, (1979).

Haussmann, G.J., Krewson, S., and Kruger, C.H., "Rapid Pyrolysis and Combustion of Pulverized Montana Rosebud Subbituminous Coal", Western States Section, The Combustion Institute, Salt Lake City, UT, (1988).

Hi11, S.C., Smoot, L.D., and Smith, P.J., "Prediction of Nitrogen Oxide Furmation in Turbulent Coal F? ames", 20th Symposium (Int) on Combustion, The Combustion Institute, Pittsburgh, PA, 1391-1400, (1984).

Hobbs, M.L., "Modeling Countercurrent Fixed-Bed Coal Gasification", Ph.D. Dissertation, Brigham Young University, Provo, Utah, (1990).

Huber, A.M., "Effect of Sorbent on Sulfur Pollutant Species in an EntrainedFlow Coal Gasifier", M.S. Thesis, Brigham Young University, Provo, Utah, (1989).

Laurendeau, N.M., "Heterogeneous Kinetics of Coal Char Gasification and Combustion", Prog. Energy Comb. Sci., 4, 221, (1978).

Laurendeau, N.M., "Heterogeneous Kinetics of Coal Char Gasification and Combustion", Prog. Energy Combust. Sci., 4, 221, (1978).

Li, K. and Rogan, R.H., "A Thermogravimetric System for Corrosive Environments at High Pressures and Temperitures", Thermochimica Acta, 26, 185-190, (1978).

Lowry, H.H., Chemistry of Coal Uiilization, John Wiley and Sons, Inc., New York, NY, 1963.

Lynch, L.J., Sakurovs, R., Webster, D.S., and Redlich, P.J., Fuel, 67, 1036, (1988).

Lynch, L.J., Webster, D.S., Sakurovs, R., Barton, W.A., and Maher, T.P., Fuel, $67,579,(1988 a)$.

Merrick, D., "Mathematical Models of the Thermal Decomposition of Coal. 2. Specific Heats and Heats of Reaction", Fue1, 62, 540, (1983).

Mills, K.C. and Rhine, J.M., "The Measurement and Estimation of the Physical Properties of Slags Formed During Coal Gasification: 2. Properties Relevant to Heat Transfer", Fle1, 68, 201, (1989).

Mitchel1, J.W. and Tarbell, J.M., "A Kinetic Model of Nitric Oxide Formation During Pulverized Coal Combustion", AIChE J., 28, 302, (1982). 
Mitchel1, R.E., "On the Products of the Heterogeneous Oxidation Reaction at the Surfaces of Burning Coal Char Particies", 22nd Symposium (Int) on Combustion, The Combustion Institute, Pittsburgh, PA, 69-78, (1988).

Pershing, D.W. and Wendt, J.O.L., "Pulverized Coal Combustion: The Influence of Flame Temperature and Coal Composition on Thermal and Fuel NOx", 16th Symposium (Int) on Combustion, The Combustion Institute, Pittsburgh, PA, 389, (1977).

Poh1, J.H. and Sarofim, A.F., "Devolatilization and Oxidation of Coal Nitrogen", 16th Symposium (Int) on Combustion, The Combustion Institute. Pittsburgh, PA, 491, (1977).

Sakurovs, R. and Lynch, J.L., Private Communication, (1990).

Scott, J.E., "U.S. Cual Test Program on BGC-Lurgi Slagging Gasifier", Final Report AP-1922, Research Prijest 1267-1, Electric Power Research Institute, Palo Alto, California, (1982).

Serio, M.A., Solomon, P.R., Charpenay, S., Yu, Z.Z., and Bassilakis, R., ACS Div of Fuel Chem. Preprints, 35(3), 808, (1990).

Serio, M.A., Solomon, P.R., Kroo, E., Bassilakis, R.. Malhotra, R., and McMilien, D., ACS Div. of Fuel Chem. Preprints, 35, (1), 61, (1990a).

Silcox, G.D., "Analysis of the $\mathrm{SO}_{2}$-Lime Reaction System: Mathematical Modeling and Experimental Studies Emphasis on Stoker pplications", Ph.D. Dissertation, The University of Utah, (1985).

Solomon, P.R., Hamblen, D.G., Carangelo, R.M., Serio, M.A., and Deshpande, G.V., Energy and Fuel, 2, 405, (1988).

Solomon, P.R., Serio, M.A., Hamblen, D.G., Smoot, L.D., and Brewster, B.S., "Measurement and Modeling of Advanced Coal Conversion processes", 3rd Annual Report under DOE-METC Contract No. DE-AC21-86MC23075, Advanced Fuel Research, Hartford, CT, (1989C).

Solomon, P.R., Chien, P.L., Carangelo, R.M., Serio, M.A., and Markham, J.R., "New Ignition Phenomenon in Coal Combustion", Combustion and Flame, 79, $214-215,(1990)$.

Solomon, P.R., Serio, M.A., Hamblen, D.G., Smoot, L.D., and Brewster, B.S., "Measurement and Modeling of Advariced Coal Conversion Processes", 14th Quarterly Report under DOE-METC Contract No. DE-AC21-86MC23075, Advanced Fuel Research, Hartford, CT, (1990)a).

Solomon, P.R., Serio, M.A., Carangelo, R.M., Bassilakis, R., Yu, Z.Z., Charpenay, S., and Whelan, J., "Analys is of Coal by TG-FTIR and Pyrolysis Modeling", Presented at the Pyrolysis '90 Meeting in Holland, (June 1990b), To be Published in Journal of Analytical and Applied Pryolysis.

Solomon, P.R., Serio, M.A., Hamblen, D.G., Yu, Z.Z., and Charpenay, S., ACS Div. of Fuel Chem. Preprints, 35(2), 479, (1990c). 
Solomon, P.R., Markham, J.R., Zhang, Y.P., and Carange10, R.M., ACS Div. of Fuel Chem. Preprints, 35(3), 746, (1990d).

Solomon, P.R.: Hamblen, D.G., Yu, Z.Z., and Serio, M.A., Fuel, 69, 754, $(1990 \mathrm{e})$.

Thimsen, D., Maurer, R.E., Poole, A.R., Pui, D., Liu, B., and Kittelson, D., "Fixed-Bed Gasification Research Using U.S. Coals. Volume 1. Program and Facility Description", Fixed-Bed Gasification Research Using U.S. Coals, 1984, Volume 1, Work Performed under U.S. Dept. of Energy, Morgantown, WV, Contract No. DOE/ET/10205-1689 by Black, Sivalls and Bryson, Inc., Houston, TX.

Thorsness, C.B. and Kang, S.W., "Further Development of a General-Purpose, Packed-Bed Model for Analys is of Underground Coal Gasification Processes", Eleventh Annual Underground Coal Gasification Symposium, Denver, Colorado, (1985).

Tichenor, D.A., Mitchel1, K.R., Hencken, K.R., and Niksa, S., "Simultaneous In-Situ Measurement of the Size, Temperature, and Velocity of Particles in a Combustion Environment", 20th Symposium (Int) on Combustion, The Combustion Institute, Pittsburgh, PA, 1213, (1984).

Tognotti, Longwel1 and Sarofim, A., 23rd Symoosium (Int) on Combustion, The Combustion Institute, Pittsburgh, PA, (1990).

Treptau, M.H. and Miller, D.J., "An Internally Heated Weighed Reactor Thermobalance for Gas-Solid Reaction Studies", Ind. Eng. Chem. Res., 26, 2007-2011, (1987).

Wang, S.C. and Wen, C.Y., "Experimental Evaluation of Nonisothermal Solid-Gas Reaction Model", AIChE J., 18, 1231, (1972).

Wells, W.F., "Reactivities of Selected Coal Chars with Oxygen", Ph.D. Dissertation, Brigham Young University, Provo, UT, (1990).

Wendt, J.O.L., Bose, A.C., and Hein, K.R.G., "Fuel Nitrogen Mechanisms Governing NO Abatement for Low and High Rank Coals", 1988 Joint Symposium on Stationary Combustion $\mathrm{NO}_{x}$ Control, San Francisco, CA, March 609, (1989).

Williams, J.R. and Wendlandt, W.W., "A High Pressure Thermobalance", Thermochimica Acta, 7, 253-260, (1973). 


\section{APPENDIX A}

\section{FG-OVC Model Implementation Notes}




\section{FG-DVC MODEL IMPLEMENTATION NOTES}

\section{FG Submodel}

The basic model describes the weight loss of char to tar and gas, where the initial char is a raw coal. The basic equations are as follows:

$$
\begin{aligned}
& d W_{C} / d t=-d W_{G} / d t-d W_{T} / d t \\
& d W_{G} / d t=\text { (gas rate constant) }{ }^{\star} W_{C} \\
& d W_{T} / d t=\text { (from DVC) }
\end{aligned}
$$

where $W_{C}, W_{T}$, and $W_{G}$ are the weight fractions of char, tar and gas, and $t$ is the time.

In order to determine the effective rate constants for gas evolution, the $W_{c}$ is subdivided using a distribution function describing the various gas forming fractions, i.e., the chemical functional groups, with initial norm of unity (the yo(i)'s of the General Model Paper (GMP)). This allows different rate constants to be applied to each functional group. Tar evolution is assumed to be a completely independent process, which depends on the molecular weight distribution of the char (through the vapor pressure dependence on the molecular weight), and on the volumetric gas flow rate (which sweeps out the tar at its equilibrium vapor pressure). Tar is evolved from each functional group in the char in proportion its fraction in the char. The details of this are discussed in GMP, and in the next section.

Additional competing reactions can be added to Equation 1 in the same manner, by adding a term to Equation 1, and addirig an additional rate equation like Equations 2 and 3 . Thus the equation set becomes:

$$
\begin{aligned}
& d W_{C}(i, t) / d t=-d W_{G}(i, t) / d t-d W_{T}(i, t) / d t \\
& d W_{G}(i, t) / d t=(g a s \text { rate constant }(i)) * W_{C}(i, t) \\
& d W_{T}(i, t) / d t=\left(d W_{T}(t) / d t\right)_{D v c} * W_{C}(i, t) /\left(\sum W_{C}(i, t)\right) \\
& W_{C}(i, t)=W_{C 0}{ }^{*} f_{C G}(i, t)
\end{aligned}
$$

where

$$
\begin{array}{lll}
\mathrm{W}_{\mathrm{CO}} & = & \text { the whole starting char }(=1.0) \\
\mathrm{f}_{\mathrm{CG}}(\mathrm{i}, \mathrm{t}) & = & \text { the mass fraction of the starting char (coal) which can } \\
& \text { form gas species } \mathrm{i} \text { at time } \mathrm{t},
\end{array}
$$

and where we have used the fact that the tar and gas evolutions are independent, which is implicit in Equation 1 (they are in separate terms). The sum over all $i$ in Equations $4-7$ yields Equations 1-3.

In order to implement the distributed activation energy reaction kinetics, each of these distribution functions is further subdivided into fractions of material having a given activation energy, $\mathrm{E}$ : 
$f_{C G}(i, E, t)=$ the mass fraction of the starting char which, at time $t$, can evolve gas species $i$, with Arrhenius parameters given by frequency factor $A(i)\left[\mathrm{sec}^{-1}\right]$, and activation energy between $E$ and $E+d E$.

where the integrals of these f(E)'s over all $E$ are equal to the corresponding f's in Equation 7. Using these definitions of the distributed rate kinetics, one has:

$$
\begin{aligned}
& d W_{C}(i, E, t) / d t=-d W_{G}(i, E, t) / d t-d W_{T}(i, E, t) / d t+I_{C}(i, t) \\
& d W_{G}(i, E, t) / d t=r(i, E) * W_{C}(i, E, t)+I_{G}(i, t) \\
& d W_{T}(i, E, t) / d t=\left(d W_{T}(t) / d t\right)_{D V C} * W_{C}(i, E, t) / W_{C}(t)+I_{T}(i, t)
\end{aligned}
$$

where

and

$$
\begin{aligned}
& W_{c}(i, E, t)=W_{C O}{ }^{*} f_{C G}(i, E, t) \\
& W_{c}(i, t)=\int W_{c}(i, E, t) d E \\
& W_{c}(t)=\Sigma W_{c}(i, t)
\end{aligned}
$$

$I_{c}(i, t) \quad$ is additional reactions affecting the char pools

$I_{T}(i, t) \quad$ is additional reactions affecting the tar pools,

$\mathrm{I}_{G}(\mathrm{i}, \hat{\imath}) \quad$ is additional reactions affecting the gas pools.

$$
r(i, E)=A(i){ }^{\star} \exp (-E / R T)
$$

(similar definitions exist for the integrals and sums of the gas and tar poois)

If one substitutes Equation 11 into Equations 8-10, one finds that the problem separates into decoupled equations for the f's, and we need only solve differential equations for these distribution functions, which can then be used to evaluate $W_{C}, W_{T}$, and $W_{G}$. This is the approach used in GMP, with the $x$ and $y$ 's. In practice, one usually wants to add terms to Equations 8-10 to describe interpool transfers, the $I(t)$ 's, (for example, to allow methyl group to preferentially accumulate in the tar), so that one needs to solve not only the for the distribution function, but also for Equations 8-10 as well.

The actual mass fractions we are interested in are $W_{C}(i, t), W_{G}(i, t)$ and $W_{T}(i, t)$. Thus we need to perform the appropriate integrals over activation energy in Equations 8-10 to obtain the required differential equations.

$$
\begin{aligned}
& d W_{C}(i, t) / d t=-d W_{G}(i, t) / d t-d W_{T}(i, t) / d t+I_{C}(i, t) \\
& d W_{G}(i, t) / d t=\int r(i, E) \star W_{C}(i, E, t) d E+I_{G}(i, t) \\
& d W_{T}(i, t) / d t=\left(d W_{T}(t) / d t\right)_{D V C} \star W_{C}(i, t) / W_{C}(t)+I_{T}(i, t)
\end{aligned}
$$

plus equations describing the time dependence of the distribution functions. 
If we define average kinetic rate constants as follows:

$$
\langle r(i)\rangle=\int r(i, E)^{*} f_{C G}(i, E, t) d E / \int f_{C G}(i, E, t) d E
$$

then we obtain

$$
\begin{aligned}
& d W_{C}(i, t) / d t=-d W_{G}(i, t) / d t-d W_{T}(i, t) / d t+I_{C}(i, t) \\
& d W_{G}(i, t) / d t=\langle r(i)\rangle * W_{C}(i, t)+I_{G}(i, t) \\
& d W_{T}(i, t) / d t=\left(d W_{T}(t) / d t\right)_{D V C} * W_{C}(i, t) / W_{C}(t)+I_{T}(i, t)
\end{aligned}
$$

These, together with equations describing the time dependence of the distribution functions, are the basic differential equations we use.

\section{DVC Submodel}

The DVC submodel is described fully in GMP. To implement this using the two coordination number percolation theory, as described in the Network Paper, we define two bond types (referred to as bridges and cross-links), each bond type having its own coordination number and probability of occupation. The bridges ( with probability of occupation, $p(t)$ ) are broken with a distributed kinetic rate (in much the same manner as the gas functional groups above). The cross-links (with probability of occupation, $q(t)$ ) are formed in conjunction with the evolution of $\mathrm{CO}_{2}$ and $\mathrm{CH}_{4}$. To cope with the problem of cross-linking tar to char, the cross-linking rate for $d q / d t$ is divided by $W_{c}(t)$, i. e., the percolation is done on the whole coal basis. The current version of the model assumes that bridges are only broken (never formed), and cross-links are only formed (never broken). To model the hydrogen abstraction, the population of bridges is subdivided into labile and non-labile (un-breakable) bridges, where each time a labile bridge is broken, an additional labile bridge is converted into a non-labile bridge. Thus the differential equations needed for the percolation part of the model are:

$$
\begin{aligned}
& d p_{L}(t) / d t=-2 .{ }^{*}\langle r(B, t)\rangle{ }^{*} p_{L}(t) \\
& d p(t) / d t=-1 .{ }^{*}\langle r(B, t)\rangle{ }^{*} p_{L}(t) \\
& d q(t) / d t=\Sigma\left(d W_{G}(i, t) / d t\right)^{\star} X(i) / M(i) / W_{C}(t)
\end{aligned}
$$

where

$$
\begin{aligned}
& p_{L}(t)=\quad \text { the number fraction of bridge sites containing labile bridges } \\
& p(t)=\begin{array}{l}
\text { the number fraction of bridge sites containing either labile or } \\
\text { non-labile brigdes }
\end{array} \\
& q(t)=\quad \text { the number fraction of occupied cross-link sites. } \\
& X(i)=\begin{array}{l}
\text { the number of cross-links formed for each molecule of gas } i \\
\text { formed. (moles } x \text {-link } / \text { mole gas } i)^{\star}(\mathrm{gm} / \mathrm{mole} \text { coal) }
\end{array} \\
& M(i)=\quad \text { the molecular weight of gas species } \mathrm{i} .[\mathrm{gm} / \mathrm{mole}]
\end{aligned}
$$


and

$$
\begin{aligned}
& \left\langle r(B, t)>=\int r(B, E)^{\star} f_{B}(E, t) d E / \int f_{B}(E, t) d E\right. \\
& r(B, E)=A(B)^{\star} \exp (-E / R T)
\end{aligned}
$$

where

$$
\begin{aligned}
& f_{B}(E, t)=\quad \text { the fraction of the starting bridges which can break at time } t, \\
& \text { with Arrhenius parameters given by frequency factor } A(B)\left[\sec ^{-1}\right], \\
& \text { and activation energy between } E \text { and } E+d E \text {. }
\end{aligned}
$$

The $p(t)$ and $q(t)$ computed from these three differential equations is then used to compute the molecular weight distribution function, $F_{n}(p, q)$, from percolation theory. $F_{n}(p, q)$ is the weight fraction of $n$-mers in the char, and is a function only of $p, q$, and the two coordination numbers:

This $F_{n}(p, q)$ is converted to the mass distribution function needed for the tar submodel by using a molecular weight distribution of monomers.

where

$$
\begin{aligned}
& N_{C 1}(t)=\Sigma_{n} G(i, n) * F_{n}(p, q) / M T(i) \\
& x_{1}=\left(N_{C 1}-N_{T 1}\right) / \Sigma\left(N_{C 1}-N_{T 1}\right)
\end{aligned}
$$

$$
\begin{aligned}
& F_{n}(p, q)=\quad \text { mass fraction of coal in n-mers [gm n-mer/gm coal] } \\
& N_{C I}(t)=\text { fraction of coal in the } i^{\text {th }} \text { mass bin [mole } i / g m \text { coal] } \\
& N_{T 1}(t)=\text { fraction of tar in the } i^{\text {th }} \text { mass bin [mole } \mathrm{i} / \mathrm{gm} \text { coal] } \\
& \mathrm{G}(\mathrm{i}, \mathrm{n})=\text { fraction of } n \text {-mers in the } i^{\text {th }} \text { mass bin [gm } i / g m n \text {-mer] } \\
& M T(i)=\text { Effective Molecular weight of the } i^{\text {th }} \text { mass bin. [gm i/mole i] } \\
& x_{1}=\text { the mole fraction of material in the } i^{\text {th }} \text { mass bin. [mole } \mathrm{i} / \mathrm{mole}
\end{aligned}
$$

To allow for the fact that some of the tar has already evolved from the char, we use for tar evolution only the difference between $N_{C \text { and } N} T$, (or zero if the result is negative).

From Equation 4 of the GMP, we have that

$$
\begin{aligned}
\mathrm{dN}_{\mathrm{T}} / \mathrm{dt} & =\mathrm{P}_{1} X_{1} /\left(\mathrm{P}_{\mathrm{o}}+\Delta \mathrm{P}\right) * \Sigma \text { (gas flow, including tar) } \\
& =\mathrm{P}_{1} \mathrm{X}_{1} /\left(\mathrm{P}_{\mathrm{o}}+\Delta \mathrm{P}\right) *\left(\Sigma\left(\mathrm{W}_{\mathrm{G}}(\mathrm{i}, \mathrm{t}) / \mathrm{M}(\mathrm{i})\right)+\Sigma \mathrm{dN} / \mathrm{dt}\right)
\end{aligned}
$$

where

$$
\begin{aligned}
& P_{1}=\quad \begin{array}{l}
\text { the equilibrium vapor pressure of the } j^{\text {th }} \text { molecular weight } \\
\text { component computed using Suuberg's correlation. [atm] }
\end{array} \\
& P_{0} \quad=\quad \text { ambient pressure[atm] }
\end{aligned}
$$




$$
\Delta P=\text { Fudge factor }[\mathrm{atm}]
$$

By summing Equation 26 over J, we can obtain an expression for $\Sigma \mathrm{dN} / \mathrm{dt}$, and eliminate the $\mathrm{dN} / \mathrm{dt}$ from the right hand side of this equation.

$$
\left.d N_{T} / d t=P_{1} X_{1} /\left(P_{0}+\Delta P \cdot \Sigma_{1} P_{1} X_{1}\right) * \Sigma_{1}\left(W_{G}(i, t) / M(i)\right)\right)
$$

and finally:

$$
\left(d W_{T}(t) / d t\right)_{D V C}=\Sigma d N_{T} / d t * M T(j)
$$

which is the expression needed to evaluate Equation 18.

The differential Equations $16-21$ and 27, together with the differential equations for the distributed rate distribution functions are the equations we actually need to integrate.

\section{Distributed Rate Submodel (the f's)}

In the original versions of the FG and FG-DVC models, the $f(E) d E$ were approximated by initializing them to a gaussian distribution and subdividing the range covering \pm 3 standard deviations into 21 equal energy incremonts. This approach gives 21 differential equations for each functional group and bridge (each subdivision decreases with the first order kinetics given by the rate constants determined by Equation 14). This means that the shape of the $f(E)$ changes with time. More recently, we have approximated this model by assuming that the shape remains fixed in time, but that the lower cutoff point changes in such a way as to give the same area under the $f(E) d E$ curve as before. This gives a single differential equation for each distribution instead of 21 . In this section, we derive this equation.

We start with the observation that

$$
d W_{G}(i, t) / d t=-\left.\left(d W_{C}(i, t) / d t\right)\right|_{\text {(lar, other held fixed) }}
$$

and thus we differentiate Equation 12 with respect to time. Since only the lower bound of the integral; $E_{m}(i, t)$, varies with time, the result, after using Equation 29, is

$$
\begin{aligned}
& d W_{G}(i, t) / d t=W_{C O}{ }^{*} f_{C G}\left(i, E_{m}(i, t)\right) * d E_{m}(i, t) / d t \\
& =W_{C}(i, t) / \int f_{C G}(i, E) d E * f_{C G}\left(i, E_{m}(i, t)\right) * d E_{m}(i, t) / d t
\end{aligned}
$$

Ujing Equations 17 and 30 , ignoring for the moment the $I(t)$ term, we find

$$
d E_{m}(i, t) / d t=\langle r(i)\rangle^{*} \int f_{C G}(i, E) d E / f_{C G}\left(i, E_{m}(i, t)\right)
$$

For simplicity, we use a truncated gaussian, so that

$$
\begin{aligned}
& \int f_{C G}(i, E) d E=\operatorname{erfc}\left(Z_{1}(t)\right) / \operatorname{erfc}\left(Z_{1}(0)\right) \\
& Z_{1}(t)=\left(E_{m}(i, t)-E_{j}\right) / \sqrt{ } 2 \sigma_{1}
\end{aligned}
$$

where $E_{1}$ and $\sigma_{1}$ are the parameters of the gaussian distribution.

If the $I(t)$ terms are not zero, then we must make suitable assumptions as to how these terms affect the distribution functions. For the cases considered to date, we have assumed that 
they do not modify Equation 31. For example, material removed from a given functional group by mechanisms other than the bond breaking associated with freeing up the functional group, is removed from each activation energy subpool in proportion to its current quantity. Another assumption which could easily by implemented, is to assume that these terms are added to Equation 31, thus affecting the $E_{m}$ 's.

\section{Summary of Active Differential Equations}

$$
\begin{aligned}
& d W_{C}(i, t) / d t=-d W_{G}(i, t) / d t-d W_{T}(i, t) / d t+I_{C}(i, t) \\
& d W_{G}(i, t) / d t=\langle r(i)\rangle * W_{C}(i, t)+I_{G}(i, t) \\
& d W_{T}(i, t) / d t=\left(d W_{T}(t) / d t\right)_{D V C} * W_{C}(i, t) / W_{C}(t)+I_{T}(i, t) \\
& d p_{L}(t) / d t=-2 . *\langle r(B, t)\rangle{ }^{*} p_{L}(t) \\
& d p(t) / d t=-1 .{ }^{*}\langle r(B, t)\rangle{ }^{*} p_{L}(t) \\
& d q(t) / d t=\Sigma\left(d W_{G}(i, t) / d t\right)^{\star} X(i) / W_{C}(t) \\
& \left.d N_{T /} / d t=P_{\mid} X_{1} /\left(P_{0}+\Delta P \cdot \Sigma_{1} P_{1} X_{1}\right) * \Sigma_{1}\left(W_{G}(i, t) / M(i)\right)\right) \\
& d E_{m}(i, t) / d t=\langle r(i)\rangle * \int f_{C G}(i, E) d E / f_{C G}\left(i, E_{m}(i, t)\right)
\end{aligned}
$$

If the gas composition is not needed, the 27 equations represented by Equation 17 can be eliminated. Similarly, if the tar functional group composition is not needed, the 27 equations represented by Equation 18 can be replaced by the single Equation 28. The 6 or 7 mass bins represented by Equation 27 may be excessive for determining the tar vapor pressures. 

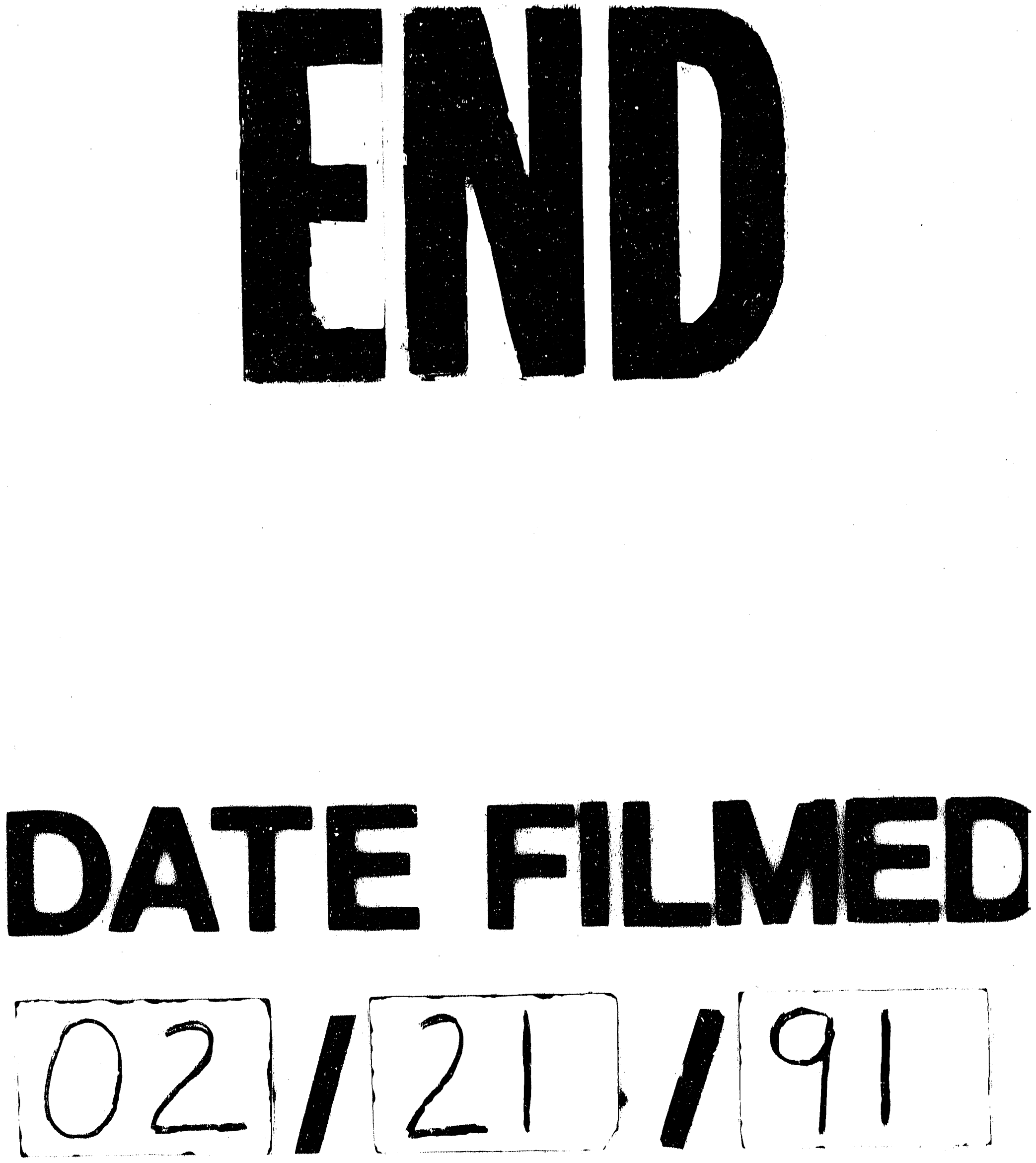
